\title{
PARTIAL CHARACTERIZATION OF BT RESISTANCE AND THE BACTERIOME OF WESTERN CORN ROOTWORM
}

\author{
A Dissertation \\ presented to \\ the Faculty of the Graduate School \\ at the University of Missouri-Columbia
}

by

Dalton C. Ludwick

Dr. Deborah Finke, Dissertation Supervisor

MAY 2018 
The undersigned, appointed by the dean of the Graduate School, have examined the dissertation entitled

\section{CHARACTERIZING BT RESISTANCE AND THE BACTERIOME OF WESTERN CORN ROOTWORM}

Presented by Dalton Ludwick, a candidate for the degree of doctor of philosophy, and hereby certify that, in their opinion, it is worthy of acceptance.

Advisor, Dr. Deborah Finke

Co-Advisor, Dr. Bruce Hibbard

Dr. Mark Ellersieck

Dr. Thomas Coudron 


\section{ACKNOWLEDGEMENTS}

I would like to thank Drs. Bruce Hibbard and Deborah Finke for the opportunity to pursue a dissertation in entomology, their support, and guidance during the program. Furthermore, I would like to thank Drs. Thomas Coudron and Mark Ellersieck for providing thoughts, which improved my program and research experiences. My opportunities to explore teaching undergraduate and graduate students were made possible by Drs. Bruce Barrett and William Lamberson. I would also like to thank Dr. Lisa Meihls for her guidance in writing and statistical analyses during her time as a post-doctoral fellow with Dr. Bruce Hibbard.

I would like to take this opportunity to thank the many undergraduate students and Julie Barry who have helped collect these and many other data. I would like to thank the co-authors who have entrusted experiments to me as a newer researcher. Importantly, I would like to thank the many experiments that failed made those that were successful more important to my development.

I would like to thank so many individuals, some of whom will not be named here. My family often supported my development to pursue academic life in an area without many academic opportunities. Ms. Denise Nelson, Mr. Mark Lemmon, and Mr. Dan Oilar all made my success during high school possible. Their support helped me earn the Jack \& Ladene McAndrew Memorial Flagship Scholarship provided by their son, Mark McAndrew. Lastly, I would like to thank my wife, Olivia Ludwick, for supporting me during the highs and lows of my academic pursuits. 


\section{TABLES OF CONTENTS}

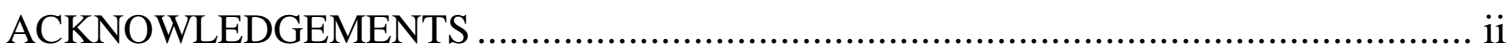

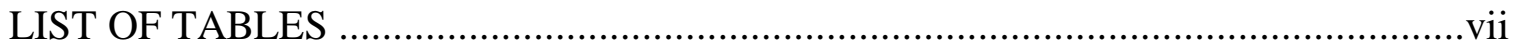

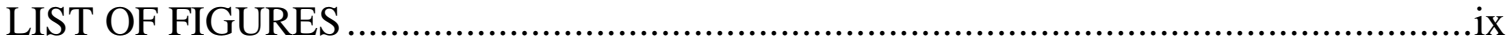

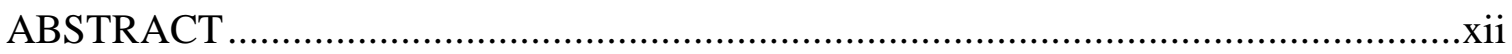

Chapter 1. Rootworm management: status of GM traits, insecticides and potential new tools

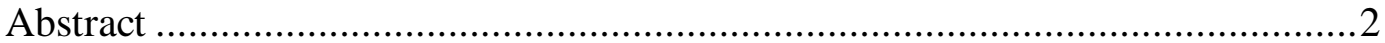

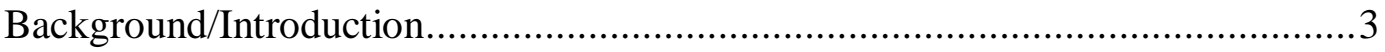

A Historical Perspective on Diabrotica Management, Research and Resistance

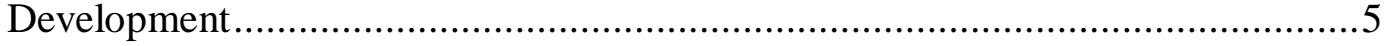

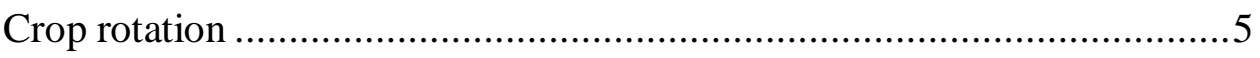

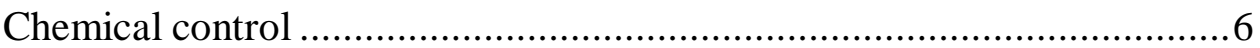

Biological control agents .......................................................................8

Bt Maize, Mortality and Implications for Resistance Management ......................8

Refuges, theory and concerns of resistance development ...........................8

Transgenic maize targeting Diabrotica spp.............................................10

Microbes and their implications for Bt resistance .................................... 13

Changing guidelines for resistance management .....................................13

Future concerns and efforts..................................................................... 15

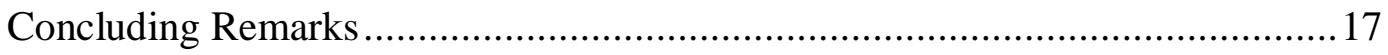

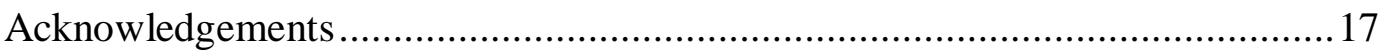

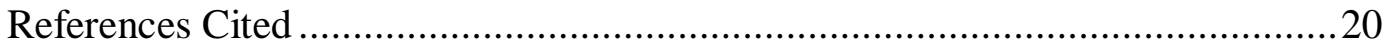

Chapter 2: Minnesota field population of western corn rootworm (Coleoptera:

Chrysomelidae) shows incomplete resistance to Cry34/Cry35Ab1 and Cry3Bb1 ............38

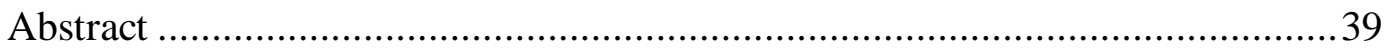

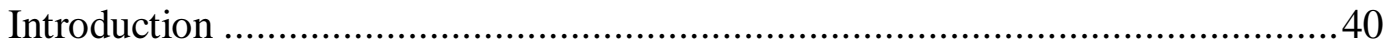

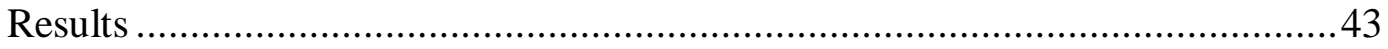

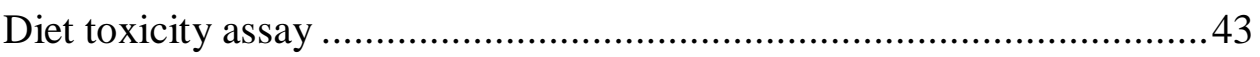


Cry34/35Ab1 43

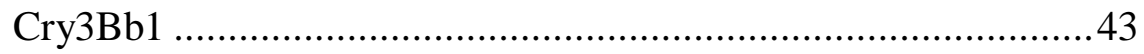

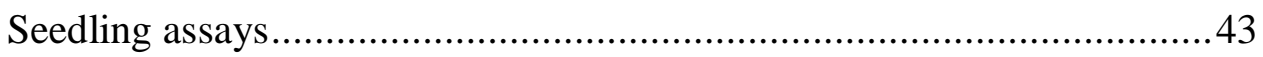

Relative larval recovery (Bt/non-Bt) for DAS-59122-7 ...............43

Relative larval weight (Bt/non-Bt) for DAS-59122-7 ...................44

Relative larval head capsule width (Bt/non-Bt) for

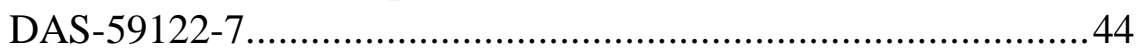

Relative larval recovery (Bt/near isoline) for MON88017 ...........45

Relative larval weight (Bt/near isoline) for MON88017 ..............45

Relative larval head capsule width (Bt/near isoline) for

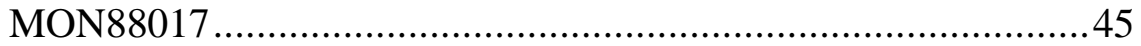

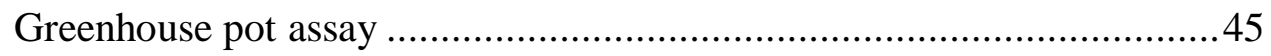

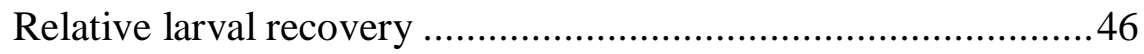

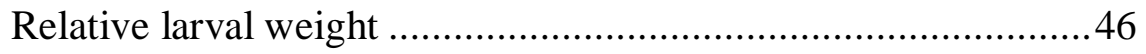

Relative head capsule width ......................................................... 46

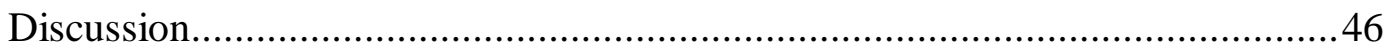

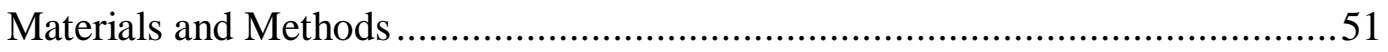

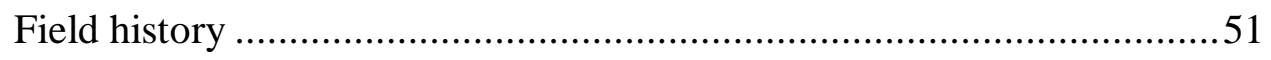

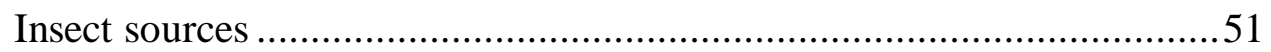

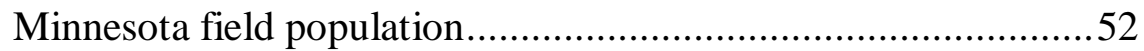

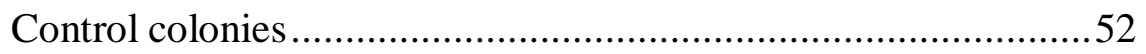

MON88017-selected colony ......................................................53

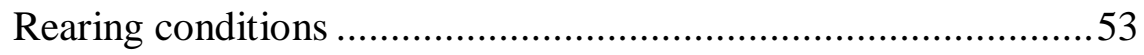

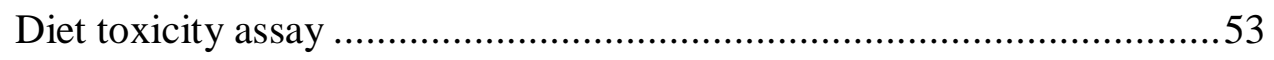

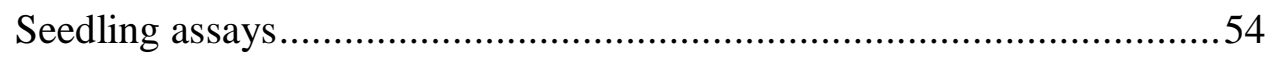

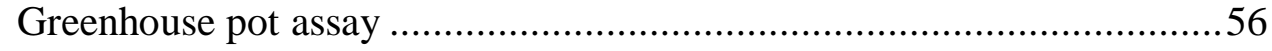

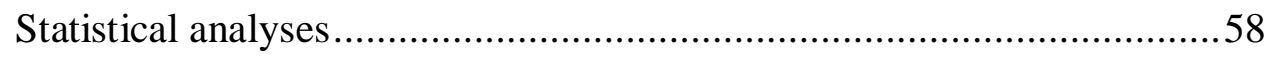

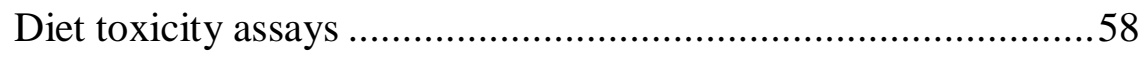

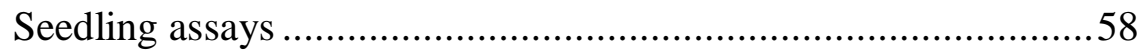




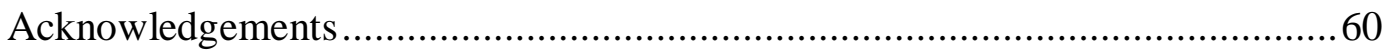

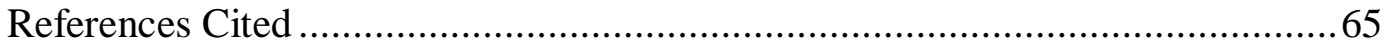

Chapter 3: A new artificial diet for western corn rootworm larvae is compatible with and

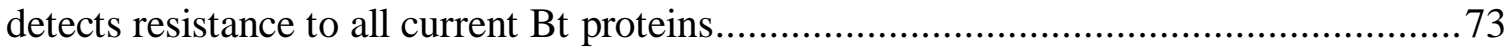

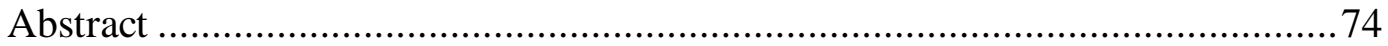

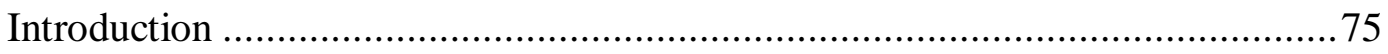

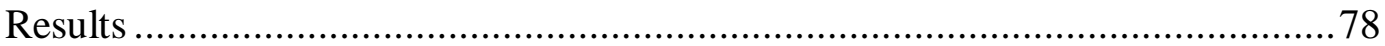

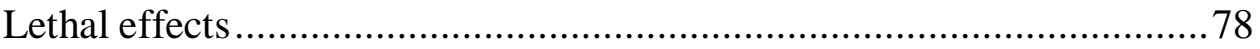

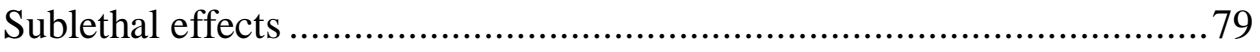

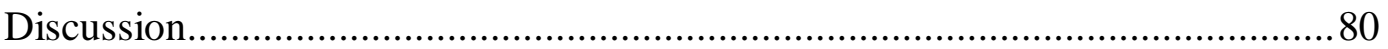

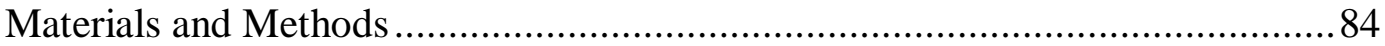

Artificial diet and Bt protein ................................................ 84

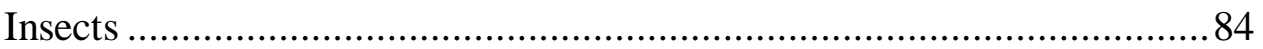

Equipment sterilization............................................................ 86

Egg sterilization................................................................. 86

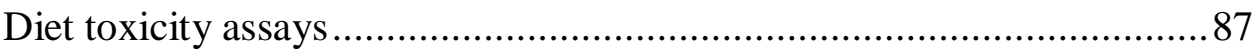

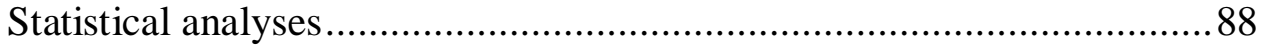

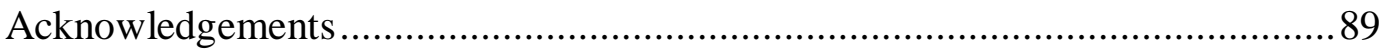

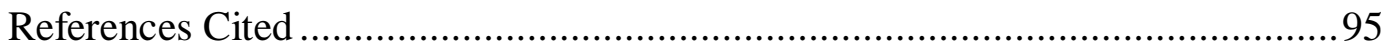

Chapter 4: Survey of bacteria associated with western corn rootworm life stages reveals no difference between insects reared in different soils.......................................... 102

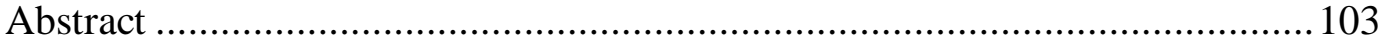

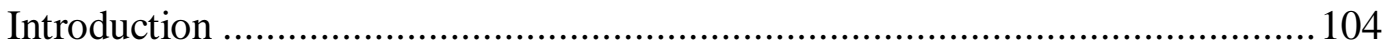

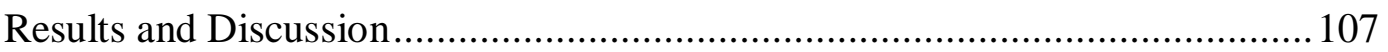

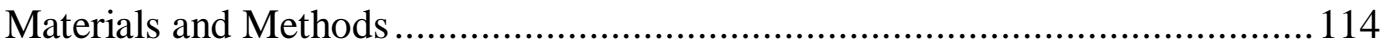

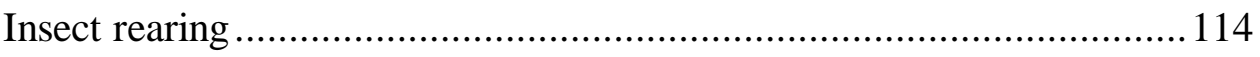

Seedling mats .................................................................. 115

Non-diapausing insects ................................................. 115 
Diapausing insects ..................................................... 115

DNA Extraction and Quantification .................................... 117

Library construction and sequencing ................................. 117

Informatics analysis .................................................... 117

Statistical analysis ................................................... 119

Acknowledgements .................................................................... 119

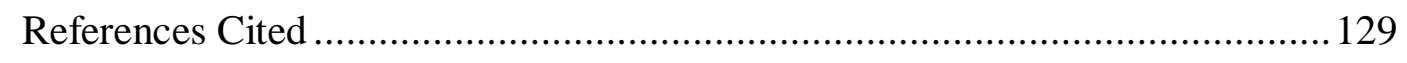

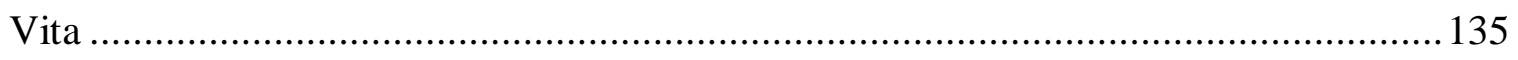




\section{LIST OF TABLES}

1. Effects of various hypothetical efficacies with a $20 \%$ block refuge on the total number of insects produced from refuge plants versus Bt plants 18

2. Efficacies of Bt products with current events targeting Diabrotica spp. and the effect they have on the number of insects produced from refuge plants versus $\mathrm{Bt}$ plants 19

3. $\mathrm{LC}_{50}$ and $\mathrm{EC}_{50}$ calculations for larvae exposed to Cry34/35Ab1 and Cry3Bb1 for 5 days in a diet overlay bioassay

4. Analysis of variance for variables in all experiments ......................................62

5. Buffers, dose, and proteins used with each colony ...................................... 90

6. Concentrations $\left(\mu \mathrm{g} / \mathrm{cm}^{2}\right)$ to kill 50 percent $\left(\mathrm{LC}_{50}\right)$, cause 50 percent weight inhibition ( $\mathrm{EC}_{50}$ values), and cause 50 percent molt inhibition $\left(\mathrm{MIC}_{50}\right)$ with 95 percent confidence intervals for corresponding colony, diet, and Bt protein treatments

7. Results of PERMANOVA testing for differences in $\beta$-diversity between western corn rootworm (WCR) and soil samples collected from two different sites, based on the Bray-Curtis distance. $p$ values and $\mathrm{F}$ values are shown in the upper right and lower left portions of the table, respectively

8. Results of PERMANOVA testing for differences in $\beta$-diversity between western corn rootworm (WCR) and soil samples collected from two different sites, based on the Jaccard distance. $p$ values and $\mathrm{F}$ values are shown in the upper right and lower left portions of the table, respectively 
9. Unique operational taxonomic units (OTUs) found in all insect samples regardless

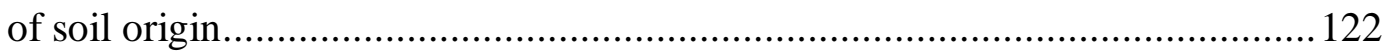




\section{LIST OF FIGURES}

1. Results of seedling assay on DAS-59122-7 (A-C) and seedling assay on MON88017 (D-F). (A \& D) Relative survival (Bt data/overall average of non-Bt data) of larvae on DAS-59122-7 and MON88017. (B \& E) Relative average weight of recovered larvae on DAS-59122-7 and MON88017. (C \& F) Relative head capsule width of recovered larvae on DAS-59122-7 and MON88017. Uppercase letters indicate significant differences between populations using rank transformed data. Bar heights represent the means of the treatment and error bars

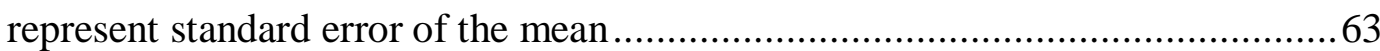

2. Results of greenhouse pot assay. (A) Relative survival (Bt data/overall average of non-Bt data) of larvae on DAS-59122-7 and MON88017. (B) Relative dry weight of recovered larvae. Letters over lines indicate the main effect of corn. (C)

Relative head capsule width of recovered larvae. Uppercase letters indicate significant differences between corn types within populations. Lowercase letters indicate significant differences between populations within corn type. All data were analyzed following a rank transformation. Bar heights represent the means of the treatment

3. Impact of Bt Protein on Mortality. Percent mortality of Brookings-ND (a-d) with exposure to Bt proteins on proprietary and WCRMO-1 diets, and mortality of Brookings-ND and selected colonies (e-h) with exposure to Bt proteins on the WCRMO-1 diet. Mortality was calculated as the number of larvae that died following exposure to Bt protein(s) divided by the initial number infested. Bars 
represent the standard error of the mean (SEM). The dashed line represents 50 percent mortality

4. Impact of Bt Protein on Dry Weight. Dry weight per larva (mg) of Brookings-ND (a-d) with exposure to Bt proteins on proprietary and WCRMO-1 diets, and dry weight per larva of Brookings-ND and selected colonies (e-h) with exposure to $\mathrm{Bt}$ proteins on the WCRMO-1 diet. Dry weight per larva was calculated as the dry weight of larvae recovered following exposure to Bt protein(s) divided by the initial number infested. Bars represent the standard error of the mean (SEM),....03

5. Impact of Bt Protein on Molting. Molting of Brookings-ND (a-d) with exposure to Bt proteins on proprietary and WCRMO-1 diets, and molting of Brookings-ND and selected colonies (e-h) with exposure to Bt proteins on the WCRMO-1 diet. First, the molting rate on the buffer was calculated by dividing the number of larvae which molted by the initial number of larvae. This established a baseline response of the insect to the diet and buffer. All values for each colony, including the buffer dose (Dose 1) for the same colony, were then divided by the buffer dose value to establish relationships relative to the buffer dose. Each of the resulting values were then multiplied by 100 . Bars represent the standard error of the mean (SEM). .94

6. Stacked bar charts showing relative abundances of microbial classes detect in corn rootworms at different life stages (A) and in soil from which rootworm samples were collected (B). Horizontal bars below the vertical bars indicate original of soil; black bars $=$ Columbia, $\mathrm{MO}$, white bars $=$ Higginsville, $\mathrm{MO} \ldots . .123$ 
7. Main effect of life stage on microbial richness in western corn rootworm (A, $p<0.001)$, or the soil from which WCR samples were collected $(\mathrm{B}, p=0.040)$. Significant pairwise differences are indicated by like letters (Kruskal-Wallis oneway ANOVA on ranks with Dunn's post hoc)..... 124

8. Principal coordinate analysis based on Bray-Curtis similarity between microbial communities detected in western corn rootworm (WCR) at various life stages and soil samples collected from two different sites

9. Main effect of life stage on microbiota $\alpha$-diversity in western corn rootworms (A, $p<0.001)$, or the soil from which the WCR samples were collected $(\mathrm{B}, p=0.040)$. Significant pairwise differences indicated like letters (Kruskal-Wallis one-way ANOVA on ranks with Dunn's post hoc) 126

10. Principal coordinate analysis based on Jaccard similarity between microbial communities detected in western corn rootworms (WCR) at various life stages and soil samples collected from two different sites

11. Number and mean relative abundance (above bars) of operational taxonomic units (OTUs) detected at increasing prevalence in adult western corn rootworm samples 


\begin{abstract}
Western corn rootworm (Diabrotica virgifera virgifera LeConte) has been a pest of corn (Zea mays L.) for more than one century. In that time, this insect has spread across the United States and has also had several introductions into Europe. Though corn growers have applied a number of control tactics over the years, including crop rotation, synthetic insecticides, and transgenic corn, this insect is persistently an issue for much of the corn growing areas in the United States and Europe. Western corn rootworm is infamous for its ability to overcome the tactics that are used against it, several times within a single decade. Transgenic corn expressing one or more protein(s) from Bacillus thuringiensis Berliner (Bt) have been used against this insect for more than one decade. Western corn rootworm had developed resistance to three of the four proteins (Cry3Bb1, mCry3A, and eCry3.1 Ab) and had been documented before the start of this dissertation. Immediately prior to the start of this dissertation, information existed that resistance to the fourth protein (Cry34/35Ab1) may have occurred in a Minnesota population. In this dissertation, we placed insects from control colonies or the field population in containers with corn expressing the Cry34/35Ab1 protein or in containers with artificial diet covered by the protein. The results of these three experiments indicated that incomplete resistance to Cry34/35Ab1 and Cry3Bb1 had occurred. The artificial diets used in the first experiment are proprietary and owned by separate companies. Efforts in separate studies led to the formulation of an improved artificial for western corn rootworm larvae which is now available to the public. This single, artificial diet was tested for its ability to detect resistance to the different proteins currently targeting western corn rootworm. Laboratory colonies of insects selected for resistance to each protein were compared to susceptible
\end{abstract}


insects on the new diet for their ability to survive and develop. The proprietary diets were also used to make comparisons about the similarity of the diets to the new, public diet. The new diet performed similarly to proprietary diets in terms of mortality and developmental rates. Indeed, the new diet was able to detect resistance to all proteins and documented strong differences between Cry34/35Ab1-resistant insects and susceptible insects for the first time. Lastly, we investigated which bacteria were associated with this insect. Laboratory insects were raised in two geographically and microbially distinct soils on non-Bt corn. Insects were collected at different time points to understand which bacteria were present in each life stage and across all life stages. Bacteria in soil samples were also identified and compared to those found in the insect to determine which bacteria were unique to the insect. These results suggest that 16 different bacteria are found in every western corn rootworm, some of which appear to only occur in the insect. The knowledge of bacteria associated with western corn rootworm may one day help us better understand the mechanisms of Bt resistance and how to better optimize nutrition. 


\section{Chapter 1}

Rootworm management: status of GM traits, insecticides and potential new tools*

Ludwick, D.C., and B.E. Hibbard. 2016. Rootworm Management: Status of GM Traits, Insecticides and Potential New Tools. CAB Reviews: Perspectives in Agriculture, Veterinary Science, Nutrition and Natural Resources 11. https://doi.org/10.1079/PAVSNNR201611048. 


\begin{abstract}
Western corn rootworm (Diabrotica virgifera virgifera LeConte) and northern corn rootworm (Diabrotica barberi (Smith and Lawrence)) are major pests of maize in the USA. These pests have been managed with a variety of tactics over the last century. Both Diabrotica spp. have adapted to crop rotation in different ways in certain regions of the USA as well as to some of the insecticides targeted at them. D. v. virgifera has adapted to more of the chemical control measures and transgenic control methods. Discussed in this review are the challenges associated with managing both species, and how current management strategies might be combined and implemented to help manage damage from these species. Also, we discuss the potential for new technologies, such as RNA interference, to be used in the future.
\end{abstract}




\section{BACKGROUND/INTRODUCTION}

Since 1909, western corn rootworm (Diabrotica virgifera virgifera LeConte) has been known to attack the roots of maize, Zea mays L. (Spencer et al. 2009; Meinke et al. 2009; Miller et al. 2009; Gassmann et al. 2009; Gillette 1912). Over the last century, the range of D. v. virgifera as a pest of maize has expanded beyond Fort Collins, Colorado to cover 39 states in the USA, Mexico, two provinces of Canada, three countries in Central America and 29 countries in Europe (Baca 1994; CABI 2016). There is some evidence that the pest followed the migration of maize northward from Mexico thousands of years ago (Meinke et al. 2009).

Economic losses caused by D. v. virgifera and Diabrotica barberi have been estimated between one and two billion dollars (Metcalf 1986; Mitchell 2011). These estimates include yield losses through direct and indirect routes, and include management costs. D. v. virgifera eggs have a developmental threshold of $11.1^{\circ} \mathrm{C}$ and hatch in the soil after accumulating the needed number of degree days (Wilde 1971; Levine et al. 1992), which depends somewhat on the location and temperature fluctuations. Upon hatch, neonate larvae find respiring plant roots by orienting to carbon dioxide (Strnad et al. 1986; Hibbard and Bjostad 1988; Bernklau and Bjostad 1998). Using behavioral bioassays, it is possible to distinguish hosts from nonhosts (Bernklau et al. 2015). Host recognition cues involved in this assay include monogalactosyldiacylglycerols (MGDGs) and other cues, which were recently isolated identified from corn root extracts (Bernklau and Bjostad 2005) based on the same behavioral bioassays. Long-chain free fatty acids and short-chain sugars were similarly isolated and identified as D. v. virgifera larval feeding stimulants 
(Bernklau et al. 2013). Maize is its primary host, but larvae can develop at least partially on many grass species and can develop to the adult stage on a number of these plants (Clark and Hibbard 2004, Oyediran et al. 2004). Larvae continue to develop and consume root tissue until the insect reaches the pupal stage, at which time it creates an earthen cell. Adults will begin to emerge approximately 10 days later, with males emerging first due to protandry (Branson 1987). Overall timing of adult emergence (June-August) will vary depending on accumulated degree days (Wilde 1971; Levine et al. 1992).

Larval feeding can have an array of impacts on the maize plant's development. Root regrowth is often triggered, depending on maize genotype, by root damage (Robert et al. 2015). If root damage is minor, then the plant may be better off than had its roots not been damaged at all, especially under dry conditions (Gray and Steffey 1998; Mahmoud et al. 2016). At higher densities, the root feeding may cause severe and permanent damage to the root system. Such severe root damage can limit the ability of the plant to uptake moisture and nutrients from the soil, which then impacts yield (Kahler et al. 1985; Riedell 1990; Gavloski et al. 1992; Hou et al. 1997). Often, the ability of the plant to stand upright is impacted, so an additional yield loss component is due to unharvested grain (Spike and Tollefson 1991). Adult feeding typically does not have an impact on the plant's yield unless densities are very high prior to anthesis (Culy et al. 1992; Capinera et al. 1986).

Rearing and handling techniques for D. v. virgifera on a large scale have been well established for decades (Jackson 1986). Non-diapausing colonies of D. v. virgifera populations, allow some research to be expedited (Branson et al. 1976). Unfortunately, research with $D$. barberi is lacking because adult handling techniques have not been able to produce sufficient numbers of eggs for large experiments. Additionally, a non- 
diapausing strain of $D$. barberi does not exist, hampering research in many aspects with this species. The non-diapausing trait has been documented in varying degrees (Patel and Apple 1967; Fisher et al. 1994) and may make a non-diapausing strain a real possibility.

\section{A HISTORICAL PERSPECTIVE ON DIABROTICA MANAGEMENT, RESEARCH, AND RESISTANCE DEVELOPMENT}

Crop rotation. D. v. virgifera has been a difficult pest to manage in the USA. Crop rotation, where a non-host is planted following a host, was initially recommended (Gillette 1912). This tactic was the only control tactic for the first half of the twentieth century. Management with this tactic is still by far the most effective management tactic in most areas against both species. Unfortunately, scientists in Illinois discovered a strain of $D . v$. virgifera, which had lost its fidelity to lay eggs only in the maize fields (Levine et al. 2002). Instead, D. v. virgifera females began to lay eggs in both maize and soybean fields in this region. The strain began near Urbana, Illinois, and has since spread to larger portions of Illinois, Indiana, and to a lesser extent in surrounding states (Gray et al. 2009).

Larval gut tissue of D. v. virgifera has a diverse microbial community (Dematheis 2012a). In D. v. virgifera, a shift in adult gut microbiota enterotype was associated with increased resistance to soybean defense compounds, and likely contributed to the development of resistance to crop rotation (Chu et al. 2013). Comparison of gut microbiota between rotation resistant $D . v$. virgifera populations and wild-type $D . v$ virgifera populations revealed shifts in the microbial community composition upon adaptation to soybean tissue diet in adult D. v. virgifera. Note that D. v. virgifera larvae cannot survive 
on soybean tissues. Manipulation of the gut microbiota through the use of antibiotics reduced the resistance to soybean defence compounds to a level similar to that of wild-type D. v. virgifera (Chu et al. 2013).

Similar to $D$. v. virgifera, $D$. barberi has developed a mechanism to circumvent the effectiveness of crop rotation. 'Extended diapause' means some eggs hatch two or more winters after being laid in the soil (Krysan et al. 1986). Because larvae die if eggs hatch when corn is absent, extended diapause allows D. barberi to selectively adapt to local crop rotations, putting all corn at risk. Extended diapause had been a problem in parts of Minnesota, Wisconsin, South Dakota and Iowa prior to the population crashes of $D$. barberi when Bt corn targeting rootworm started to dominate the landscape. Areas formerly dominated by D. barberi (parts of Minnesota, Wisconsin, South Dakota and Iowa) had a drastic reversal in the dominant Diabrotica species, with D. v. virgifera becoming the predominant species. More recently, D. barberi populations have recovered in some of these areas as documented by the Wisconsin Department of Agriculture (Wisconsin Department of Agriculture 2012). D. barberi populations spiked dramatically in 2015, nearly a decade after the populations crashed. Scattered extended diapause problems have just begun to resurface in rotated corn fields in Minnesota (Ken Ostlie, personal communication). In Missouri, where extended diapause has not been documented, populations of $D$. barberi were also found in large numbers in first year corn during the 2016 growing season (Unglesbee 2016). These developments suggest changes are underway within $D$. barberi populations.

Chemical control. Near the middle of the twentieth century, soil applied insecticides became available for Diabrotica spp. management (Metcalf 1986). 
Cyclodienes were broadcast over the entire field, thereby exposing all larvae to the pesticide. This widespread exposure likely hastened the development of resistance by $D$. v. virgifera, which was documented within just a few years (Ball and Weekman 1962). Cyclodiene resistance has persisted decades beyond the ban of this pesticide class (Parimi et al. 2006; Wang et al. 2013). Insecticides applied directly over rows of maize were referred to as banded insecticides. Two insecticide classes replaced the cyclodienes (carbamates and organophosphates) but were more expensive, so these pesticides were only applied over the row. No resistance has developed using this application method. Current theory suggests that roots outside the insecticidal zone provide a built-in 'refuge' to produce susceptible adults (Pereira et al. 2015). Refuges will be discussed below in reference to transgenic corn targeting D. v. virgifera.

A practice sometimes referred to as 'beetle bombing' uses foliar applications of the insecticide to prevent gravid females from laying eggs in maize fields, thus reducing the insect's impact on next year's crop (Pruess et al. 1974). Beetle bombing with organophosphates and carbamates resulted in $D$. v. virgifera adults developing resistance to insecticides within these two classes in the same Nebraska region where resistance to cyclodienes evolved (Meinke et al. 1998). This resistance also significantly impacted the larval susceptibility to organophosphates and carbamates (Wright et al. 2000).

More recently, a newer class of insecticide, pyrethroids, has been used to control D. v. virgifera adults. Interestingly, foliar applications of this insecticide are also used to control other pests, such as the two spotted spider mite (Tetranychus urticae Koch) or western bean cutworm (Striacosta albicosta (Smith)). While the application of the insecticide may be used to control other pests, D. v. virgifera adults are likely to be exposed 
and experience the selection pressure. Multiple applications within a season and non-target effects have likely contributed to the development of bifenthrin resistance for $D . v$. virgifera (Pereira et al. 2015).

Biological control agents. Currently, there are several different options being explored in the biological control area, all of which are entomopathogenic organisms. Two genera of entomopathogenic fungi, Metarhizium and Beauvaria, have been investigated for their potential as a biological control agent of D. v. virgifera (Mulock and Chandler 2001; Meissle et al. 2009; Pilz et al. 2011; Petzold-Maxwell et al. 2012, 2013). No commercial products are available as a result of the entomopathogenic fungus work. A great deal of research has gone into studying entomopathogenic nematodes and their interactions with D. v. virgifera (Petzold-Maxwell 2012, 2013; Rassmann et al. 2005; Hiltpold et al. 2010, 2012). Heterorhabditis and Steinernema spp. have been the two genera of focus in recent studies involving nematode-rootworm interactions. Nematodes are available for management of D. v. virgifera in parts of Europe (Toepfer et al. 2014). Again, little work with these biological control agents has been done with $D$. barberi, likely due to a shortfall in available eggs for studies.

\section{BT MAIZE, MORTALITY AND IMPLICATIONS FOR RESISTANCE MANAGEMENT}

Refuges, theory and concerns of resistance development. Transgenic maize hybrids expressing crystalline proteins with insecticidal activity derived from a soildwelling bacterium, Bacillus thuringiensis Berliner (Bt), have been available since 1996 
(USDA-APHIS 1995). Since organic growers used Bt to control pests, concern over the possibility of Bt resistance development were heightened more than for insecticides and contributed to the U.S. Environmental Protection Agency's (EPA) mandate for insect resistance management (IRM) plans to be in place to slow the development of Bt resistance. Products were registered with a structured refuge in hopes of slowing resistance development (EPA 1998b). The IRM plans for the first Bt crops in the USA implemented a $20 \%$ structured refuge. More recently, refuge requirements for seed blends of single events were set at 10 and $5 \%$ for pyramided products in the USA. The structured refuge strategy is optimal if toxin mortality is very high, initial frequency of alleles bestowing resistance is low, fitness costs of resistance are present, targeted insects mate randomly in the field and resistance to the Bt toxin is recessive (Gould 1998; Tabashnik and Gould 2012). The mortality caused by a Bt product is perhaps the most important because this can lead to a landscape in which resistant alleles from the Bt crop are vastly overwhelmed by susceptible alleles from the refuge.

The mathematics on why the level of toxicity is so important in the effectiveness of refuge is clarified in Table 1. If a toxin kills $90 \%$ of susceptible larvae, survivorship from a perfect $20 \%$ block refuge compared with an $80 \%$ Bt field is only $2.5: 1((0.2$ proportion of field $\times 1.0$ survivors $) /(0.1$ survivors $\times 0.8$ proportion of the field $))$. The minimum definition of 'high dose' in the field is that $99.99 \%$ of susceptible larvae die following exposure to a transgenic plant (EPA 1998a). The ratio of insects produced from a perfect $20 \%$ block refuge with a hypothetical efficacy of $99.99 \%$ would be $2500: 1$ (( 0.2 proportion of field $\times 1.0$ survivors $) /(0.0001$ survivors $\times 0.8$ proportion of the field $))$. This ratio is considered a minimum: 'Think in terms of thousands to one or millions to one.' 
Said Bruce Tabashnik during his talk at the Entomological Society of America in 2014 when referring to these ratios. The refuge program has been quite successful for some products, especially those which are truly high dose (Tabashnik et al. 2013). Even growers who do not plant Bt crops sometimes benefit from those who do plant Bt crops (Hutchison et al. 2010). The structured refuge program has been less successful in instances in which the Bt crop is not high dose (Tabashnik et al. 2013). There are some that believe that the era of the Cry toxin is ending (Porter et al. 2016).

Transgenic maize targeting Diabrotica spp. In 2003, the first hybrids expressing a Bt-derived insecticidal protein (Cry3Bb1, event MON863) active against Diabrotica spp. was registered for commercial use (EPA 2013). Over the next decade, four more proteins (Cry34Ab1/Cry35Ab1, mCry3A and eCry3.1Ab) and four additional events (DAS-59122-7, MIR604, MON88017 and 5307) were registered for commercial sale (EPA 2005, 2007, 2015). Event MON863 with an antibiotic marker was replaced by event MON88017, which also expressed Cry3Bb1, but came with resistance to glyphosate as a selectable marker. Expression of both Cry34Ab1 and Cry35Ab1 proteins are required for activity against Diabrotica spp. Some of the genes responsible for the expression of these Bt proteins have been stacked in maize hybrids resulting in pyramid Bt products. Pyramided products are designed to extend the life of both proteins by improving efficacy and adding multiple modes of action (Roush 1998). Maize products expressing the eCry3.1Ab protein are only sold in hybrids that also express the mCry $3 \mathrm{~A}$ simultaneously under the product name Agrisure Duracade ${ }^{\circledR}$.

Concerns of resistance development led to laboratory selection experiments with D. v. virgifera. Within three generations of selection, colonies of $D$. v. virgifera developed 
nearly complete resistance to Cry3Bb1 (Meihls et al. 2008). Nearly complete resistance to maize expressing mCry $3 \mathrm{~A}$ or eCry3.1Ab singly was also selected for within a few generations (Meihls et al. 2012; Frank et al. 2013). Each laboratory selection attempt for Cry3Bb1, mCry3A and eCry3.1Ab has been successful (Meihls et al. 2008, 2012; Frank et al. 2013; Oswald et al. 2011). Maize expressing Cry34/35Ab1 has been much more difficult to develop resistance to and complete resistance has not yet been achieved after more than 20 generations of selection. For example, after 10 generations of selection, survival of D. v. virgifera on Cry34/35Ab1-expressing maize was only $20 \%$ relative to a near-isoline (Lefko et al. 2008). Deitloff et al. (2016) evaluated refuge scenarios by selecting D. v. virgifera on Cry34/35Ab1 in a laboratory setting. A seed mix scenario failed to delay the development of resistance after 10 generations.

The highest published estimate for mortality was for the combination of eCry3.1 Ab + mCry3A with an efficacy of $99.91 \%$ (Hibbard et al. 2011). However, this efficacy with a $5 \%$ refuge only provides a ratio of 58 susceptible insects for each adult from the Bt portion of the maize field (Table 2). Cry3Bb1 (Event MON863) registration initially required a $20 \%$ block refuge. The ratio of insects from refuge to Bt was 16.56:1, and for mCry $3 \mathrm{~A}$, it is only 4.88:1 (Table 2). Since these ratios are not remotely close 'thousands to one or millions to one' as for truly high dose products, it is not surprising that resistance developed quite quickly to these events in the field (Gassmann et al. 2011, 2014; Zukoff et al. 2016), especially since the only instance in which the refuge concept was tested with lower dose events, it did not delay resistance when deployed in the manner currently dominating the market (Deitloff et al. 2016). As with other strategies, Bt maize has not remained as effective after its popularity as a management strategy has increased. Since the first report 
of field-evolved resistance to Cry3Bb1, other states have documented $D$. v. virgifera populations with Cry3Bb1 resistance (Zukoff et al. 2016; Wangila et al. 2015; Schrader et al. 2016). Unfortunately, some level of resistance to Cry3Bb1 confers cross-resistance to both mCry3A and eCry3.1Ab (Zukoff et al. 2016). One publication has documented incomplete resistance to Cry34/35Ab1 (Gassmann et al. 2016). Single-gene products are just now beginning to be phased out of the market. Unfortunately, all current commercial transgenic products including pyramids targeting Diabrotica spp. also are not considered 'high-dose' so refuges are likely to do little, if anything as currently implemented (Deitloff et al. 2016).

While the Bt proteins expressed by transgenic maize hybrids do add protection against Diabrotica spp., limited studies have shown that the efficacy is less for D. barberi versus D. v. virgifera (Table 2). Given Bt's reduced efficacy against D. barberi, there were early concerns that populations of $D$. barberi might develop resistance to Bt before $D . v$. virgifera. This scenario did not manifest; instead, D. barberi populations crashed during the time frame when Bt corn targeting Diabrotica spp. became widely adopted. $D . v$. virgifera populations later blossomed from development of $\mathrm{Bt}$ resistance. Why has $\mathrm{Bt}$ resistance not yet developed in D. barberi? It is tempting to infer reduced capacity for resistance, but a more likely explanation may lie in their resistance to crop rotation via extended diapause (Krysan et al. 1986). The extended diapause biotype predominates in the geographical region mentioned above. Thus, only one $D$. barberi generation every 2 years would delay resistance to $\mathrm{Bt}$ corn at least two fold. D. v. virgifera resistance to $\mathrm{Bt}$ took six years to develop (2003-2009). Given this length of time with D. v. virgifera, signs 
of $D$. barberi Bt resistance could be expected to occur soon, assuming similar mechanism of resistance and gene frequencies are present in both species.

Microbes and their implications for Bt resistance. Microbes have been documented to influence the susceptibility of lepidopteran insects targeted by Bt plants. Gut microbiota actually appear to be required for Bt susceptibility in lepidopteran pests (Caccia et al. 2016; Broderick et al. 2006; Paramasiva 2014a, 2014b; Visweshwar et al. 2015). Gut microbes also play a role in crop rotation resistance in D. v. virgifera, but the role of gut microbiota in Bt resistance and susceptibility is unknown (Dematheis et al. 2012a). Feeding of D. v. virgifera larvae on corn root tissue was shown to affect root rhizosphere microbiota composition, indicating complex, multitrophic interactions (Dematheis et al. 2012b).

Changing guidelines for resistance management. Previously, registrants were required to conduct annual, random sampling programs to monitor susceptibility as a condition of registration (EPA 2003, 2005, 2007, 2015). In order to comply, registrants collected both random populations and targeted populations (fields with greater than expected damage) when possible (i.e. if notified before adults died, resources available for collection, etc.), and eggs produced were collected. These eggs were then overwintered, allowed to hatch and then tested in diet toxicity assays and possibly plant assays. When resistance developed to Cry3Bb1 and mCry3A, the US EPA convened a Scientific Advisory Panel (SAP) to discuss changes to resistance monitoring programs. After considering the recommendations of the SAP, the EPA altered the compliance requirements for registrants. Registrants are no longer required to conduct random sampling; instead, they are required to collect adults from fields with performance issues, 
when possible, to test the offspring. Furthermore, registrants are now encouraged to conduct plant assays instead of diet toxicity assays (EPA 2016).

Registrants and academic researchers can use a variety of assays to test $D . v$. virgifera populations for Bt resistance and product efficacy characterizations. Researchers tend to use just one assay to make characterizations (Gassmann et al. 2014; Wangila et al. 2015). There are at least three different plant assays that could be used, each with the capability to estimate the survival rate and developmental parameters (Zukoff et al. 2016). Developmental parameters are extremely valuable to characterize Bt resistance, but have not always been used. The first plant assay, a seedling assay, uses many maize seeds (Bt and non-Bt) and eggs or larvae in a relatively small, plastic container with a few dozen germinated seeds. The second and third assays, a single plant and greenhouse pot assay, are not much different. The single plant assay uses neonate larvae $(<24 \mathrm{~h}$ old $)$ on a V5 maize plant (Bt or non-Bt). Larvae are left to feed for 17 days before being extracted and data collected (Gassmann et al. 2011; Gassmann et al. 2016). Greenhouse pot assays may use larvae or eggs but still uses V5 maize plants like the single plant assay. While each assay is likely capable of detecting resistance, there may be one assay or one variable that is best able to discriminate between susceptible and resistant populations and this could also be toxin specific. Further research is needed to clarify optimal assays.

As discussed above, resistance monitoring programs by registrants were previously conducted using diet-toxicity assays. Data generated and submitted to the EPA for different proteins have not been comparable due to different proprietary artificial diet formulations used by each of the major companies. Since these diets are proprietary, academic researchers must obtain special permission to access to them. This issue may have 
influenced the EPA towards a shift away from diet toxicity assays in resistance monitoring programs. If a single, public and easy-to-use artificial diet can be generated for this purpose, then some of the problems will be addressed. Data from resistance monitoring programs could be compared for the different Bt proteins. Secondly, a public diet would allow academic researchers to conduct these assays with their own toxins or other toxins for which they are able to access.

Future concerns and efforts. Due to the very adaptive nature of Diabrotica spp., we propose areas of research that could be further improved upon or investigated for applications to rootworm management. Soil insecticides often do not significantly control D. v. virgifera population levels (Gray et al. 1992). When feeding stimulants were added to thiamethoxam, the level of the toxin needed to kill $50 \%$ of the larvae was reduced by more than 100 000-fold (Bernklau et al. 2011). This demonstrates that understanding the chemical ecology of this pest can improve management strategies. Repellant properties of methyl anthranilate from corn root extract have been documented (Bernklau et al. 2016). Perhaps by placing methyl anthranilate in furrow with non-Bt maize plants, larvae could be pushed to plants with insecticides or transgenic maize as part of a push-pull strategy analogous to other similar strategies utilized in other systems.

Earlier work on host location cues, specifically CO2 (Strnad et al. 1986; Hibbard and Bjostad 1988; Bernklau and Bjostad 1998), is now being utilized in experiments with an attract-and-kill strategy (Schumann et al. 2014). Through use of CO2-emitting capsules, larvae were attracted to maize roots treated with the insecticide tethfluthrin. Similarly, use of a repellant may create a similar effect as the attract-and-kill strategy. As more research 
is conducted with Diabrotica spp. ecology and chemical ecology, additional management strategies may become available in the future.

Molecular biology, like chemical ecology, continues to give insight into finding additional management strategies. By understanding how cells work, different processes can be manipulated to control D. v. virgifera. Baum et al. (2007) was the first to discuss the potential of RNA interference (RNAi) for the control of D. v. virgifera. Expression of specific double-stranded RNA fragments by plants elicits a defense mechanism where cells no longer transcribe targeted genes into proteins. Depending on how many redundancies are present in the insect genome, the insect may begin to deteriorate or even die if the protein plays a crucial role in the survival of the insect. Monsanto Company was the first to announce a maize product, which utilizes RNAi technology. This product, announced as SmartStax Pro, will express two Bt events (MON88017 and DAS-59122-7) targeting Diabrotica spp. and RNAi technology with one target gene (DvSnf7). SmartStax Pro is registered for commercial use by the US EPA, but awaiting import approval in China. Recently, at least two other companies have announced plans to use RNAi in a product. DuPont Pioneer announced two Diabrotica spp. target genes that will be expressed simultaneously by maize plants. Syngenta has announced a product where dsRNA is applied as a soil treatment rather than through a transgenic plant.

Lastly, one recently published scientific breakthrough may help to overcome $\mathrm{Bt}$ resistance (Badran et al. 2016). Phage-assisted continuous evolution takes advantage of naturally occurring processes to expedite Bt toxin evolution. These evolved Bt toxins have a high binding affinity for new receptors on the midgut tissue. This technique allowed the 
researchers to improve the efficacy of the Cry1Ac by 335-fold, even against Cry1 Ac resistant insects. This tool might be effective for overcoming Bt resistance.

\section{CONCLUDING REMARKS}

Diabrotica spp. have a long history of adapting to management practices. Some practices have remained effective for several decades, while others begin to lose efficacy within just a few generations of selection. Until high dose transgenic maize hybrids targeting Diabrotica spp. are created, current refuge strategies are likely inadequate to significantly delay resistance development by these pests (Tables 1, 2). Multiple management tactics should be employed by growers, industry and regulatory agencies, when possible, to combat the adaptive nature of these pests (Andow et al. 2016). While some new products are nearing the market, it is clear that Diabrotica spp. will continue to adapt. Continued research on all aspects of Diabrotica spp. is needed if maize growers are to have permanent success against $D$. v. virgifera and $D$. barberi. This needs to include adaptive IRM approaches and pro-active, integrated IRM-pest management strategies (Andow et al. 2016).

\section{ACKNOWLEDGEMENTS}

We thank CAB Reviews for the invitation to write this review. We thank USDAARS and the University of Missouri for funding this work. 
Table 1. Effects of various hypothetical efficacies with a 20 percent block refuge on the total number of insects produced from refuge plants versus Bt plants.

\begin{tabular}{ll}
\hline $\begin{array}{l}\text { Hypothetical } \\
\text { Efficacy (\%) }\end{array}$ & Ratio of insects from refuge \\
\hline 90 & versus transgenic ${ }^{1}$ \\
99 & $2.5: 1$ \\
99.9 & $25: 1$ \\
99.99 & $2,50: 1$ \\
99.999 & $25,000: 1$ \\
ed through use of this formula: $(1 \times$ percent refuge size $) /($ corrected \\
\end{tabular}

${ }^{1}$ Ratio calculated through
survival $\times$ percent $\mathrm{Bt}$ size) 
Table 2. Efficacies of Bt products with current events targeting Diabrotica spp. and the effect they have on the number of insects produced from refuge plants versus Bt plants.

\begin{tabular}{|c|c|c|c|c|}
\hline $\begin{array}{l}\text { Protein in Current or Former } \\
\text { Commercial Events } \\
(\text { Scenario })^{1}\end{array}$ & $\begin{array}{l}\text { D. } v . \\
\text { virgifera } \\
\text { Efficacy } \\
(\%)^{2}\end{array}$ & $\begin{array}{l}\text { Calculated } \\
\text { Ratio }^{3}\end{array}$ & $\begin{array}{l}\text { D. barberi } \\
\text { Efficacy }(\%)^{2}\end{array}$ & $\begin{array}{l}\text { Calculated } \\
\text { Ratio }^{3}\end{array}$ \\
\hline Cry3Bb1 (Field) ${ }^{5}$ & 98.49 & $16.56: 1$ & 86.39 & $1.84: 1$ \\
\hline Cry34/35Ab1 (Field) $)^{7,8}$ & 97.3 & $9.26: 1$ & 78.94 & 1.19:1 \\
\hline mCry3A (Field $)^{8}$ & 94.88 & $4.88: 1$ & 86.68 & $1.88: 1$ \\
\hline eCry3.1Ab (Field $)^{9,10,11}$ & 99.79 & 119.05:1 & 95.92 & $6.13: 1$ \\
\hline $\begin{array}{l}\text { Cry3Bb1 + Cry34/35Ab1, } \\
\text { pure (Field) } \\
\text { mCry3A + eCry3.1Ab, pure } \\
\text { (Field) }\end{array}$ & $\begin{array}{l}99.14 \\
99.9^{11}\end{array}$ & $6.12: 1$ & $\begin{array}{l}97.71 \\
96.26^{13}\end{array}$ & $2.30: 1$ \\
\hline
\end{tabular}

${ }^{1}$ Refuge size assumed to be 20 percent block refuge for single toxin products and 5 percent for pyramided toxin products sold as refuge-in-bag; Refuge-in-bag products have a smaller requirement than block refuges for single toxin products

${ }^{2}$ Highest efficacy data used

${ }^{3}$ Ratio calculated through use of this formula: $(1 \times$ percent refuge size $) /($ corrected survival $\times$ percent Bt size)

${ }^{4}$ Data from Meihls et al. (2008)

${ }^{5}$ Data from Clark et al. (2012)

${ }^{6}$ Data from Binning et al. (2010)

${ }^{7}$ D. v. virgifera data from Storer et al. (2006), D. barberi data from Table 7 of Head et al. (2014)

${ }^{8}$ Data from Hibbard et al. (2010)

${ }^{9}$ Commercial hybrids express mCry3 A and eCry3.1Ab proteins

${ }^{10}$ This treatment is not commercially available but was used to evaluate the likelihood of resistance development

${ }^{11}$ Data from Hibbard et al. (2011)

${ }^{12}$ Data from Tables 4 and 8 of Head et al. (2014)

${ }^{13}$ Data from Frank et al. (2015) 


\section{References Cited}

Andow, D.A., S.G. Pueppke, A.W. Schaafsma, A.J. Gassmann, T.W. Sappington, L.J. Meinke, P.D. Mitchell, T.M. Hurley, R.L. Hellmich, and R.P. Porter. 2016. Early Detection and Mitigation of Resistance to Bt Maize by Western Corn Rootworm (Coleoptera: Chrysomelidae). Journal of Economic Entomology 109 (1): 1-12. https://doi.org/10.1093/jee/tov238.

Baca, F. 1994. New Member of the Harmful Entomofauna of Yugoslavia Diabrotica virgifera virgifera LeConte (Coleoptera: Chrysomelidae). Zaštita Bilja 45: 125-31.

Badran, A.H., V.M. Guzov, Q. Huai, M.M. Kemp, P. Vishawnath, W. Kain, A.M. Nance, et al. 2016. Continuous Evolution of Bacillus thuringiensis Toxins Overcome Insect Resistance. Nature 533: 58-63.

Ball, H.J., and G.T. Weekman. 1962. Insecticide Resistance in the Adult Western Corn Rootworm in Nebraska. Journal of Economic Entomology 55 (439-441).

Baum, J.A., T. Bogaert, W. Clinton, G.R. Heck, P. Feldmann, O. Ilagan, S. Johnson, et al. 2007. Control of Coleopteran Insect Pests through RNA Interference. Nature Biotechnology 25 (11): 1322-26. https://doi.org/10.1038/nbt1359.

Bernklau, E. J., and L. B. Bjostad. 2008. Identification of Feeding Stimulants in Corn Roots for Western Corn Rootworm (Coleoptera: Chrysomelidae) Larvae Identification of Feeding Stimulants in Corn Roots for Western Corn Rootworm (Coleoptera: Chrysomelidae) Larvae 101 (2): 341-51. 
Bernklau, E.J., and L.B. Bjostad. 1998a. Behavioral Responses of First-Instar Western Corn Rootworm (Coleoptera: Chrysomelidae) to Carbon Dioxide in a Glass Bead Bioassay. Journal of Economic Entomology 91: 444-56.

Bernklau, E.J., L.B. Bjostad, and B.E. Hibbard. 2011. Synthetic Feeding Stimulants Enhance Insecticide Activity against Western Corn Rootworm Larvae, Diabrotica virgifera virgifera (Coleoptera: Chrysomelidae). Journal of Applied Entomology 135 (1-2): 47-54. https://doi.org/10.1111/j.1439-0418.2009.01502.x.

Bernklau, E.J., B.E. Hibbard, D.L. Dick, C.D. Rithner, and L.B. Bjostad. 2015. Monogalactosyldiacylglycerols as Host Recognition Cues for Western Corn Rootworm Larvae (Coleoptera: Chrysomelidae). Journal of Economic Entomology 108 (2): 539-48. https://doi.org/10.1093/jee/tov025.

Bernklau, E.J., B.E. Hibbard, A.P. Norton, and L.B. Bjostad. 2016. Methyl Anthranilate as a Repellent for Western Corn Rootworm Larvae (Coleoptera: Chrysomelidae). Journal of Economic Entomology 109 (4): 1683-90. https://doi.org/10.1093/jee/tow090.

Binning, R. R., S. A. Lefko, A. Y. Millsap, S. D. Thompson, and T. M. Nowatzki. 2010. Estimating Western Corn Rootworm (Coleoptera: Chrysomelidae) Larval Susceptibility to Event DAS-59122-7 Maize. Journal of Applied Entomology 134 (7): 551-61. https://doi.org/10.1111/j.1439-0418.2010.01530.x.

Branson, T.F. 1976. The Selection of A Non-diapause Strain of Diabrotica virgifera virgifera (Coleoptera: Chrysomelidae). Entomologia Experimentalis et Applicata 19 (2): 148-54. https://doi.org/10.1111/j.1570-7458.1976.tb02591.x. 
Branson, T F. 1987. The Contribution Of Prehatch And Posthatch Development To Protandry In The Chrysomelid, Diabrotica virgifera virgifera. Entomologia Experimentalis et Applicata 43 (3): 205-8.

Broderick, N.A., K.F. Raffa, and J. Handelsman. 2006. Midgut Bacteria Require for Bacillus thuringiensis Insecticidal Activity. Proceedings of the National Academy of Sciences 103: 15196-99.

Caccia, S., I.D. Lelio, A.L. Storia, A. Marinelli, P. Varricchio, E. Franzetti, N. Banvuls, et al. 2016. Midgut Microbiota and Host Immunocompetence Underlie Bacillus thuringiensis Killing Mechanism. Proceedings of the National Academy of Sciences 113: 9486-91.

Capinera, J.L., N.D. Epsky, and D.C. Thompson. 1986. Effects of Adult Western Corn Rootworm (Coleoptera: Chrysomelidae) Ear Feeding on Irrigated Field Corn in Colorado. Journal of Economic Entomology 79: 1609-12.

Chu, C.C., J.L. Spencer, M.J. Curzi, J.A. Zavala, and M.J. Seufferheld. 2013. Gut Bacteria Facilitate Adaptation to Crop Rotation in the Western Corn Rootworm. Proceedings of the National Academy of Sciences 110: 11917-22.

Clark, T. L., D. L. Frank, B. W. French, L. J. Meinke, D. Moellenbeck, T. T. Vaughn, and B. E. Hibbard. 2012. Mortality Impact of MON863 Transgenic Maize Roots on Western Corn Rootworm Larvae in the Field. Journal of Applied Entomology 136 (10): 721-29. https://doi.org/10.1111/j.1439-0418.2012.01709.x.

Clark, T.L., and B.E. Hibbard. 2004. Comparison of Nonmaize Hosts to Support Western Corn Rootworm (Coleoptera: Chrysomelidae) Larval Biology. 
Environmental Entomology 33 (3): 681-89. https://doi.org/10.1603/0046-225X33.3.681.

Culy, M.D., C.R. Edwards, and J.R. Cornelius. 1992. Effect of Silk Feeding by Western Corn Rootworm (Coleoptera: Chrysomelidae) on Yield and Quality of Inbred Corn in Seed Corn Production Fields. Journal of Economic Entomology 85 (2440-2446).

Deitloff, J., M.W. Dunbar, D.A. Ingber, B.E. Hibbard, and A.J. Gassmann. 2016. Effects of Refuges on the Evolution of Resistance to Transgenic Corn by the Western Corn Rootworm, Diabrotica virgifera virgifera LeConte. Pest Management Science 72 (1): 190-98. https://doi.org/10.1002/ps.3988.

Dematheis, F., U. Zimmerling, C. Flocco, B. Kurtz, S. Vidal, S. Kropf, and K. Smalla. 2012. Multitrophic Interaction of the Rhizosphere of Maize: Root Feeding of Western Corn Rootworm Larvae Alters the Microbial Community Composition. PLoS ONE.

Dematheis, Flavia, Benedikt Kurtz, Stefan Vidal, and Kornelia Smalla. 2012. Microbial Communities Associated with the Larval Gut and Eggs of the Western Corn Rootworm. PLoS ONE 7 (10). https://doi.org/10.1371/journal.pone.0044685.

CABI. 2015. Diabrotica virgifera virgifera (Western Corn Rootworm)."

[EPA] Environmental Protection Agency. 1998. Final Report of the FIFRA Scientific Advisory Panel Subpanel on Bacillus Thuringiens (Bt) Plant-Pesticides and Resistance Management.” 
[EPA] Environmental Protection Agency. 2003. Bacillus thuringiensis Cry3Bb1 Protein and the Genetic Material for Its Production (Vector zmir121) in Event MON863 Corn Fact Sheet."

[EPA] Environmental Protection Agency. 2005. Bacillus thuringiensis Cry34Ab1 and Cry35Ab1 and the Genetic Material Necessary for Their Production (Plasmid Insert PHP 17662) in Event DAS-59122-7 Corn (006490) Fact Sheet."

[EPA] Environmental Protection Agency. 2007. Biopesticide Registration Action Document. Modified Cry3A Protein and the Genetic Material Necessary for Its Production (via Elements of pZM26) in Event MIR604 Corn SYNIR604-8."

[EPA] Environmental Protection Agency. 2015. Bacillus thuringiensis eCry3.1Ab Protein and the Genetic Material Necessary for Its Production (Vector PSY12274).”

[EPA] Environmental Protection Agency. 2016. EPA's Changes to the Bt Corn Rootworm Resistance Management Program.”

Fisher, J.R., J.J. Jackson, and A.C. Lew. 1994a. Temperature and Diapause Development in the Egg of Diabrotica barberi (Coleoptera: Chrysomelidae). Environmental Entomology 23 (2): 464-71. https://doi.org/10.1093/ee/23.2.464.

Frank, D.L., R. Kurtz, N.A. Tinsley, A.J. Gassmann, L.J. Meinke, D. Moellenbeck, M.E. Gray, et al. 2015. Effect of Seed Blends and Soil-Insecticide on Western and Northern Corn Rootworm Emergence from mCry3A + eCry3.1Ab Bt Maize. Journal of Economic Entomology $108 \quad$ (3): 1260-70. https://doi.org/10.1093/jee/tov081. 
Frank, D.L., A. Zukoff, J. Barry, M.L. Higdon, and B.E. Hibbard. 2013. Development of Resistance to eCry3.1Ab-Expressing Transgenic Maize in a Laboratory-Selected Population of Western Corn Rootworm (Coleoptera: Chrysomelidae). Journal of Economic Entomology 106 (6): 2506-13. https://doi.org/10.1603/EC13148.

Gassmann, A. J., J. L. Petzold-Maxwell, E. H. Clifton, M. W. Dunbar, A. M. Hoffmann, D. A. Ingber, and R. S. Keweshan. 2014. Field-Evolved Resistance by Western Corn Rootworm to Multiple Bacillus thuringiensis Toxins in Transgenic Maize. Proceedings of the National Academy of Sciences 111 (14): 5141-46. https://doi.org/10.1073/pnas.1317179111.

Gassmann, A.J. 2016. Resistance to Bt Maize by Western Corn Rootworm: Insights from the Laboratory and the Field. Current Opinion in Insect Science 15: 111-15. https://doi.org/10.1016/j.cois.2016.04.001.

Gassmann, A.J., J.L. Petzold-Maxwell, R.S. Keweshan, and M.W. Dunbar. 2011. Field-Evolved Resistance to Bt Maize by Western Corn Rootworm. PLoS ONE 6 (7). https://doi.org/10.1371/journal.pone.0022629.

Gassmann, A.J., R.B. Shrestha, S.R.K. Jakka, M.W. Dunbar, E.H. Clifton, A.R. Paolino, D.A. Ingber, et al. 2016. Evidence of Resistance to Cry34/35Ab1 Corn by Western Corn Rootworm (Coleoptera: Chrysomelidae): Root Injury in the Field and Larval Survival in Plant-Based Bioassays. Journal of Economic Entomology 109 (4): 1872-80. https://doi.org/10.1093/jee/tow110. 
Gavloski, J.E., G.H. Whitfield, and C.R. Ellis. 1992. Effect of Larvae of Western Corn Rootworm (Coleoptera: Chrysomelidae) and Mechanical Root Pruning on Sap Flow and Growth of Corn. Journal of Economic Entomology 85: 1434-41.

Gillette, C P. 1912. Diabrotica virgifera Lec. as a Corn Rootworm. Journal of Economic Entomology 5: 364-66.

Gould, F. 1998. Sustainability of Transgenic Insecticidal Cultivars: Integrating Pest Genetics and Ecology. Annual Review of Entomology 43: 701-26.

Gray, M.E., A.S. Felsot, K.L. Steffey, and E. Levine. 1992. Planting Time Application of Soil Insecticides and Western Corn Rootworm (Coleoptera, Chrysomelidae) Emergence: Implications for Long-Term Management Programs. 85: 544-53.

Gray, M.E., T.W. Sappington, N.J. Miller, J. Moeser, and M.O. Bohn. 2009. Adaptation and Invasiveness of Western Corn Rootworm: Intensifying Research on a Worsening Pest. Annual Review of Entomology. Vol. 54. https://doi.org/10.1146/annurev.ento.54.110807.090434.

Gray, M.E., and K.L. Steffey. 1998. Corn Rootworm (Coleoptera: Chrysomelidae) Larval Injury and Root Compensation of 12 Maize Hybrids: An Assessment of the Economic Injury Index. Journal of Economic Entomology 91 (3): 723-40. https://doi.org/10.1093/jee/91.3.723.

Head, G., L.A. Campbell, M. Carroll, T. Clark, T. Galvan, W. M. Hendrix, P.L. Prasifka, P. Price, N.P. Storer, and L.A. Stork. 2014. Movement and Survival of Corn Rootworm in Seed Mixtures of SmartStax ${ }^{\circledR}$ Insect-Protected Corn. Crop Protection 58. Elsevier Ltd: 14-24. https://doi.org/10.1016/j.cropro.2013.12.023. 
Hibbard, B.E., and L.B. Bjostad. 1988. Behavioral Responses of Western Corn Rootworm Larvae to Volatile Semiochemicals from Corn Seedlings. Journal of Chemical Ecology 14 (6): 1523-39. https://doi.org/10.1007/BF01012424.

Hibbard, B.E., T.L. Clark, M.R. Ellersieck, L.N. Meihls, A.A. El Khishen, V. Kaster, H.-Y. Steiner, and R. Kurtz. 2010. Mortality of Western Corn Rootworm Larvae on MIR604 Transgenic Maize Roots: Field Survivorship Has No Significant Impact on Survivorship of F1 Progeny on MIR604. Journal of Economic Entomology 103 (6): 2187-96. https://doi.org/10.1603/EC10179.

Hibbard, Bruce E., Daniel L. Frank, Ryan Kurtz, Eric Boudreau, Mark R. Ellersieck, and J. Frederick Odhiambo. 2011. Mortality Impact of Bt Transgenic Maize Roots Expressing eCry3.1Ab, mCry3A, and eCry3.1Ab Plus mCry3A on Western Corn Rootworm Larvae in the Field. Journal of Economic Entomology 104 (5): 1584-91. https://doi.org/10.1603/EC11186.

Hiltpold, I., B.E. Hibbard, B.W. French, and T.C.J. Turlings. 2012. Capsules Containing Entomopathogenic Nematodes as a Trojan Horse Approach to Control the Western Corn Rootworm. Plant and Soil 358 (1-2): 11-25. https://doi.org/10.1007/s11104-012-1253-0.

Hiltpold, I., S. Toepfer, U. Kuhlmann, and T.C.J. Turlings. 2010. How Maize Root Volatiles Influence the Efficacy of Entomopathogenic Nematodes against the Western Corn Rootworm? Chemoecology 20: 155-62. 
Hou, X., L.J. Meinke, and T.J. Arkebauer. 1997. Soil Moisture and Larval Western Corn Rootworm Injury: Influence on Gas Exchange Parameters in Corn. Agronomy Journal 89 (5): 709-17.

Hutchison, W.D., E.C. Burkness, P.D. Mitchell, R.D. Moon, T.W. Leslie, S.J. Fleischer, M. Abrahamson, et al. 2010. Areawide Suppression of European Corn Borer with Bt Maize Reaps Savings to Non-Bt Maize Growers. Science 330 (6001): 222-25. https://doi.org/10.1126/science.1190242.

Jackson, J.J. 1986. Rearing and Handling of Diabrotica virgifera virgifera and Diabrotica undecimpunctata Howardi. In Methods for the Study of Pest Diabrotica, edited by J.L. Krysna and T.A. Miller, 25-47. New York, New York: Springer-Verlag.

Kahler, A.L., A.E. Olness, G.R. Sutter, C.D. Dybing, and O.J. Devine. 1985. Root Damage by Western Corn Rootworm and Nutrient Content in Maize. Agronomy Journal 77: 769-74.

Krysan, J.L., K.R. Ostlie, W.S. Cranshaw, D.E. Foster, and T.F. Branson. 1986. Two Years before the Hatch: Rootworms Adapt to Crop Rotation. Bulletin of the Entomological Society of America 32: 250-53.

Lefko, S. A., T. M. Nowatzki, S. D. Thompson, R. R. Binning, M. A. Pascual, M. L. Peters, E. J. Simbro, and B. H. Stanley. 2008. Characterizing Laboratory Colonies of Western Corn Rootworm (Coleoptera: Chrysomelidae) Selected for Survival on Maize Containing Event DAS-59122-7. Journal of Applied Entomology 132 (3): 189-204. https://doi.org/10.1111/j.1439-0418.2008.01279.x. 
Levine, E., H. Oloumi-Sadeghi, and C.R. Ellis. 1992. Thermal Requirements, Hatching Patterns, and Prolonged Diapause in Western Corn Rootworm (Coleoptera: Chrysomelidae) Eggs. Journal of Economic Entomology 85: 2425-32.

Levine, E., J.L. Spencer, S.A. Isard, D.W. Onstad, and M.E. Gray. 2002. Adaptation of the Western Corn Rootworm to Crop Rotation: Evolution of a New Strain in Response to a Management Practice. American Entomologist 48: 94-107.

Mahmoud, M.A.B., R.E. Sharp, M.J. Oliver, D.L. Finke, M.R. Ellersieck, and B.E. Hibbard. 2016. The Effect of Western Corn Rootworm (Coleoptera: Chrysomelidae) and Water Deficit on Maize Performance under Controlled Conditions. Journal of Economic Entomology 109 (2): 684-98. https://doi.org/10.1093/jee/tow011.

Meihls, L.N., M.L. Higdon, M.R. Ellersieck, B.E. Tabashnik, and B.E. Hibbard. 2012. Greenhouse-Selected Resistance to Cry3Bb1-Producing Corn in Three Western

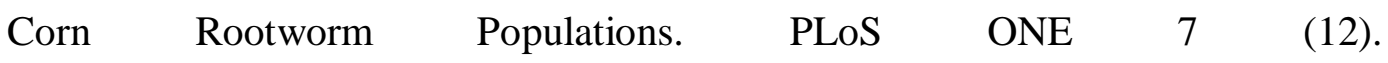
https://doi.org/10.1371/journal.pone.0051055.

Meihls, L.N., M.L. Higdon, B.D. Siegfried, N.J. Miller, T.W. Sappington, M.R. Ellersieck, T.A. Spencer, and B.E. Hibbard. 2008. Increased Survival of Western Corn Rootworm on Transgenic Corn within Three Generations of on-Plant Greenhouse Selection. Proceedings of the National Academy of Sciences of the United States of America $105 \quad$ (49): 19177-82. https://doi.org/10.1073/pnas.0805565105. 
Meinke, L.J., T.W. Sappington, D.W. Onstad, T. Guillemaud, N.J. Miller, J. Komáromi, N. Levay, L. Furlan, J. Kiss, and F. Toth. 2009. Western Corn Rootworm (Diabrotica virgifera virgifera LeConte) Population Dynamics. Agricultural and Forest Entomology 11 (1): 29-46. https://doi.org/10.1111/j.14619563.2008.00419.x.

Meinke, L.J., B.D. Siegfried, R.J. Wright, and L.D. Chandler. 1998. Adult Susceptibility of Nebraska Western Corn Rootworm ( Coleoptera : Chrysomelidae ) Populations to Selected Insecticides Part of the Entomology Commons Adult Susceptibility of Nebraska Western Corn Rootworm. Journal of Economic Entomology 91 (3): 594-600.

Meissle, M., C. Pilz, and J. Romeis. 2009. Susceptibility of Diabrotica virgifera virgifera (Coleoptera: Chrysomelidae) to the Entomopathogenic Fungus Metarhizium anisopliae When Feeding on Bacillus thuringiensis Cry3Bb1-Expressing Maize. $\begin{array}{lllll}\text { Applied and } & \text { Environmental Microbiology } 75 & \text { (12): 3937-43. }\end{array}$ https://doi.org/10.1128/AEM.00432-09.

Metcalf, R.J. 1986. Foreword. In Methods for the Study of Pest Diabrotica, edited by J.L. Krysan and T.A. Miller, vii-xv. New York, New York: Springer-Verlag.

Miller, N.J., T. Guillemaud, R. Giordano, B.D. Siegfried, M.E. Gray, L.J. Meinke, and T.W. Sappington. 2009. Genes, Gene Flow and Adaptation of Diabrotica virgifera virgifera. Agricultural and Forest Entomology 11 (1): 47-60. https://doi.org/10.1111/j.1461-9563.2008.00398.x. 
Mitchell, P. 2011. Costs and Benefits of Controlling Pest Diabrotica in Maize in the United States. In 24th IWG Conference, 24-26. Freiburg, Germany.

Mulock, B., and L. Chandler. 2000. Field-Cage Studies of Beauveria Bassiana (Hyphomycetes: Moniliaceae) for the Suppression of Adult Western Corn Rootworm, Diabrotica virgifera virgifera (Coleoptera: Chrysomelidae). Biocontrol Science and Technology 10 (1): 51-60. https://doi.org/10.1080/09583150029387.

Mulock, B.S., and L.D. Chandler. 2001. Effect of Beauveria Bassiana on the Fecundity of Western Corn Rootworm, Diabrotica virgifera virgifera (Coleoptera: Chrysomelidae). Biological Control $22 \quad$ (1): 16-21. https://doi.org/10.1006/bcon.2001.0952.

Oswald, K.J., B.W. French, C. Nielson, and M. Bagley. 2011. Selection for Cry3Bb1 Resistance in a Genetically Diverse Population of Nondiapausing Western Corn Rootworm (Coleoptera: Chrysomelidae). Journal of Economic Entomology 104 (3): 1038-44. https://doi.org/10.1603/EC10312.

Oyediran, I.O., B.E. Hibbard, and T.L. Clark. 2004. Prairie Grasses as Hosts of the Western Corn Rootworm (Coleoptera: Chrysomelidae). Environmental Entomology 33 (3): 740-47. https://doi.org/10.1603/0046-225X-33.3.740.

Paramasiva, I., H.C. Sharma, and P.V. Krishnayya. 2014. Antibiotics Influence the Toxicity of the Delta Endotoxins of Bacillus thuringiensis towards the Cotton Bollworm, Helicoverpa armigera. BMC Microbiology 14.

Paramasiva, I., Y. Shouche, G.J. Kulkarni, P.V. Krishnayya, S.M. Akbar, and H.C. Sharma. 2014. Diversity in Gut Microflora of Helicoverpa armigera Populations 
from Different Regions in Relation to Biological Activity of Bacillus thuringiensis $\delta$-Endotoxin Cry1Ac. Archives of Insect Biochemistry and Physiology 87 (201213).

Parimi, S., L.J. Meinke, B. Wade French, L.D. Chandler, and B.D. Siegfried. 2006. Stability and Persistence of Aldrin and Methyl-Parathion Resistance in Western Corn Rootworm Populations (Coleoptera: Chrysomelidae). Crop Protection 25 (3): 269-74. https://doi.org/10.1016/j.cropro.2005.04.017.

Patel, K K, and J W Apple. 1967. Ecological Studies on the Eggs of the Northern Corn Rootworm. Journal of Economic Entomology 60: 496-500.

Pereira, A.E., H. Wang, S.N. Zukoff, L.J. Meinke, B.W. French, and B.D. Siegfried. 2015. Evidence of Field-Evolved Resistance to Bifenthrin in Western Corn Rootworm (Diabrotica virgifera virgifera LeConte) Populations in Western Nebraska and Kansas. PLoS ONE 10 (11): 1-16. https://doi.org/10.1371/journal.pone.0142299.

Petzold-Maxwell, J. L., S. T. Jaronski, and A. J. Gassmann. 2012. Tritrophic Interactions among Bt Maize, an Insect Pest and Entomopathogens: Effects on Development and Survival of Western Corn Rootworm. Annals of Applied Biology, 43-55. https://doi.org/10.1111/j.1744-7348.2011.00515.x.

Petzold-Maxwell, J.L., S.T. Jaronski, E.H. Clifton, M.W. Dunbar, M.A. Jackson, and A.J. Gassmann. 2013. Interactions Among Bt Maize, Entomopathogens, and Rootworm Species (Coleoptera: Chrysomelidae) in the Field: Effects on Survival, 
Yield, and Root Injury. Journal of Economic Entomology 106: 622-32. https://doi.org/10.1603/EC12375.

Pilz, C., J. Enkerli, R. Wegensteiner, and S. Keller. 2011. Establishment and Persistence of the Entomopathogenic Fungus Metarhizium anisopliae in Maize Fields. Journal of Applied Entomology 135 (6): 393-403. https://doi.org/10.1111/j.14390418.2010.01566.x.

Porter, P., K. Siders, and S. Vyavhare. 2016. Shuffling the Deck Chairs in Bt Crops. Texas A\&M AgriLife Extension. 2016.

Pruess, K.P., J.F. Wilkowski, and E.S. Raun. 1974. Population Suppression of Western Corn Rootworm by Adult with ULV Malathion. Journal of Economic Entomology 67: $651-55$.

Rassmann, S., T.G. Kollner, J. Degenhartdt, I. Hiltpold, S. Toepfer, U Kuhlmann, J. Gershenzon, and T.C.J. Turlings. 2005. Recruitment of Entomopathogenic Nematodes by Insect-Damaged Maize Roots. Science 434: 732-77.

Riedell, W.E. 1990. Rootworm and Mechanical Damage Effects on Root Morphology and Water Relations in Maize. Crop Science 30: 1434-41.

Robert, C.A.M., S. Schirmer, J. Barry, B. Wade French, B.E. Hibbard, and J. Gershenzon. 2015. Belowground Herbivore Tolerance Involves Delayed Overcompensatory Root Regrowth in Maize. Entomologia Experimentalis et Applicata 157 (1): 113-20. https://doi.org/10.1111/eea.12346. 
Roush, R.T. 1998. Two-Toxin Strategies for Management of Insecticidal Transgenic Crops: Can Pyramiding Succeed Where Pesticide Mixtures Have Not? Philosophical Transactions of the Royal Society B: Biological Sciences 353 (1376): 1777-86. https://doi.org/10.1098/rstb.1998.0330.

Schrader, P.M., R.E. Estes, N.A. Tinsley, A.J. Gassmann, and M.E. Gray. 2017. Evaluation of Adult Emergence and Larval Root Injury for Cry3Bb1-Resistant Populations of the Western Corn Rootworm. Journal of Applied Entomology 141 (1-2): 41-52. https://doi.org/10.1111/jen.12329.

Schumann, M., A. Patel, M. Vemmer, and S. Vidal. 2014. The Role of Carbon Dioxide as an Orientation Cue for Western Corn Rootworm Larvae within the Maize Root System: Implications for an Attract-and-Kill Approach. Pest Management Science $70(642-650)$.

Spencer, J.L., B.E. Hibbard, J. Moeser, and D.W. Onstad. 2009. Behaviour and Ecology of the Western Corn Rootworm (Diabrotica virgifera virgifera LeConte). Agricultural and Forest Entomology 11 (1): 9-27. https://doi.org/10.1111/j.14619563.2008.00399.x.

Spike, B.P., and J.J. Tollefson. 1991. Yield Response of Corn Subjected to Wesetern Corn Rootworm (Coleoptera: Chrysomelidae) Infestation and Lodging. Journal of Economic Entomology 84: 1585-90.

Storer, N.P., J.M. Babcock, and J.M. Edwards. 2006. Field Measures of Western Corn Rootworm (Coleoptera: Chrysomelidae) Mortality Caused by Cry34/35Ab1 Proteins Expressed in Maize Event 59122 and Implications for Trait Durability. 
Journal of Economic Entomology 99 (4): 1381-87. https://doi.org/10.1603/00220493-99.4.1381.

Strnad, S.P., M.K. Bergman, and W.C. Fulton. 1986. First-Instar Western Corn Rootworm (Coleoptera: Chrysomelidae) Response to Carbon Dioxide. Environmental Entomology 15: 839-42.

Strnad, S.P., and P.E. Dunn. 1990. Host Search Behaviour of Neonate Western Corn Rootworm (Diabrotica virgifera virgifera). Journal of Insect Physiology 36 (3): 201-5. https://doi.org/10.1016/0022-1910(90)90123-W.

Tabashnik, B.E., T. Brévault, and Y. Carrière. 2013. Insect Resistance to Bt Crops: Lessons from the First Billion Acres. Nature Biotechnology 31 (6): 510-21. https://doi.org/10.1038/nbt.2597.

Tabashnik, B.E., and F. Gould. 2012. Delaying Corn Rootworm Resistance to Bt Corn. Journal of Economic Entomology $105 \quad$ (3): 767-76. https://doi.org/10.1603/EC12080.

Toepfer, S., P. Knuth, M. Glas, and U. Kuhlmann. 2012. Successful Application of Entomopathogenic Nematodes for the Biological Control of Western Corn Rootworm Larvae in Europe - a Mini Review. In Proceedings of the International Conference on the German Diabrotica Research Proram.

Unglesbee, E. 2016. Rotation-Resistant Northern Corn Rootworm Suspected in Missouri. DTN/The Progressive Farmer, 2016. 
Visweshwar, R., H.C. Sharma, S.M.D. Akbar, and K. Sreeramulu. 2015. Elimination of Gut Microbes with Antibiotics Confers Resistance to Bacillus thuringiensis Toxin Proteins in Helicoverpa armigera (Hubner). Applied Biochemistry and Biotechnology 177: 1621-37.

\section{Wang, H., B.S. Coates, H. Chen, T.W. Sappington, T. Guillemaud, and B.D. Siegfried.} 2013. Role of a Gamma-Amino Butyric Acid (GABA) Receptor Mutation in the Evolution and Spread of Diabrotica virgifera virgifera Resistance to Cyclodiene Insecticides. Insect Molecular Biology 22: 473-84.

Wangila, D.S., A.J. Gassmann, J.L. Petzold-Maxwell, B.W. French, and L.J. Meinke. 2015. Susceptibility of Nebraska Western Corn Rootworm (Coleoptera: Chrysomelidae) Populations to Bt Corn Events. Journal of Economic Entomology 108 (2): 742-51. https://doi.org/10.1093/jee/tou063.

Wilde, G.E. 1971. Temperature Effects on Development of Western Corn Rootworm Eggs. Journal of the Kansas Entomological Society 44: 185-87.

Wisconsin Department of Agriculture. 2012. Wisconsin Pest Bulletin.”

Wright, R.J., M.E. Scharf, L.J. Meinke, X. Zhou, B.D. Siegfried, and L.D. Chandler. 2000. Larval Susceptibility of an Insecticide-Resistant Western Corn Rootworm (Coleoptera: Chrysomelidae) Population to Soil Insecticides: Laboratory Bioassays, Assays of Detoxification Enzymes, and Field Performance. Journal of Economic Entomology 93 (1): 7-13.

Zukoff, S.N., K.R. Ostlie, B. Potter, L.N. Meihls, A.L. Zukoff, L. French, M.R. Ellersieck, B.W. French, and B.E. Hibbard. 2016. Multiple Assays Indicate 
Varying Levels of Cross Resistance in Cry3Bb1-Selected Field Populations of the Western Corn Rootworm to mCry3A, eCry3.1Ab, and Cry34/35Ab1. Journal of Economic Entomology 109 (3): 1387-98. https://doi.org/10.1093/jee/tow073. 


\section{Chapter 2}

Minnesota field population of western corn rootworm (Coleoptera: Chrysomelidae) shows incomplete resistance to Cry34/Cry35Ab1 and Cry3Bb1*

Ludwick, D. C., L. N. Meihls, K. R. Ostlie, B. D. Potter, L. French, and B. E. Hibbard. 2017. Minnesota Field Population of Western Corn Rootworm (Coleoptera: Chrysomelidae) Shows Incomplete Resistance to Cry34Ab1/Cry35Ab1 and Cry3Bb1. Journal of Applied Entomology 141 (1-2): 28-40. https://doi.org/10.1111/jen.12377. 


\begin{abstract}
The western corn rootworm, Diabrotica virgifera virgifera LeConte (Coleoptera: Chrysomelidae), is commonly managed with transgenic corn (Zea mays L.) expressing insecticidal proteins from the bacteria Bacillus thuringiensis Berliner (Bt) in the United States of America. Colonies of this pest have been selected in the laboratory on each commercially available transformation event; some field populations are also resistant. In the current study, progeny of a western corn rootworm population collected from a Minnesota corn field planted to SmartStax ${ }^{\circledR}$ corn were evaluated for resistance to corn hybrids expressing Cry3Bb1 (event MON88017) or Cry34/35Ab1 (event DAS-59122-7) and to the individual constituent proteins in diet-overlay bioassays. Results from all of these assays suggest that this population has resistance to Cry3Bb1 and has incomplete resistance to Cry34/35Ab1. In diet toxicity assays, larvae of the MN population had resistance ratios of 4.71 and $>13.22$ for Cry34/35Ab1 and Cry3Bb1 proteins, respectively, compared with the control colonies. In all on-plant assays, the relative survival of the MN population on the DAS-59122-7 and MON88017 hybrids was significantly greater than the control colonies. Larvae of the MN population had inhibited development when reared on DAS-59122-7 compared with larvae reared on the non-Bt hybrid, indicating resistance was incomplete. Overall, these results document resistance to Cry3Bb1 and an incomplete resistance to Cry34/35Ab1 in a SmartStax ${ }^{\circledR}$ performance problem field.
\end{abstract}




\section{BACKGROUND/INTRODUCTION}

At the end of the $20^{\text {th }}$ century, the United States Environmental Protection Agency (EPA) approved the commercialization of crops expressing Cry toxins derived from Bacillus thuringiensis $(\mathrm{Bt})$. The first corn (Zea mays $\mathrm{L}$.) product expressing a Bt toxin active against lepidopteran pests of corn was registered in 1995 (USDA-APHIS 1995) and became commercially available in 1996 . Farmers have quickly adopted transgenic crops expressing Bt protein since commercialization in 1996. Currently, Bt corn is planted on $81 \%$ of acres for the benefit of enhanced protection from herbivores (UDSA-NASS 2015). Area-wide suppression of some pests, such as European corn borer, Ostrinia nubilalis (Hübner), has been reported following widespread adoption with both those planting $\mathrm{Bt}$ and those not growing Bt corn benefiting from several \$billion in cumulative savings (Hutchison et al. 2010). In 2003, the first corn product with Bt toxins (event MON863, Cry3Bb1) active against corn rootworms was approved for commercial sale (EPA 2003). Over the next decade, three more proteins, including Cry34Ab1/Cry35Ab1 (hereafter Cry34/35Ab1, event DAS-59122-7), mCry3A (event MIR604), and eCry3.1Ab (event 5307) were commercialized for management of corn rootworms (EPA 2005, 2007, 2015).

Three Bt proteins (Cry3Bb1, mCry3A, and Cry34/35Ab1) targeting western corn rootworm (Diabrotica virgifera virgifera LeConte) are expressed singly in corn hybrids. Some examples of single-traits products are: YieldGard ${ }^{\mathrm{TM}}$ VT Triple Pro (Cry3Bb1, event MON88017), Agrisure ${ }^{\mathrm{TM}} \mathrm{RW}$ or 3111 (mCry3A), and Herculex RW ${ }^{\mathrm{TM}}$ (Cry34/35Ab1). Hybrids expressing multiple proteins targeting the same pest in a single plant, referred to as pyramids, are also available commercially and some of the pyramid products are: SmartStax ${ }^{\circledR}\left(\operatorname{Cry} 3 \mathrm{Bb} 1+\right.$ Cry34/35Ab1), Agrisure ${ }^{\circledR} 3122(\mathrm{mCry} 3 \mathrm{~A}+$ Cry34/35Ab1) and 
Optimum $^{\circledR}$ Intrasect Xtreme $($ Cry34/35Ab1 + mCry3A). The most recent Bt protein, eCry3.1 Ab (event 5307), was approved for commercialization in 2013, and is sold only as a pyramid $(\mathrm{mCry} 3 \mathrm{~A}+\mathrm{eCry} 3.1 \mathrm{Ab})(\mathrm{EPA} 2015)$ under the product name, Agrisure Duracade $^{\circledR}$.

Pyramided products, like those mentioned above, can significantly delay resistance by having more than one mode of action, but the occurrence of cross-resistance between incorporated proteins decreases the efficacy of the pyramid (Roush 1998). Resistance is defined as a genetically based shift in overall susceptibility (e.g. survival, development, etc.) as a result of a population's exposure to a toxin (National Research Council 1986; Tabashnik 1994). In more practical terms, resistance means a population exposed to a toxin has greater fitness or survival on the toxin than a population or colony that has never been exposed to the toxin. The presence of a single-trait product within the dispersal distance of a pyramided product was suggested to decrease the longevity of both products in modeling studies (Zhao et al. 2005; Onstad and Meinke 2010).

The potential durability of each Bt protein targeting western corn rootworm was previously evaluated under laboratory conditions. Laboratory colonies of western corn rootworm were selected for resistance to single Bt proteins (Lefko et al. 2008; Meihls et al. 2008, 2011, 2012; Oswald et al. 2012; Frank et al. 2013). Some wild populations have also rapidly developed resistance to corn expressing the Cry3Bb1 protein (Gassmann et al. 2011). Planting cornfields with hybrids expressing Cry3Bb1 for three or more consecutive years was correlated with resistance development. Since the initial documentation of fieldevolved resistance to Cry3Bb1 in Iowa (Gassmann et al. 2011), resistance has also been reported for populations in Nebraska, Minnesota, and Illinois (Wangila et al. 2015; Zukoff 
et al. 2016; Schrader et al. 2016). Cross-resistance between Cry3Bb1 and mCry3A has been documented previously (Gassmann et al. 2014) and more recently between Cry3Bb1, mCry3A, and eCry3.1 Ab (Zukoff et al. 2016). The documented resistance of wild western rootworm populations to Cry3Bb1 (Gassmann et al. 2011), mCry3A (Gassmann et al. 2014), and their cross-resistance with eCry3.1 Ab (Zukoff et al. 2016) increases selection pressure on the second protein in any pyramid containing any of the proteins (Zhao et al. 2005; Onstad and Meinke 2010).

Against this backdrop of relatively widespread field resistance to Cry3Bb1 and mCry3A, field performance issues have been infrequent with corn expressing Cry34/35Ab1 and laboratory development of Cry34/35Ab1 resistance has been slower. In multiple laboratory studies to select for Cry34/35Ab1 resistance, complete resistance (i.e. survival on Bt is equivalent to isoline) was not attained (Lefko et al. 2008; Deitloff et al. 2015) even after more than 20 generations of selection (Stephen Thompson, DuPont Pioneer, personal communication). Contrary to what was observed with Cry34/35Ab1 selection attempts, nearly complete resistance to the other three Bt proteins (Cry3Bb1, mCry3A, eCry3.1Ab) under laboratory selection was obtained within six generations or fewer (Meihls et al. 2008, 2011; Frank et al. 2013). Survival on corn expressing Cry34/35Ab1 was only $\sim 20 \%$ of the near-isoline survival even after 10 generations of selection (Lefko et al. 2008), which likely contributes to delaying resistance in the field.

The EPA mandates that fields with single or pyramided events that experience nodal injury ratings (Oleson et al. 2005) greater than 1.0 for a single protein and 0.5 for pyramided proteins be investigated by product registrants for performance issues (Andow et al. 2016). Due to these requirements, a field in Brown County, MN reported greater- 
than-expected damage on SmartStax ${ }^{\circledR}$, and triggered the interest of researchers. Fieldevolved Cry34/35Ab1 had not been documented until very recently (Gassmann et al. 2016). This study's objective was to characterize the western corn rootworm population for resistance or susceptibility to one or both proteins expressed by SmartStax ${ }^{\circledR}$ corn hybrids.

\section{RESULTS}

\section{Diet Toxicity Assay}

Cry34/35Ab1. Based on confidence intervals, the $\mathrm{LC}_{50}$ and $\mathrm{EC}_{50}$ values were significantly greater for the $\mathrm{MN}$ field population than those of the diapausing control colony (Table 3). The $\mathrm{LC}_{50}$ value of the $\mathrm{MN}$ field population was 4.71 times greater than the control colony. The $\mathrm{EC}_{50}$ value of the $\mathrm{MN}$ field population was 3.78 times greater than the diapausing control colony.

Cry3Bb1. When confidence intervals were compared with the non-diapausing control colony, the $\mathrm{MN}$ field population had significantly greater $\mathrm{LC}_{50}$ and $\mathrm{EC}_{50}$ values. Resistance ratios of the MN field population and MON88017-selected population were both $>13.22$ (Table 3). Relative potency (i.e. the $\mathrm{EC}_{50}$ of the selected population divided by the $\mathrm{EC}_{50}$ for the control colony) of the $\mathrm{MN}$ field and MON88017-selected sources were 3.07 and $>15.42$, respectively.

\section{Seedling Assays}

Relative larval recovery (Bt/non-Bt) for DAS-59122-7. Survival of the MN field population on DAS-59122-7 relative to the non-Bt survival (0.68 \pm 0.09$)$ was significantly greater than the non-diapausing $(0.17 \pm 0.09)$ and diapausing control $(0.27 \pm 0.12)$ colonies,

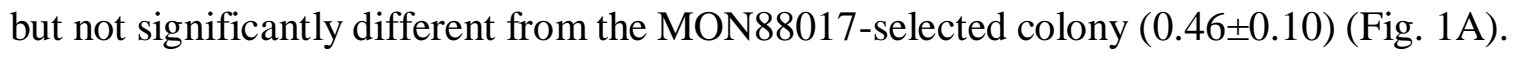


Relative survival of the MON88017-selected laboratory colony $(0.46 \pm 0.10)$ on DAS59122-7 was also significantly greater than that of its paired non-diapausing control colony $(0.17 \pm 0.09)$.

Relative larval weight (Bt/non-Bt) for DAS-59122-7. The relative weights of two insect sources (MN field population and the diapausing control colony) were significantly greater than the relative weight of the non-diapausing control colony (Fig. 1B). Relative weights of larvae from the MN field population were significantly more than the relative weights of the MON88017-selected colony following exposure to DAS-59122-7 relative to its paired non-Bt hybrid. The MON88017-selected colony was intermediate in relative weight, and not significantly different from the diapausing control or non-diapausing control colonies. The relative weight of the MON88017-selected colony on DAS-59122-7 was only $0.18 \pm 0.04$ relative to weight of the same colony on the paired non-Bt hybrid (Fig. 1B).

Relative larval head capsule width (Bt/non-Bt) for DAS-59122-7. There was a significant effect of insect source on the average relative head capsule width for larvae reared on DAS-59122-7 versus its paired non-Bt hybrid. Larvae of the MN field population had significantly larger relative head capsule widths on DAS-59122-7 versus its paired non-Bt hybrid than larvae of the diapausing control, non-diapausing control, or MON88017-selected colonies (Fig. 1C). Larvae of the MON88017-selected colony had head capsule widths significantly larger than those of the paired non-diapausing control colony, though they did not differ significantly from those of the diapausing control colony. The non-diapausing control colony had the smallest relative head capsule widths overall. 
Relative larval recovery (Bt/near-isoline) for MON88017. The relative survival of the MON88017-selected laboratory colony on MON88017 versus its near-isoline was largest $(1.11 \pm 0.20)$ and was significantly greater than the diapausing control colony $(0.09 \pm 0.04)$ (Fig. 1D; Table 4). The relative survival of the MN field population was intermediate between the MON88017-selected and the diapausing control colonies. The MN field population, which had been exposed to Cry3Bb1-expressing corn for four years previously, had significantly greater relative survival on Cry3Bb1-expressing seedlings $(0.43 \pm 0.11)$ than the diapausing control colony $(0.09 \pm 0.04)$ (Fig. 1D). However, this level of relative survival for the $\mathrm{MN}$ field population did not achieve the high level observed with the MON88017-selected colony (selected on Cry3Bb1-expressing corn for $>35$ generations).

Relative larval weight (Bt/near-isoline) for MON88017. When reared on MON88017 seedlings, larvae of the MN field population and the MON88017-selected colony weighed significantly more than those of the diapausing control colony relative to weight on near-isoline plants (Fig. 1E). Despite the low relative survival of the MN field population on Cry3Bb1-expressing seedlings versus the MON88017-selected colony, the MN field larvae that did survive had relative larval weights $(0.75 \pm 0.08)$ similar to those of the MON88017-selected colony (Fig. 1E).

Relative larval head capsule width (Bt/near-isoline) for MON88017. There were no significant differences between the head capsule width of the MN field population and MON88017-selected colony (Fig. 1F; Table 4).

\section{Greenhouse Pot Assay}


Relative larval recovery. Larval recovery was significantly impacted by the main effects of insect source, corn type, and trial (Table 4). The relative survival of the MN field population was significantly greater $(0.63 \pm 0.12 ; 0.5 \pm 0.15)$ than the diapausing control colony $(0.25 \pm 0.05 ; 0.08 \pm 0.04)$ on DAS-59122-7 and MON88017, respectively (Fig. 2A). Additionally, the survival of both populations was significantly greater on DAS-59122-7 than MON88017.

Relative larval weight. Relative larval weight was significantly impacted by the main effects of corn type and trial (Table 4). When averaged across insect sources, relative larval weight on DAS-59122-7 was lower than relative larval weight on MON88017 (Fig. 2B).

Relative head capsule width. Relative head capsule width was affected by the main effects of insect source, corn type, trial, and the insect source $\times$ corn type interaction (Table 4). The relative head capsule width was greater for the MN field population than the diapausing control colony on MON88017, but not DAS-59122-7 (Fig. 2C).

\section{DISCUSSION}

Complete resistance to Cry34/35Ab1 has not been reported in the refereed literature. Even after 10 generations of selection in the laboratory, colony fitness (survival to adulthood in this instance) of two selected colonies on DAS-59122-7 was only 20\% of the same colonies on near-isoline corn (Lefko et al. 2008). There also was no difference between selected and control populations in diet assays (Nowatzki et al. 2008) despite between 15- and 58-fold increases in survival (Lefko et al. 2008). In contrast, nearly complete resistance to Cry3Bb1, mCry3A, and eCry3.1 Ab was reported within just a few generations of laboratory selection every time it was tried (Meihls et al. 2008, 2011, 2012; 
Oswald et al. 2011; Frank et al. 2013) and when data were available, these had significant differences in diet assays also. Until very recently (Gassmann et al. 2016), field populations collected from corn expressing Cry34/35Ab1 had not been shown to demonstrate either incomplete or complete resistance. Now, two populations of western corn rootworm (Gassmann et al. 2016 and this study) located more than $160 \mathrm{~km}$ from one another have developed incomplete resistance to Cry34/35Ab1. This suggests that resistance to Cry34/35Ab1 is developing independently in multiple rootworm populations as has occurred with resistance to Cry3Bb1 (Gassmann et al. 2011; Wangila et al. 2015; Zukoff et al. 2016). As laboratory selection experiments have shown Cry34/35Ab1 resistance to take many generations of selection (Lefko et al. 2008; Deitloff et al. 2016), the level of resistance to Cry34/35 Ab1 found in the MN field population is not close to full resistance. Instead, we present evidence that progeny of adults collected from the SmartStax ${ }^{\circledR}$ corn field in Minnesota show evidence of incomplete resistance to Cry34/35Ab1-expressing corn in multiple bioassays.

The $\mathrm{MN}$ field population had significantly greater $\mathrm{LC}_{50}$ and $\mathrm{EC}_{50}$ values in the Cry34/35Ab1 and Cry3Bb1 diet toxicity assay when compared with the control colonies (Table 3). Although the MN field population's Cry34/35Ab1 diet toxicity data fall within the range of data collected from field populations in the past (EPA 2014), these data were significantly greater than those of the diapausing control colony. Historical data for western corn rootworm populations exposed to Cry34/35Ab1 in diet toxicity assays is highly variable. This variability could be due to changes in the length of assays as well as differences in baseline susceptibility between western corn rootworm populations (EPA 2014), or even how the $\mathrm{LC}_{50}$ and $\mathrm{EC}_{50}$ values were calculated. Even selected populations 
with greater than a 15-fold increase in survivorship did not show significantly elevated LC $_{50}$ values (Nowatzki et al. 2008), so it could also be that the resistance mechanism to Cry34/35Ab1 cannot be detected in diet assays. Plant-based bioassay data from this study (Figs. 1A, 1C, and 2A; Table 3) also suggest this population had both resistance to Cry3Bb1 and incomplete resistance to Cry34/35Ab1. Since resistance to both toxins in SmartStax ${ }^{\circledR}$ was present at some level, this may have been the cause for the high damage to SmartStax ${ }^{\circledR}$ corn in the Minnesota field where adults were collected. This damage may have been prevented by following best management practices (Andow et al. 2016) for western corn rootworm, such as rotating to soybean or another non-host, rotating modes of action, or planting corn expressing multiple proteins (EPA 2016), as was done to this field following this discovery.

Baseline survival data are available for western corn rootworm larvae exposed to DAS-59122-7; Binning et al. (2010) observed 33\% survivorship on DAS-59122-7 relative to near-isoline survivorship after $17 \mathrm{~d}$ for two previously unexposed populations. Survivorship of the MN population was 2.1- and 1.9-fold greater in seedling and greenhouse pot assays, respectively, when compared to the Binning et al. (2010) data. Earlier data for an unexposed colony fed Cry3Bb1-expressing corn (Meihls et al. 2008) documented a relative survival of 0.25 . When we compared the MN survival data to the previous relative survival rate of a control colony on Cry3Bb1-expressing corn, we observed 1.7- and 2.0-fold increases in rates of relative survival in the seedling and greenhouse pot assays, respectively.

The $\mathrm{Cry} 3 \mathrm{Bb} 1 \mathrm{LC}_{50}$ and $\mathrm{EC}_{50}$ values of larvae from the $\mathrm{MN}$ field population were at least 18.6- and 12-fold greater than the greatest baseline $\mathrm{LC}_{50}$ and $\mathrm{EC}_{50}$ values recorded 
for different Nebraska field populations of western corn rootworm prior to the commercialization of Cry3Bb1 (Siegfried et al. 2005). For Cry3Bb1 diet toxicity studies, the MON88017-selected and MN populations were too resistant for accurate calculation of $\mathrm{LC}_{50}$ values in our study because the highest dose provided by Monsanto, $170.8 \mu \mathrm{g} / \mathrm{cm}^{2}$, produced less than $50 \%$ mortality in the population. In future work, higher doses of Cry3Bb1 will need to be included when performing diet toxicity testing on potentially resistant populations if accurate data are to be collected.

The population collected from the Minnesota SmartStax ${ }^{\circledR}$ field included some teneral adults, which means these recently emerged insects were most certainly from this field. However, there is no way to determine what percentage of adults collected had emerged from this field versus neighboring fields. This field was consistently planted later than neighboring fields, and movement of adults from nearby fields into late pollinating fields can be significant (Naranjo 1994). Some of the data indicate that the MN field population was resistant to both Cry3Bb1 and Cry34/35Ab1 (Figs. 1A, 1C-F, and 2A; Table 3), but also demonstrate resistance was not complete (Figs. 1A-F, and 2A-C). Due to the reduced development on DAS-59122-7 hybrid compared to the non-Bt hybrid, incomplete resistance is the only logical conclusion. This experiment also emphasizes the need to use multiple techniques to evaluate potential resistance(s) in populations (Zukoff et al. 2016).

The field where the MN field population was collected had been planted to Cry3Bb1-expressing corn from 2009-2012 and appears to have put a significant strain on the durability of the pyramided product, SmartStax ${ }^{\circledR}$. This observation supports previous modeling studies (Zhao et al. 2005; Onstad and Meinke 2010). As we are not certain of 
the origin(s) of all collected insects, we offer some possible causes for the failure of the SmartStax ${ }^{\circledR}$ product which include: 1) a large CryBb1-resistant population overwhelmed the Cry34/35Ab1 toxin, 2) an influx of adults of a Cry34/35Ab1-resistant population from another field, such as a Herculex field on the same farm also had performance issues in 2013 or several fields within $25 \mathrm{~km} \mathrm{SSW}$ of this site had unusual amounts of feeding on Herculex and SmartStax ${ }^{\circledR}$ hybrids in 2012, or 3) two separate populations of western corn rootworm resistant to Cry3Bb1 or Cry34/35Ab1 could be present in the same field.

These results indicate the early stages of resistance development (i.e. incomplete resistance) as larvae showed some developmental delays on corn expressing Cry34/35Ab1 (Rudeen and Gassmann 2013; Shrestha et al. 2016) or Cry3Bb1 when compared to the respective isolines. When the SmartStax ${ }^{\circledR}$ field damage is coupled with these data, these points indicate the $\mathrm{MN}$ field population was significantly less susceptible to corn expressing Cry34/35Ab1 than other populations tested in this study or other studies (Gassmann et al. 2011, 2016; Shrestha et al. 2016; Wangila et al. 2015). Insects were only evaluated on corn expressing Cry34/35Ab1 or Cry3Bb1 separately, so we cannot draw conclusions about what these data mean for a pyramided product. We present the second case of a shift in susceptibility by western corn rootworm to corn expressing Cry34/35Ab1.

Cry34/35Ab1-expressing corn has been on the market since 2006 (EPA 2005). Field failures have been much more common with the other single gene products targeting rootworm than corn expressing Cry34/35Ab1. However, as this product ages, and gains market share as a pyramid with other genes, selection continues to increase. This is especially the case in areas with resistance to Cry3Bb1, mCry3A, and/or eCry3.1 Ab (Zhou et al. 2005; Zukoff et al. 2016). Industry, regulatory agencies, and growers need to be 
mindful that shifts in susceptibility to toxins become more likely as selection increases (Porter et al. 2012). As shifts in susceptibility begin to occur, such as documented here, best management practices must be implemented quickly to prevent further development and spread of rootworm genotypes with increased tolerance to Cry34/35Ab1 (Andow et al. 2016). Since no fully independent, new modes of action have been registered for commercial use in transgenic corn against rootworms as since 2006, preserving Cry34/35Ab1 for as long as possible is vital for rootworm management for the foreseeable future.

\section{MATERIAL AND METHODS}

\section{Field History}

In 2013, a grower in Brown County, MN, reported greater-than-expected damage to SmartStax ${ }^{\circledR}$ corn, which expresses both Cry34/35Ab1 and Cry3Bb1 proteins. In each of the previous $4 \mathrm{yr}$, the field was planted to corn expressing Cry3Bb1. We investigated the field, confirmed Bt expression of both Cry3Bb1 and Cry34Ab1 proteins through lateral flow strip testing (Envirologix, Portland, ME), sampled roots to verify corn rootworm injury, and confirmed more than one node of injury per SmartStax ${ }^{\circledR}$ plant. After the greaterthan-expected damage was documented, adult insects were collected and eggs were subsequently obtained. Following this incidence of greater-than-expected damage, a best management practice was implemented (rotation to soybean, Andow et al. 2016) to prevent further survival of this population.

\section{Insect Sources}


Minnesota field population. Western corn rootworm adults were collected from the field on 25 September 2013. Adults recovered from this field were delivered to French Agricultural Research in Lamberton, MN, on the day of collection where they were allowed to mate, if needed, and oviposit. Plastic containers $(8 \mathrm{~cm}$ wide $\times 5 \mathrm{~cm}$ deep $)$ with unsieved field soil from the area were provided as an oviposition substrate and resulting eggs were overwintered at $7-8{ }^{\circ} \mathrm{C}$ after adjustment periods of 2 wk each at $24{ }^{\circ} \mathrm{C}$ and $15{ }^{\circ} \mathrm{C}$. Oviposition dishes with eggs were provided to the USDA-ARS Plant Genetics Research Unit in Columbia, MO on 28 May 2014. Insects from this population will, hereafter, be referred to as "MN field".

Methods for flotation of western corn rootworm eggs from soil were modified from Števo and Cagaán̆ (2012) for our purposes. Briefly, a 2M MgSO 4 solution was prepared by mixing $493 \mathrm{~g}$ of Epsom salts $\left(\mathrm{MgSO}_{4} \cdot 7 \mathrm{H}_{2} \mathrm{O}\right)$ (Vi-Jon Inc., Smyrna, Tennessee, USA) per liter of water. The Epsom salt solution was then placed in a 2 liter graduated cylinder and 0.47 liter of soil was carefully added. Extracted eggs were collected with a transfer pipette and placed into a $0.15 \%$ agar solution for suspension. Eggs were gently stirred to create a homogenous solution. Five $1 \mathrm{ml}$ samples were counted to estimate the number of eggs per $\mathrm{ml}$, allowing for extrapolation to the entire solution.

Control colonies. Control western corn rootworm colonies originated from the USDA-ARS laboratory in Brookings, SD, and included both the primary diapausing colony (Jackson 1986) and the primary non-diapausing colony (Branson 1976). Both colonies were collected prior to the release of transgenic crops. Insects from the primary diapausing colony will, hereafter, be referred to as "diapausing control". Insects from the primary non-diapausing colony will, hereafter, be referred to as "non-diapausing control". 
A shipment of the non-diapausing control eggs was received from the USDA-ARS laboratory in Brookings, SD, and the colony was maintained for multiple generations at the USDA-ARS laboratory in Columbia, MO. Eggs of the diapausing control were shipped from the USDA-ARS laboratory in Brookings, SD, and removed from cold storage as needed for experiments.

MON88017-selected colony. This colony was developed in 2013 by mixing three MON88017-selected colonies from Meihls et al. $(2008,2012)$ to reduce labor and maintenance costs. Insects of this colony will, hereafter, be referred to as "MON88017selected". This non-diapausing colony from the USDA-ARS laboratory in Columbia, MO had been reared on a Cry3Bb1-expressing corn hybrid, DKC 61-88 (Monsanto Company, St. Louis, Missouri, USA) and its non-Bt near-isoline corn hybrid, DKC 61-79 (Monsanto Company) as described in Meihls et al. (2012) and more recently reared continuously on Cry3Bb1-expressing corn for more than 35 generations. A near-isoline corn hybrid shares similar genetics to the Bt corn hybrid but does not contain the Bt gene.

Rearing conditions. Non-diapausing insects were reared under the following conditions at the Columbia, MO, site. Western corn rootworm adults were reared in cages (30 $\mathrm{cm}^{3}$, Megaview Science Co., Ltd., Taichung, Taiwan) with a photoperiod of 14:10 (L:D) h at $25^{\circ} \mathrm{C}$. Adults were fed isoline leaf tissue, zucchini slices, adult artificial diet (Frontier Agricultural Sciences, Newark, Delaware, USA), and water. Petri dishes containing 70 mesh sieved autoclaved field soil served as an oviposition site for females and were replaced on a weekly basis. Eggs were recovered from oviposition plates by washing through a 60 mesh sieve.

\section{Diet Toxicity Assay}


Diet toxicity assays were conducted in June 2014 by Custom Bio-Products in Maxwell, IA, with methods similar to Siegfried et al. (2005). The Cry34Ab1 and Cry35Ab1 proteins were provided by Dow AgroSciences. The Cry3Bb1 protein was provided by Monsanto Company. Briefly, neonate larvae of the non-diapausing control, MON88017selected, and MN field sources were exposed to increasing concentrations of Cry3Bb1 protein overlaid on artificial diet $\left(0-170.80 \mu \mathrm{g} / \mathrm{cm}^{2}\right)$ for $5 \mathrm{~d}$. Neonate larvae of the diapausing control and MN field sources were exposed to increasing concentrations of both Cry34Ab1 and Cry35Ab1 proteins overlaid on artificial diet $\left(0-60 \mu \mathrm{g} / \mathrm{cm}^{2}\right)$ for $5 \mathrm{~d}$. Testing with Cry3Bb1 and Cry34/35Ab1 were conducted separately at a similar time. Larval survival and weight data were recorded upon completion.

\section{Seedling Assays}

For the assay, a two-way factorial (western corn rootworm source $\times$ corn type) arrangement was used in a randomized complete block design for the seedling assay with DAS-59122-7 corn (DuPont Pioneer, variety 33Y76) and its paired non-Bt hybrid (DuPont Pioneer, variety $34 \mathrm{H} 31)$. The same experimental design was used for a separate seedling assay with MON88017 corn and its near-isoline. All corn seeds used in this study were untreated, but were still washed with a $10 \%$ bleach solution before being dried and used in assays.

Eggs were placed in a $0.15 \%$ agar solution and gently stirred to achieve uniform egg density. The number of eggs per ml were counted a minimum of three times, averaged, and then dispensed at the targeted rate into the bottom of a plastic container $(15 \times 10 \mathrm{~cm}$ GladWare®, The Glad Products Company, Oakland, California, USA). Different rates were used due to limited egg availability of some insect sources. The number of eggs per 
container for each insect source was as follows: MON88017-selected (250 eggs), diapausing control (312 eggs), non-diapausing control (250 eggs), and MN field (200 eggs). Based on hatch rates and hatch delays from subsamples taken earlier, eggs of the MN field population and diapausing control colony were incubated at $23{ }^{\circ} \mathrm{C}$ on 7 August 2014, and 11 August 2014, respectively, in $2 \mathrm{~cm}$ of growth medium and $20 \mathrm{ml}$ of tap water per plastic container. Growth medium for all experiments was mixed by volume at a 2:1 ratio of soil:Pro-Mix BX potting medium (Premier Horticulture Inc., Quakertown, Pennsylvania, USA) and then autoclaved. Pre-incubation was done to achieve a more synchronized hatch at a similar corn stage of all insect sources before adding seed. For the MON88017-selected and non-diapausing control colonies, eggs, tap water, and $2 \mathrm{~cm}$ of growth medium were added to plastic containers on 15 August 2014.

Corn seed (13 ml, 50 kernels) were spread across the growth medium surface (eggs at bottom) and covered with approximately $4 \mathrm{~cm}$ of growth medium followed by 80 ml of tap water on 15 August 2014. Containers that had seed from DAS-59122-7 or its paired non-Bt hybrid were then placed into the model LIFLY-VIEW incubator (Sheldon Manufacturing, Inc., Cornelius, Oregon, USA) at $25^{\circ} \mathrm{C}$. Containers that were planted with MON88017 or its near-isoline were placed in a Conviron (Model E15, Controlled Environments, Inc., Pembina, North Dakota, USA) set to run at $25^{\circ} \mathrm{C}$. The two seedling assays were run simultaneously in separate growth chambers due to space limitations. Two subsamples of 50-100 eggs from each insect source were placed onto moistened filter paper in Petri dishes and then placed in each growth chamber to observe the start of hatch. Similar time to first hatch was observed for each insect source after the planned pre-incubation of the MN field and diapausing control insect sources described above. 
Containers with corn seedlings were removed from the incubator $14 \mathrm{~d}$ after the first larva was observed in hatch plates held in the same growth chamber. Aboveground plant tissue was cut and the growth medium with root tissue was placed into Tullgren funnels with a 60-W incandescent light bulb for $2 \mathrm{~d}$. Larvae were collected in $473 \mathrm{ml}$ jars containing approximately $2.5 \mathrm{~cm}$ of water with jars inspected daily. Larvae were then transferred to scintillation vials containing $95 \%$ ethanol after $1 \mathrm{~d}$ and $2 \mathrm{~d}$. Counts of each sample were done under a dissecting microscope, head capsule width measurements were made using an ocular micrometer, and larvae were weighed after drying in an oven (Thelco model 16, GCA/Precision Scientific Co., Chicago, Illinois, USA). For samples that contained more than 10 larvae, a subsample of 10 larvae was taken and the head capsule widths of larvae were measured using an ocular micrometer. If samples contained fewer than 10 larvae, then the head capsule widths of all larvae were measured. Weights were recorded after desiccation in an oven (scale model AB135-S FACT, Mettler Toledo Inc., Columbus, Ohio, USA).

\section{Greenhouse Pot Assay}

Two trials with five replications each were set up as a two-way factorial (western corn rootworm insect source $\times$ corn type) arrangement in a randomized complete block design. These trials were planted $8 \mathrm{~d}$ apart and infested with eggs $7 \mathrm{~d}$ apart. Both trials contained only the diapausing control and $\mathrm{MN}$ field sources. In each replication within each trial, the same four corn hybrids described above were used: MON88017 and its nearisoline, and DAS-59122-7 and its paired non-Bt hybrid. Larvae from these insect sources were exposed to all four corn hybrids in each replication of both trials. 
Clay pots (Model 100043015, Home Depot, Columbia, Missouri, USA) filled with growth medium (as described above) were watered until saturation prior to the planting of seeds. Pots contained 3.3 liter of growth medium identical to that used in the seedling assays. Two corn seeds were planted per pot equidistant from the center at a depth of $\sim 2.5$ cm. A 114- $\mu$ m stainless steel mesh screen (TWP Inc., Berkeley, California) was glued over the pot drainage hole to prevent larval escape. Following coleoptile emergence, the entirety of the smaller seedling was removed to achieve one corn plant per pot.Pots were watered to saturation as needed throughout the entirety of the experiment. Once plants reached the V3-V4 growth stages (Ritchie et al. 1992), a small hole was bored 1-2 cm from the base of the plant to a depth of $\sim 2.5 \mathrm{~cm}$ and used as the infestation site. All pots were infested with $\sim 80$ eggs of one of the two insect sources. Extra pots not used in the replications were infested with $\sim 80$ eggs from the diapausing control colony to be checked for larval development.

To monitor start of hatch, small subsamples of western corn rootworm eggs were placed in Petri dishes as described previously. Two or more Petri dishes were placed in the greenhouse with the pots, and two or more were placed in a Percival at $25{ }^{\circ} \mathrm{C}$ for each insect source. Petri dishes were evaluated daily to determine the start of hatch. Again, similar time to first hatch was observed for each insect source. By monitoring the extra pots from each planting date, we were able to estimate when larvae were at or close to the third instar. Once third instars were observed for a planting date, aboveground biomass was cut 5-7.6 cm from the growth medium surface. Growth medium with root tissue was treated the same as above in the seedling assays with one difference. Due to the volume of growth medium and tissue in pots, each sample was kept in a Tullgren funnel for $4 \mathrm{~d}$. Each funnel's 
jar was checked on day 2 and 4. Larvae were collected and processed using the same methods as the seedling assay.

\section{Statistical Analysis}

Diet Toxicity Assays. All data were analyzed using SAS ${ }^{\circledR}$ software version 9.4 (SAS 2013). Prior to analysis, protein concentrations were converted to a log scale $(\log \operatorname{lose}=\log (\operatorname{conc}+.01)) / \log (3)$ for $\mathrm{Cry} 34 / 35 \mathrm{Ab} 1$ and $\log \operatorname{lose}=\log 2($ conc +.01$)$ for Cry3Bb1. These log scale conversions were done due to the tripling and doubling of nonzero doses for Cry34/35Ab1 and Cry3Bb1, respectively. $\mathrm{LC}_{50}$ (i.e. concentration required to produce mortality of $50 \%$ of the larvae) on artificial diet bioassays was determined using a probit analysis (PROC PROBIT). Larval weight was analyzed using a nonlinear regression (PROC NLIN). Average larval weight was calculated per replicate by dividing total larval weight by initial number of larvae (essentially giving dead larvae a weight of 0 as in Siegfried et al. (2005)). Average larval weight was then used to determine the $\mathrm{EC}_{50}$ (i.e. concentration required to produce a $50 \%$ weight reduction of the larvae). The resistance ratios were calculated by dividing the $\mathrm{LC}_{50}$ of the selected insect source by the control insect source. Relative potency values were calculated by dividing the $\mathrm{EC}_{50}$ of the selected source by the control insect source. For both analyses, only replicates with control mortality $<20 \%$ were considered.

Seedling Assays. Data from DAS-59122-7 and MON88017 seedling assays were analyzed separately. All variables were first converted to relative values based on performance on Bt corn relative to performance on non-Bt corn (i.e., recovery from Bt for each replication/overall average recovery from the paired non-Bt hybrid for that insect source, producing a relative survival value), rank transformed as outlined by Conover and 
Iman (1981), and then analyzed using a generalized linear mixed model (PROC GLIMMIX). The data were not normally distributed and common transformations did not result in homogeneity of variance, thus rank transformations were necessary to meet the assumptions of the analysis (Snedecor and Cochran 1989). All variables (relative survival, relative weight, and relative head capsule width) were run as separate analyses. Larval data were analyzed as a randomized complete block, two-way factorial (four western corn rootworm sources $\times$ two corn types for DAS-59122-7, three western corn rootworm sources $\times$ two corn types for MON88017). Analysis of the MON88017 relative head capsule width data excluded the diapausing control due to a low number of replications. The model contained the main effect of insect source. Replications were included as random variables.

Greenhouse Pot Assay. Larval data were analyzed as a randomized complete block two-way factorial (two western corn rootworm sources $\times$ four corn types) using a generalized linear mixed model. Again, all variables were first converted to relative values based on performance on Bt corn relative to performance on non-Bt corn. All larval data were first rank transformed (Conover and Iman 1981) and then analyzed with a Poisson distribution (dist=poisson option in PROC GLIMMIX). Again, the data were not normally distributed and common transformations did not result in homogeneity of variance, so rank transformations were necessary. All variables (larval count, weight, and head capsule width) were run as separate analyses. The model contained the main effects of insect source, corn type, trial, and all possible interactions. Replications within trial were included as random variables. 


\section{ACKNOWLDGEMENTS}

We thank Monsanto Company and Dow AgroSciences, respectively, for Cry3Bb1 and Cry34/35Ab1 proteins and artificial diet for the diet toxicity studies. We also thank Monsanto Company and DuPont Pioneer for corn seed associated with plant bioassays. Collection of corn rootworm populations for this study was funded by the corn farmers of Minnesota through their corn check-off investment. A grant from Monsanto Company's Corn Rootworm Knowledge Research Program helped fund the analysis and writing of this manuscript. Also, we would like to thank Tom Clark (Monsanto Company), Miles Lepping and Nicholas Storer (Dow Agrosciences) and Clint Pilcher (DuPont Pioneer) for comments on an earlier draft. We also thank members of Dalton Ludwick's dissertation committee, Tom Coudron (USDAARS) and Debbie Finke and Mark Ellersieck (University of Missouri) for reviewing an earlier draft of this manuscript. Lastly, we thank two anonymous reviewers for their comments on this manuscript prior to publication. 
Table 3. $\mathrm{LC}_{50}$ and $\mathrm{EC}_{50}$ calculations for larvae exposed to Cry34/35Ab1 and Cry3Bb1 for five days in a diet overlay bioassay

\begin{tabular}{|c|c|c|c|c|c|c|}
\hline Protein & Colony & $\begin{array}{c}\text { Number of } \\
\text { Replications }\end{array}$ & $\begin{array}{c}\mathrm{LC}_{50} \mu \mathrm{g} / \mathrm{cm}^{2} \\
(95 \% \text { C.I. })\end{array}$ & $\begin{array}{c}\text { Resistance } \\
\text { Ratio }^{a} \\
\end{array}$ & $\mathrm{EC}_{50} \mu \mathrm{g} / \mathrm{cm}^{2}(95 \%$ C.I $)$ & $\begin{array}{l}\text { Relative } \\
\text { Potency }^{b}\end{array}$ \\
\hline \multicolumn{7}{|c|}{ Cry34/35Ab1 } \\
\hline & Diapause Cont. & 7 & $0.48(0.28-0.77)$ & & $0.68(0.47-1.00)$ & \\
\hline & Minnesota & 7 & $2.26(1.14-4.25)$ & 4.71 & $2.58(1.99-3.33)$ & 3.78 \\
\hline \multicolumn{7}{|l|}{ Cry3Bb1 } \\
\hline & Non-Diapause Cont. & 5 & $12.92(3.08-50.84)$ & & $11.08(4.28-28.70)$ & \\
\hline & Minnesota & 7 & $>170.80$ & $>13.22$ & $34.07(0.00-495,182.22)$ & 3.07 \\
\hline & MON88017-selected & 6 & $>170.80$ & $>13.22$ & $>170.80$ & $>15.42$ \\
\hline
\end{tabular}

${ }^{a}$ Resistance ratios were calculated by dividing the $\mathrm{LC}_{50}$ of the selected population by the control population.

${ }^{b}$ Relative potency values were calculated by dividing the $\mathrm{EC}_{50}$ of the selected population by the control population. 
Table 4. Analysis of variance for variables in all experiments.

\begin{tabular}{|c|c|c|c|c|c|c|}
\hline Assay Type & Variable & Effect & $\begin{array}{l}\text { Num } \\
\text { DF } \\
\end{array}$ & $\begin{array}{l}\text { Den } \\
\text { DF } \\
\end{array}$ & $\begin{array}{c}F \\
\text { Value } \\
\end{array}$ & $\operatorname{Pr}>F$ \\
\hline \multirow[t]{3}{*}{$\begin{array}{l}\text { Seedling } \\
\text { DAS- } \\
59122-7\end{array}$} & Survival & insect source & 3 & 31 & 7.3 & 0.0008 \\
\hline & Dry Weight & insect source & 3 & 21 & 7.09 & 0.0018 \\
\hline & $\begin{array}{l}\text { Head Capsule } \\
\text { Width }\end{array}$ & insect source & 3 & 27 & 7.58 & 0.0008 \\
\hline \multirow[t]{2}{*}{$\begin{array}{l}\text { Seedling } \\
\text { MON88017 }\end{array}$} & Survival & insect source & 2 & 8 & 30.44 & 0.0002 \\
\hline & $\begin{array}{l}\text { Dry Weight } \\
\text { Head Capsule } \\
\text { Width }\end{array}$ & $\begin{array}{l}\text { insect source } \\
\text { insect source }\end{array}$ & 2 & 7 & 9.37 & 0.0105 \\
\hline \multirow{23}{*}{$\begin{array}{l}\text { Greenhouse } \\
\text { Pot }\end{array}$} & & & & & & \\
\hline & Survival & trial & 1 & 8 & 6.00 & 0.0399 \\
\hline & & insect source & 1 & 24 & 24.02 & $<0.0001$ \\
\hline & & corn type & 1 & 24 & 8.39 & 0.0079 \\
\hline & & trial $\times$ insect source & 1 & 24 & 0.00 & 1.0000 \\
\hline & & $\begin{array}{l}\text { trial } \times \text { corn type } \\
\text { corn type } \times \text { insect }\end{array}$ & 1 & 24 & 0.86 & 0.3626 \\
\hline & & & 1 & 24 & 0.67 & 0.4221 \\
\hline & & insect source & 1 & 24 & 1.32 & 0.2611 \\
\hline & Dry Weight & trial & 1 & 8 & 9.02 & 0.0170 \\
\hline & & insect source & 1 & 17 & 0.72 & 0.4093 \\
\hline & & corn type & 1 & 17 & 14.67 & 0.0013 \\
\hline & & trial $\times$ insect source & 1 & 17 & 0.13 & 0.7217 \\
\hline & & $\begin{array}{l}\text { trial } \times \text { corn type } \\
\text { corn type } \times \text { insect }\end{array}$ & 1 & 17 & 0.44 & 0.5164 \\
\hline & & $\begin{array}{l}\text { source } \\
\text { trial } \times \text { corn type } \times\end{array}$ & 1 & 17 & 0.87 & 0.3647 \\
\hline & & insect source & 1 & 17 & 2.10 & 0.1652 \\
\hline & Head Capsule & & & & & \\
\hline & Width & trial & 1 & 8 & 19.14 & 0.0024 \\
\hline & & insect source & 1 & 19 & 7.49 & 0.0131 \\
\hline & & corn type & 1 & 19 & 19.96 & 0.0003 \\
\hline & & trial $\times$ insect source & 1 & 19 & 0.00 & 0.9957 \\
\hline & & $\begin{array}{l}\text { trial } \times \text { corn type } \\
\text { corn type } \times \text { insect }\end{array}$ & 1 & 19 & 1.52 & 0.2324 \\
\hline & & $\begin{array}{l}\text { source } \\
\text { trial } \times \text { corn type } \times\end{array}$ & 1 & 19 & 6.52 & 0.0194 \\
\hline & & insect source & 1 & 19 & 0.01 & 0.9236 \\
\hline
\end{tabular}



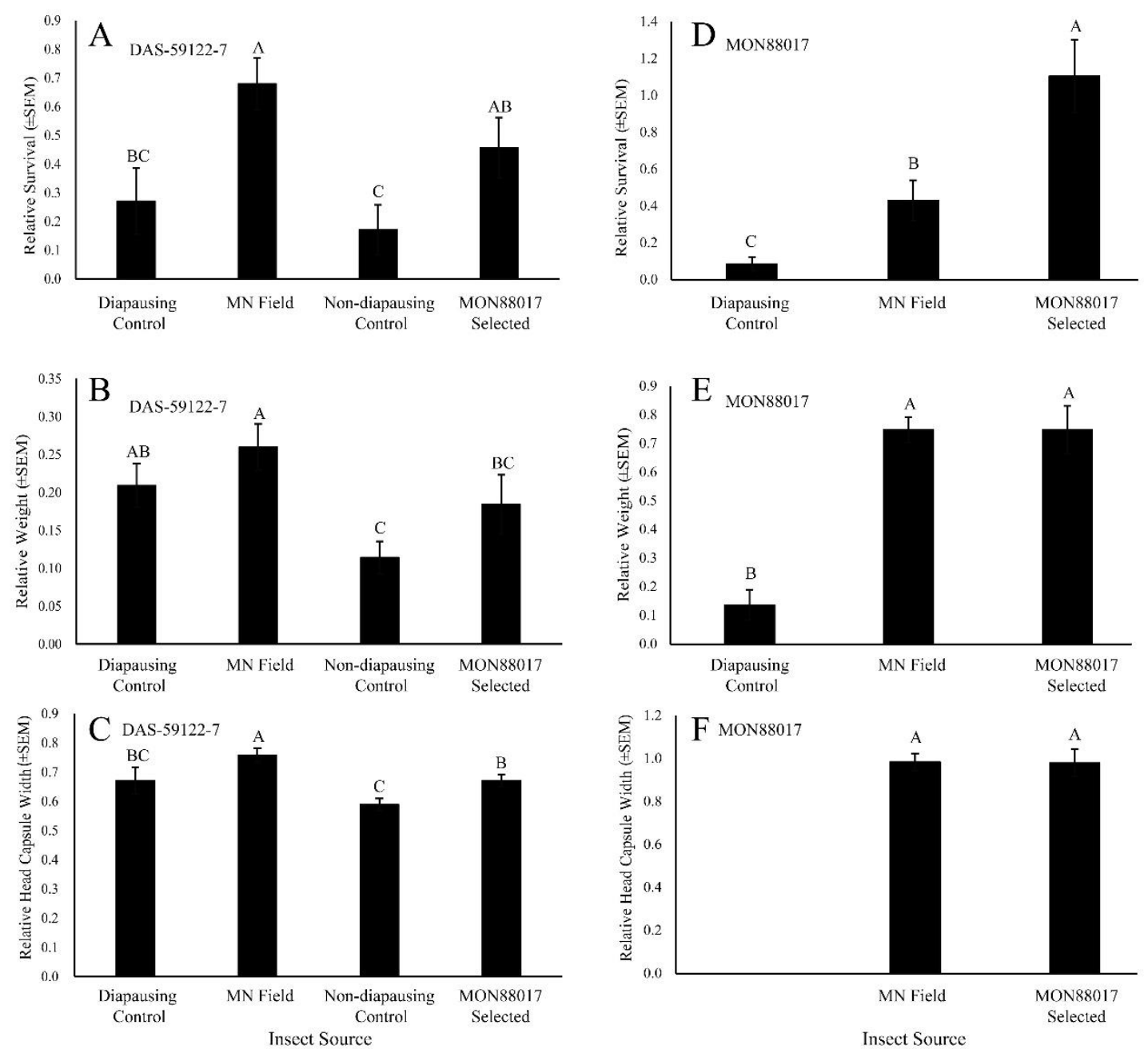

Figure 1. Results of seedling assay on DAS-59122-7 (A-C) and seedling assay on MON88017 (D-F). (A \& D) Relative survival (Bt data/overall average of non-Bt data) of larvae on DAS-59122-7 and MON88017. (B \& E) Relative average weight of recovered larvae on DAS-59122-7 and MON88017. (C \& F) Relative head capsule width of recovered larvae on DAS-59122-7 and MON88017. Uppercase letters indicate significant differences between populations using rank transformed data. Bar heights represent the means of the treatment and error bars represent standard error of the mean. 

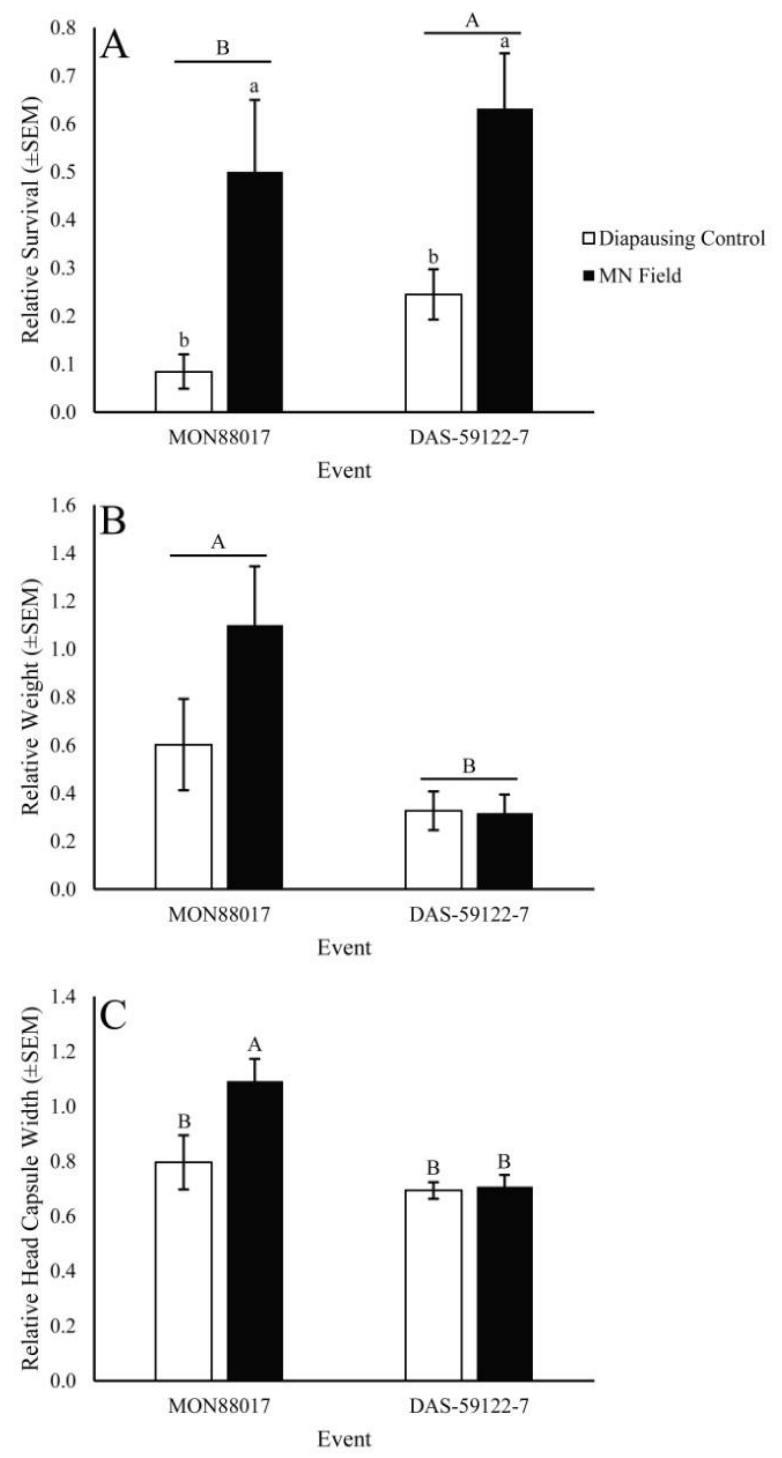

Figure 2. Results of greenhouse pot assay. (A) Relative survival (Bt data/overall average of non-Bt data) of larvae on DAS-59122-7 and MON88017. (B) Relative dry weight of recovered larvae. Letters over lines indicate the main effect of corn. (C) Relative head capsule width of recovered larvae. Uppercase letters indicate significant differences between corn types within populations. Lowercase letters indicate significant differences between populations within corn type. All data were analyzed following a rank transformation. Bar heights represent the means of the treatment. 


\section{References Cited}

Andow, D.A., S.G. Pueppke, A.W. Schaafsma, A.J. Gassmann, T.W. Sappington, L.J. Meinke, P.D. Mitchell, T.M. Hurley, R.L. Hellmich, and R.P. Porter. 2016. Early Detection and Mitigation of Resistance to Bt Maize by Western Corn Rootworm (Coleoptera: Chrysomelidae). Journal of Economic Entomology 109 (1): 1-12. https://doi.org/10.1093/jee/tov238.

Binning, R. R., S. A. Lefko, A. Y. Millsap, S. D. Thompson, and T. M. Nowatzki. 2010. Estimating Western Corn Rootworm (Coleoptera: Chrysomelidae) Larval Susceptibility to Event DAS-59122-7 Maize. Journal of Applied Entomology 134 (7): 551-61. https://doi.org/10.1111/j.1439-0418.2010.01530.x.

Branson, T.F. 1976. The Selection of A Non-diapause Strain of Diabrotica virgifera virgifera (Coleoptera: Chrysomelidae). Entomologia Experimentalis et Applicata 19 (2): 148-54. https://doi.org/10.1111/j.1570-7458.1976.tb02591.x.

Conover, W.J., and R.L. Iman. 1981. Rank Transformations as a Bridge between Parametric and Nonparametric Statistics. American Statistician 35 (3): 124-28. https://doi.org/10.1080/00031305.1981.10479327.

National Research Council. 1985. Pesticide Resistance Strategies and Tactics for Management."

Deitloff, J., M.W. Dunbar, D.A. Ingber, B.E. Hibbard, and A.J. Gassmann. 2016. Effects of Refuges on the Evolution of Resistance to Transgenic Corn by the Western Corn Rootworm, Diabrotica virgifera virgifera LeConte. Pest Management Science 72 (1): 190-98. https://doi.org/10.1002/ps.3988. 
[EPA] Environmental Protection Agency. 2003. Bacillus thuringiensis Cry3Bb1 Protein and the Genetic Material for Its Production (Vector zmir121) in Event MON863 Corn Fact Sheet. http://www.epa.gov/pesticides/biopesticides/ingredients_keep/factsheets/factsheet _006484.htm.

[EPA] Environmental Protection Agency. 2005. Bacillus thuringiensis Cry34Ab1 and Cry35Ab1 and the Genetic Material Necessary for Their Production (Plasmid Insert PHP 17662) in Event DAS-59122-7 Corn (006490) Fact Sheet. http://www.epa.gov/oppbppd1/biopesticides/ingredients_keep/factsheets/factsheet _006490.htm\#description.

[EPA] Environmental Protection Agency. 2007. Biopesticide Registration Action Document. Modified Cry3A Protein and the Genetic Material Necessary for Its Production (via Elements of pZM26) in Event MIR604 Corn SYNIR604-8. http://www.epa.gov/oppbppd1/biopesticides/ingredients/tech_docs/brad_006509. pdf.

[EPA] Environmental Protection Agency. 2014. Review of 2012 Corn Rootworm Resistance Monitoring Data for Bt Corn Products Containing Cry34/35Ab1. http://www.regulations.gov/\#!documentDetail;D=EPA-HQ-OPP-2011-09220044.

[EPA] Environmental Protection Agency. 2015. Bacillus thuringiensis eCry3.1Ab Protein and the Genetic Material Necessary for Its Production (Vector PSY12274). 
http://iaspub.epa.gov/apex/pesticides/f?p=CHEMICALSEARCH:3:0::NO:1,3,31, 7,12,25:P3_XCHEMICAL_ID:1297.

[EPA] Environmental Protection Agency. 2016. Framework to Delay Corn Rootworm Resistance. https://www.epa.gov/regulationbiotechnology-under-tsca-andfifra/framework-delaycorn-rootworm-resistance.

Frank, D.L, A. Zukoff, J. Barry, M.L Higdon, and B.E. Hibbard. 2013. Development of Resistance to eCry3.1 Ab-Expressing Transgenic Maize in a Laboratory-Selected Population of Western Corn Rootworm (Coleoptera: Chrysomelidae). Journal of Economic Entomology 106 (6): 2506-13. https://doi.org/10.1603/EC13148.

Gassmann, A.J., J.L. Petzold-Maxwell, E.H. Clifton, M.W. Dunbar, A.M. Hoffmann, D.A. Ingber, and R.S. Keweshan. 2014. Field-Evolved Resistance by Western Corn Rootworm to Multiple Bacillus thuringiensis Toxins in Transgenic Maize. Proceedings of the National Academy of Sciences of the United States of America 111 (14): 5141-46. https://doi.org/10.1073/pnas.1317179111.

Gassmann, A.J., J.L. Petzold-Maxwell, R.S. Keweshan, and M.W. Dunbar. 2011. Field-Evolved Resistance to Bt Maize by Western Corn Rootworm. PLoS ONE 6 (7). https://doi.org/10.1371/journal.pone.0022629.

Gassmann, A.J., R.B. Shrestha, S.R.K. Jakka, M.W. Dunbar, E.H. Clifton, A.R. Paolino, D.A. Ingber, et al. 2016. Evidence of Resistance to Cry34/35 Ab1 Corn by Western Corn Rootworm (Coleoptera: Chrysomelidae): Root Injury in the Field and Larval Survival in Plant-Based Bioassays. Journal of Economic Entomology 109 (4): 1872-80. https://doi.org/10.1093/jee/tow110. 
Hutchison, W.D., E.C. Burkness, P.D. Mitchell, R.D. Moon, T.W. Leslie, S.J. Fleischer, M. Abrahamson, et al. 2010. Areawide Suppression of European Corn Borer with Bt Maize Reaps Savings to Non-Bt Maize Growers. Science 330 (6001): 222-25. https://doi.org/10.1126/science.1190242.

Jackson, J.J. 1986. Rearing and Handling of Diabrotica virgifera virgifera and Diabrotica undecimpunctata Howardi. In Methods for the Study of Pest Diabrotica, edited by J.L. Krysna and T.A. Miller, 25-47. New York, New York: Springer-Verlag.

Lefko, S. A., T. M. Nowatzki, S. D. Thompson, R. R. Binning, M. A. Pascual, M. L. Peters, E. J. Simbro, and B. H. Stanley. 2008. Characterizing Laboratory Colonies of Western Corn Rootworm (Coleoptera: Chrysomelidae) Selected for Survival on Maize Containing Event DAS-59122-7. Journal of Applied Entomology 132 (3): 189-204. https://doi.org/10.1111/j.1439-0418.2008.01279.x.

Meihls, L.N., M.L. Higdon, M.R. Ellersieck, B.E. Tabashnik, and B.E. Hibbard. 2012. Greenhouse-Selected Resistance to Cry3Bb1-Producing Corn in Three Western $\begin{array}{lllll}\text { Corn } & \text { Rootworm } & \text { Populations. } & \text { PLoS } & \text { ONE }\end{array}$ https://doi.org/10.1371/journal.pone.0051055.

Meihls, L.N., M.L. Higdon, B.D. Siegfried, N.J. Miller, T.W. Sappington, M.R. Ellersieck, T.A. Spencer, and B.E. Hibbard. 2008. Increased Survival of Western Corn Rootworm on Transgenic Corn within Three Generations of on-Plant Greenhouse Selection. Proceedings of the National Academy of Sciences of the United States of America $105 \quad$ (49): 19177-82. https://doi.org/10.1073/pnas.0805565105. 
Meihls, L.N., M.L. Higdon, M. Ellersieck, and B.E. Hibbard. 2011. Selection for Resistance to mCry3A-Expressing Transgenic Corn in Western Corn Rootworm. Journal of Economic Entomology $104 \quad$ (3): 1045-54. https://doi.org/10.1603/EC10320.

Naranjo, S.E. 1994. Flight Orientation of Diabrotica virgifera virgifera and D.barberi (Coleoptera: Chrysomelidae) at Habitat Interfaces. Annals of the Entomological Society of America 87 (3): 383-94. https://doi.org/10.1093/aesa/87.3.383.

Nowatzki, T.M., S.A. Lefko, R.R. Binning, S.D. Thompson, T.A. Spencer, and B.D. Siegfried. 2008. Validation of a Novel Resistance Monitoring Technique for Corn Rootworm (Coleoptera: Chrysomelidae) and Event DAS-59122-7 Maize. Journal of Applied Entomology 132 (3): 177-88. https://doi.org/10.1111/j.14390418.2008.01270.x.

National Research Council. 1986. Pesticide resistance strategies and tactics for management. National Academy Press. Washington, D.C.

Oleson, J.D., Y.-L. Park, T.M. Nowatzki, and J.J. Tollefson. 2005. Node-Injury Scale to Evaluate Root Injury by Corn Rootworms (Coleoptera: Chrysomelidae). Journal of Economic Entomology 98 (1): 1-8.

Onstad, D.W., and L.J. Meinke. 2010. Modeling Evolution of Diabrotica virgifera virgifera (Coleoptera: Chrysomelidae) to Transgenic Corn with Two Insecticidal Traits. Journal of Economic Entomology 103 (3): 849-60. https://doi.org/10.1603/EC09199. 
Oswald, K.J., B.W. French, C. Nielson, and M. Bagley. 2011. Selection for Cry3Bb1 Resistance in a Genetically Diverse Population of Nondiapausing Western Corn Rootworm (Coleoptera: Chrysomelidae). Journal of Economic Entomology 104 (3): 1038-44. https://doi.org/10.1603/EC10312.

Porter, P., E. Cullen, T. Sappington, A. Schaafsma, S. Pueppke, D. Andow, J. Bradshaw, et al. 2012. 22 Members and Participants of North Central Coordinating Committee NCCC246 and Other Corn Entomologists.”

Ritchie, S.W., J.J. Hanway, and G.O. Benson. 1992. How a Corn Plant Develops. Iowa State University. Ames, IA.

Roush, R.T. 1998. Two-Toxin Strategies for Management of Insecticidal Transgenic Crops: Can Pyramiding Succeed Where Pesticide Mixtures Have Not? Philosophical Transactions of the Royal Society B: Biological Sciences 353 (1376): 1777-86. https://doi.org/10.1098/rstb.1998.0330.

Rudeen, M.L., and A.J. Gassmann. 2013. Effects of Cry34/35Ab1 Corn on the Survival and Development of Western Corn Rootworm, Diabrotica virgifera virgifera. Pest Management Science 69 (6): 709-16. https://doi.org/10.1002/ps.3425.

SAS. 2013. SAS Version 9.4. Cary, North Carolina: SAS Institute.

Schrader, P.M., R.E. Estes, N.A. Tinsley, A.J. Gassmann, and M.E. Gray. 2017. Evaluation of Adult Emergence and Larval Root Injury for Cry3Bb1-Resistant Populations of the Western Corn Rootworm. Journal of Applied Entomology 141 (1-2): 41-52. https://doi.org/10.1111/jen.12329. 
Shrestha, R.B., S.R.K. Jakka, B.W. French, and A.J. Gassmann. 2016. Field-Based Assessment of Resistance to Bt Corn by Western Corn Rootworm (Coleoptera: Chrysomelidae). Journal of Economic Entomology 109 (3): 1399-1409. https://doi.org/10.1093/jee/tow087.

Siegfried, B.D, T.T. Vaughn, and T. Spencer. 2005. Baseline Susceptibility of Western Corn Rootworm (Coleoptera: Crysomelidae) to Cry3Bb1 Bacillus thuringiensis Toxin. Journal of Economic Entomology $98 \quad$ (4): 1320-24. https://doi.org/10.1603/0022-0493(2005)098.

Snedecor, G.W., and W.G. Cochran. 1989. Statistical Methods. 8thed. Ames, Iowa: Iowa State University Press.

Števo, J., and L. Cagáň. 2012. Washing Solutions for the Determination of the Western Corn Rootworm Eggs in Soil. Cereal Research Communications 40 (1): 147-56. https://doi.org/10.1556/CRC.40.2012.1.16.

Tabashnik, B.E. 1994. Evolution of Resistance to Bacillus thuringiensis. Annual Review of Entomology. Vol. 39.

[USDA-APHIS] United States Department of Agriculture - Animal and Plant Health Inspection Services. 1995. Availability of Determination of Nonregulated Status for Genetically Engineered Cotton. http://www.aphis.usda.gov/brs/aphisdocs2/94_30801p_com.pdf

[USDA-APHIS] United States Department of Agriculture National Agricultural Statistics Service. 2015. Adoption of Genetically Engineered Crops in the U.S. 
http://www.ers.usda.gov/data-products/adoption-of-geneticallyengineered-cropsin-the-us/recent-trends-in-geadoption.aspx

Wangila, D.S., A.J. Gassmann, J.L. Petzold-Maxwell, B.W. French, and L.J. Meinke. 2015. Susceptibility of Nebraska Western Corn Rootworm (Coleoptera: Chrysomelidae) Populations to Bt Corn Events. Journal of Economic Entomology 108 (2): 742-51. https://doi.org/10.1093/jee/tou063.

Zhao, J.-Z., J. Cao, H.L. Collins, S.L. Bates, R.T. Roush, E.D. Earle, and A.M. Shelton. 2005. Concurrent Use of Transgenic Plants Expressing a Single and Two Bacillus thuringiensis Genes Speeds Insect Adaptation to Pyramided Plants. Proceedings of the National Academy of Sciences of the United States of America 102 (24): 8426-30. https://doi.org/10.1073/pnas.0409324102.

Zukoff, S.N., K.R. Ostlie, B.P., L.N. Meihls, A.L. Zukoff, L. French, M.R. Ellersieck, B.W. French, and B.E. Hibbard. 2016. Multiple Assays Indicate Varying Levels of Cross Resistance in Cry3Bb1-Selected Field Populations of the Western Corn Rootworm to mCry3A, eCry3.1Ab, and Cry34/35Ab1. Journal of Economic Entomology 109 (3): 1387-98. https://doi.org/10.1093/jee/tow073. 


\section{Chapter 3}

A new artificial diet for western corn rootworm larvae is compatible with and detects resistance to all current Bt toxins*

Ludwick, D.C., L.N. Meihls, M.P. Huynh, A.E. Pereira, B.W. French, T.A. Coudron, and B.E. Hibbard. 2018. Scientific Reports. In Press. 


\begin{abstract}
Insect resistance to transgenic crops is a growing concern for farmers, regulatory agencies, the seed industry, and researchers. Since 2009, instances of field-evolved Bt resistance or cross resistance have been documented for each of the four Bt proteins available for western corn rootworm (WCR) a major insect pest. To characterize resistance, WCR populations causing unexpected damage to $\mathrm{Bt}$ corn are evaluated in plant and/or diet toxicity assays. Currently, it is not possible to make direct comparisons of data from different Bt proteins due to differing proprietary artificial diets. Our group has developed a new, publicly available diet (WCRMO-1) with improved nutrition for WCR larvae. For the current manuscript, we tested the compatibility of all Bt proteins currently marketed for WCR on the WCRMO-1 diet and specific proprietary diets corresponding to each toxin using a susceptible colony of WCR. We also tested WCR colonies selected for resistance to each protein to assess the ability of the diet toxicity assay to detect Bt resistance. The WCRMO-1 diet is compatible with each of the proteins and can differentiate resistant colonies from susceptible colonies for each protein. Our diet allows researchers to monitor resistance without the confounding nutritional differences present between diets.
\end{abstract}




\section{BACKGROUND/INTRODUCTION}

Western corn rootworm (Diabrotica virgifera virgifera LeConte, WCR) has been a challenge for maize (Zea mays L.) farmers throughout much of the United States of America (USA) for decades. In 1909, this pest was discovered to attack maize roots in

Colorado (Gillette 1912). Since then, it has expanded its geographic distribution to most of the maize growing regions of North America. Multiple introductions of WCR to Europe have increased its global importance (Miller et al. 2005). More than 30 years ago, it was estimated that the species caused over $\$ 1$ billion (USD) in economic losses stemming from yield loss and control costs (Metcalf 1986).

Early attempts at managing WCR in the USA focused solely on crop rotation to a non-host such as soybean (Glycine $\max (\mathrm{L}$.$) Merrill) or sorghum (Gillette 1912). When$ they became available, management tactics included the application of insecticides for larval or adult management (Muma et al. 1949; Pruess 1974). Recently, biotechnology has allowed farmers to grow maize which expresses one or more proteins from Bacillus thuringiensis Berliner (Bt). Except for banded applications of soil insecticides, each of these options has failed in one or more regions found within the distribution of this pest (Ball and Weekman 1962; Gassmann et al. 2011, 2016; Jakka et al. 2016; Levine et al. 2002; Ludwick et al. 2017; Meinke et al. 1998; Pereira et al. 2015; Zukoff et al. 2016).

When the first Bt events targeting lepidopterans were registered, insect resistance management (IRM) programs were required. Some believe these programs are especially important for products expressing toxins at less than high-dose or species with lesser susceptibility to the proteins (Tabashnik and Gould 2012), since the likelihood of survival increases when products express toxins at less than high-dose, or when some targeted 
species are less susceptible to the toxins. Recently, biotechnology has allowed farmers to grow maize that expresses one or more proteins from Bacillus thuringiensis Berliner (Bt) for WCR control. However, modeling efforts and laboratory selection studies for current proteins targeting WCR suggested products would lose efficacy within a decade of first use (Deitloff et al. 2016; Frank et al. 2013; Kang et al. 2014; Meihls et al. 2008, 2012; Onstad 2006), and field data support this (Gassmann et al. 2011; Ludwick et al. 2017; Zukoff et al. 2016). Bt maize products targeting WCR have not yet met the high-dose criterion (Ludwick and Hibbard 2016), and this likely is a primary reason that the refuge strategy designed to delay resistance has been ineffective with this pest (Tabashnik and Carrière 2017).

Resistance monitoring efforts to determine whether a shift in the susceptibility of randomly sampled populations was required as part of the registration process and to date has used proprietary artificial diets developed by product registrants (EPA 2013a-c). While this effort meets the requirement for IRM programs, there have been issues with the diet toxicity assays. In addition to nutritional differences between diets, high levels of contamination often occurred. Changes in assay methodology and diet formulations have also occurred over the years for some Bt proteins, likely creating additional variability in the data. Some academic researchers have tended to use on-plant assays as opposed to proprietary diets and purified Bt proteins, which require special agreements with the owners. This barrier can be overcome with relationships between industry and academia, but often takes considerable time and negotiation. As a result, several studies have evaluated Bt resistance with on-plant assays only (Deitloff et al. 2016; Gassmann et al. 2011, 2014, 2016; Jakka et al. 2016; Tinsley et al. 2015; Wangila et al. 2015), and some 
with both on-plant and diet toxicity assays (Frank et al. 2013; Ingber and Gassmann 2015; Lefko et al. 2008; Ludwick et al. 2017; Meihls et al. 2008, 2011; Zukoff et al. 2016). Following initial reports of field-evolved Bt resistance using on-plant assays, the Environmental Protection Agency (EPA) proposed on-plant assays be used as a replacement for diet toxicity assays (EPA 2014) and the proposed changes for resistance monitoring have been implemented (EPA 2016). Instead of diet toxicity assays, registrants will be required to use on-plant assays to determine shifts in susceptibility, though they may continue to conduct diet toxicity assays in conjunction with on-plant assays.

Efforts have been underway to improve WCR diets and the first new publicly available diet was recently published (Huynh et al. 2017). Referred hereafter as "WCRMO1", this diet has improved characteristics compared to the only other publicly-available diet (Pleau et al. 2002) and all the proprietary diets used in the current study (Hibbard/Coudron labs unpublished data). Efforts are continuing to further improve the WCRMO-1 diet for weight gain and developmental rate. An optimum diet for WCR should match maize for survival, weight, and developmental rate parameters. If these parameters can be optimized, or can no longer be improved, then we believe a single diet should be used as a universal diet in all public diet toxicity assays. As a step toward this longer-term goal, we compared the WCRMO-1 diet to the appropriate proprietary diets for compatibility with Bt proteins. We also tested susceptible and resistant WCR colonies on the WCRMO-1 diet to evaluate the ability of the diet to detect differences in susceptibility to Bt proteins in these two phenotypes. 


\section{RESULTS}

Lethal effects. The WCRMO-1 diet was tested with each Bt protein alongside the proprietary diet of the corresponding registrant using a Bt-susceptible colony (BrookingsND, Table 5). Average mortality for the buffer dose (control) on WCRMO-1 was less than 10 percent for all but one instance (Fig. 3d). The average mortality for the buffer dose on proprietary diet $\mathrm{C}$ was between 12 and 13 percent (Figs. 3b and 3c), while the buffer dose for proprietary diets corresponding to Cry34/35Ab1 (proprietary diet A) and Cry3Bb1 (proprietary diet B) toxins was less than five percent (Figs. 3a and 3d). Based on overlapping confidence intervals between concentrations required to kill 50 percent of insects $\left(\mathrm{LC}_{50}\right)$, WCRMO-1 provided similar data as the proprietary diet for each protein except for one (Table 6). WCRMO-1 produced a significantly lower LC $_{50}$ value for eCry3.1 Ab compared to the corresponding proprietary diet, labelled as "proprietary diet C" (Table 6). This means less eCry3.1Ab was required on WCRMO-1 to kill half of the susceptible colony tested when compared to proprietary diet C.

When Bt-selected colonies were evaluated on WCRMO-1, significant differences in $\mathrm{LC}_{50}$ values were found for each Bt protein between the Brookings-ND colony and the resistant colonies (Table 6). This was the case for each selected colony on each of the four Bt toxins evaluated. Overall, resistant colonies showed minimal mortality in response to toxins. For Cry3Bb1, mCry3A, and eCry3.1, all resistant colonies had maximum mortality under 14 percent regardless of the dose (Figs. 3f-h). Only one of the DAS-59122-selected colonies reached maximum mortality $50 \%$ while the other was $41 \%$ following exposure to the highest dose Cry34/35Ab1 toxins (Fig. 3e). 
Sublethal effects. Dry weight was the only parameter where a significant difference was observed between susceptible larvae fed Bt toxin on WCRMO-1 versus a proprietary diet. For eCry3.1 Ab, the concentration required to cause a 50 percent reduction in dry weight $\left(\mathrm{EC}_{50}\right)$ for the Brookings-ND colony fed WCRMO-1 diet was significantly greater than when fed proprietary diet C (Table 6). No other significant differences were found in $\mathrm{EC}_{50}$ values between the WCRMO-1 diet and the respective proprietary diet for any of the other toxins (Table 6). Both DAS-59122-7-selected colonies had similar EC F0 $_{5}$ values compared to the Brookings-ND colony when exposed to the Cry34/35Ab1 proteins on the WCRMO-1 diet (Table 6). Both MON88017-selected colonies had significantly greater $\mathrm{EC}_{50}$ values for Cry3Bb1 protein on the WCRMO-1 when compared to the susceptible colony (Table 6). The Brookings-ND colony had a significantly lower $\mathrm{EC}_{50}$ value for eCry3.1Ab protein on the WCRMO-1 diet compared to the 5307-S colony (Table 2). Lastly, the MIR604-S colony had a significantly greater $\mathrm{EC}_{50}$ value for $\mathrm{mCry} 3 \mathrm{~A}$ protein when compared to the susceptible colony on the WCRMO-1 diet (Table 6).

There were large differences in susceptible WCR larval dry weight on the buffer dose between the WCRMO-1 and proprietary diet C (Figs. 4b and 4c). For both toxins, the insects reared on proprietary diet $\mathrm{C}$ weighed one-fifth as much as insects reared on WCRMO-1 after $10 \mathrm{~d}$ (Figs. 4b and 4c). Insects from Brookings-ND exposed to the buffer dose of Cry34/35Ab1 weighed more on WCRMO-1 than those reared on proprietary diet A. All but one colony (DAS-59122-7-S1) had greater dry weight than the Brookings-ND insects on the buffer dose (Figs. 4e-h). Additionally, some colonies had greater dry weight at the lowest Bt dose than for the buffer (Figs. 4a, 4d-f). 
Molting was significantly inhibited for all susceptible colonies on all Bt proteins (Figs. 6a-d). The dose that causes 50 percent molting inhibition $\left(\mathrm{MIC}_{50}\right)$ was significantly greater for all the Cry3-selected colonies than the Brookings-ND colony (Table 6). The $\mathrm{MIC}_{50}$ value was not significantly different for the two Cry34/35Ab1-selected colonies and the Brookings-ND colony (Table 6).

\section{DISCUSSION}

Here, we demonstrate for the first time that a single artificial diet can be used to detect resistance with all Bt proteins currently targeting WCR. Previously, different proprietary proteins were evaluated on the proprietary diet from the company that produced the protein. Use of a single diet allows for direct comparisons of toxicity between proteins without the confounding effects of nutritional differences. In general, performance of susceptible WCR was similar between the proprietary diets and the WCRMO-1 diet (Table 6, Figs. 3-5). We also documented that differences between WCR colonies selected for resistance to each Bt protein and a control WCR population can be detected in diet toxicity assays with the WCRMO-1 diet (Table 6, Figs. 3-5).

This study adds to the limited number of studies which have documented a significant difference in $\mathrm{LC}_{50}$ values between colonies or populations in Cry34/35Ab1 diet toxicity assays (Ludwick et al. 2017; Zukoff et al. 2016). Resistance ratios in the previous studies were relatively minor compared to the more than 40 -fold difference in $\mathrm{LC}_{50}$ values of the two DAS-59122-7-selected populations and the control population evaluated here (Table 6). Interestingly, a colony originally described by Lefko et al. (2008) and Nowatzki et al. (2008) showed no difference in $\mathrm{LC}_{50}$ values when compared to a control colony after being selected for more than 30 generations on DAS-59122-7 
maize (which produces the Cry34/35Ab1 toxin) using proprietary diet A (pers. communication from Stephen Thompson, DuPont Pioneer). Using the WCRMO-1 diet, significant differences in $\mathrm{LC}_{50}$ values between both DAS-59122-7-selected colonies and control colonies were documented with less than 20 generations of selection (Table 6, Figs. 3-5). The difference in $\mathrm{LC}_{50}$ values did not translate to significant differences in $\mathrm{EC}_{50}$ values; however, the DAS-59122-7-S2 colony did have a significantly greater MIC50 value than the control WCR colony (Table 6). These results suggest a possibility for more sensitive screening of Cry34/35Ab1 proteins with WCRMO-1. However, there is also a chance that the difference in $\mathrm{LC}_{50}$ values detected on the WCRMO- 1 diet is unique to the DAS-59122-7-selected colonies in this study. Additional comparisons of proprietary diet A and WCRMO-1 diets are needed to determine whether the basis of this detection is the result of nutritional or genetic factors, or a combination of the two factors.

Although we do not have the formulations for the proprietary diets tested here, life history parameters indicate that nutritive qualities varied among the diets. We previously found significant differences in molting rate, weight gain, and survival among the proprietary and WCRMO-1 diets (unpublished data). Research with lepidopteran insects has shown that the toxicity of Bt proteins can vary when protein to carbohydrate ratios are manipulated (Deans et al. 2017; Orpet et al. 2015). While lepidopteran and coleopteran insects are quite different, we may be able to draw parallels to this study. One proprietary artificial diet appears to lack significant nutritive qualities and/or attractiveness as a food source. Insects on proprietary diet $\mathrm{C}$ with buffer alone for eCry3.1 Ab and mCry3 A proteins weighed less than 18 percent of insects reared on the 
WCRMO-1 diet with buffer alone (Figs. $4 \mathrm{~b}$ and $4 \mathrm{c}$ ). Such a difference in nutritive qualities could explain the significant difference in dry weight observed between larvae fed WCRMO-1 or the proprietary diet C. However, this difference in weight gain between diets did not cause a significant difference in $\mathrm{LC}_{50}$ for the mCry3 $\mathrm{A}$ protein. Under conditions where an insect ingests food at a normal rate (i.e. rate on maize), then the $\mathrm{LC}_{50}$ is representative of the amount needed to kill targeted insects in the field. However, when a diet is less attractive, then the $\mathrm{LC}_{50}$ will likely shift towards a greater value as less diet is ingested.

Larvae were capable of molting in the 10-day time period used for these experiments, unlike previously reported assays with WCR which were terminated at five or six days depending on the protein. Previously reported assays had shorter time frames primarily due to contamination (EPA 2016). Longer assays for slower acting products (e.g. dsRNA) are possible using techniques described here and in Huynh et al. (2017). Consequently, we were able use molting as a measure of resistance, similar to studies with Ostrinia nubilalis (Hübner) (Thieme et al. 2017). Here, exuviae were clearly visible through the sealing film and provided a non-invasive determination of sublethal effects that could be recorded over time, whereas dry weight could only be collected at the end of each experiment. Recording molting data as a measure of resistance may allow for additional studies where researchers may look at genetic factors, microbes, or other variables. This approach may provide a more sensitive measure for detecting resistance in populations where no differences in $\mathrm{LC}_{50}$ or $\mathrm{EC}_{50}$ exist. For example, the DAS-59122-7S2 colony had a significantly greater $\mathrm{MIC}_{50}$ value when compared to the Brookings-ND colony while the DAS-59122-7-S1 showed no significant difference (Table 6). This was 
the only difference noted between the two DAS-59122-7 selected colonies. Future studies should include these data, when possible. Before molting data can be collected, a diet must have adequate nutrition to allow first instar larvae to molt into the second instar. Proprietary diet $\mathrm{C}$ did not produce second instar larvae, even on diet with buffer alone (Figs. 5b and 5c). All other diets produced second instar larvae on diet with buffer alone (Figs. 5a and 5d).

Nutritional improvements of an artificial diet (Huynh et al. 2017) and validation of compatibility with all current Bt proteins documented here, support the utility of the diet toxicity assay in resistance monitoring efforts. We recommend a standardized approach to how these diet toxicity assays are conducted to reduce data variability in IRM programs. Some of this variability is likely due to the alterations of some diets over the years for various reasons. Additionally, the number of days for observation varies between proteins complicating comparisons of Bt proteins. These factors likely explain some of the variability that has been reported within diet toxicity assays over the years. Shifts in susceptibility may be masked by these factors. Comparisons between current and future products could help to evaluate novel modes of action and physiological effects of protein exposure.

WCR has evaded management tactics for more than a century. Some populations of this species have developed resistance to crop rotation (Levine et al. 2002), broadcast insecticides (Ball and Weekman 1962; Meinke et al. 1998; Pereira et al. 2015), and transgenic maize expressing Bt proteins (Gassmann et al. 2011, 2014, 2016; Ludwick et al. 2017; Wangila et al. 2015; Zukoff et al. 2016)). Even with the advent of biotechnology, WCR continues to be a pest of maize. Current and future products 
targeting the species will require IRM programs to ensure product viability and longevity. Both plant and diet assays have value in detecting resistance (Zukoff et al. 2016).

\section{MATERIALS AND METHODS}

Artificial Diet and Bt Protein. Lyophilized Cry34/35Ab1 proteins and the corresponding proprietary diet were provided by Dow AgroSciences. Cry3Bb1 protein was provided in solution by Monsanto Company in addition to their proprietary diet. The lyophilized mCry3A and eCry3.1Ab proteins and their proprietary diet were provided by Syngenta Biotechnology. The WCRMO-1 diet was produced by the USDA-ARS Biological Control of Insects Research Laboratory (BCIRL) in Columbia, MO (Huynh et al. 2017). Buffers to suspend the protein in solution were prepared at BCIRL (Table 5). The sodium citrate buffer was stored at $4{ }^{\circ} \mathrm{C}$ immediately after preparation. The sodium carbonate bicarbonate buffer was stored at room temperature in a container which blocked all light.

Insects. Eggs from the non-diapausing, susceptible colony, hereafter known as Brookings-ND, were provided by the USDA-ARS laboratory in Brookings, SD. This colony is derived from a field population collected prior to the release of transgenic crops (Branson 1976), so this colony should be susceptible to all Bt proteins active against WCR.

Several resistant colonies were used in this study, all of which have been described in other studies. Two MON88017-selected colonies, MON88017-S1 and MON88017-S2, exhibited resistance to Cry3Bb1-expressing plants (event MON88017) and protein in Zukoff et al. (2016). MON88017-S1 was derived from the Canby population while MON88017-S2 was derived from Hills population in Zukoff et al. (2016). Both MON88017-selected colonies were reciprocally crossed with adults from the Brookings- 
ND colony and then reared on maize containing event MON88017 for eleven generations post Zukoff et al. (2016) at the time Cry3Bb1 diet toxicity assays were conducted.

Two DAS-59122-7-selected colonies, hereafter known as DAS-59122-7-S1 and DAS-59122-7-S2, were also used in this study. The DAS-59122-7-S1 colony was derived from a field population described in Ludwick et al. (2017). The field population had been exposed to SmartStax, a maize product which expresses both Cry34/35Ab1 (event DAS59122-7) and Cry3Bb1 proteins. DAS-59122-7-S1 had incomplete resistance to both Cry3Bb1 and Cry34/35Ab1 proteins (Ludwick et al. 2017). Eggs from this population were reared on non-Bt corn and resulting adults were then reciprocally crossed with the Brookings-ND colony to produce a non-diapausing DAS-59122-7-S1 colony. The DAS59122-7-S2 colony was started from pooled eggs of three field populations reared on nonBt maize. The resulting adults were reciprocally crossed with Brookings-ND at differing points earlier and then selected on maize containing event DAS-59122-7 similarly as in Deitloff et al. (2016). The DAS-59122-7-S1 and DAS-59122-7-S2 colonies were selected on DAS-59122-7 plants for six and 18 generations under laboratory/greenhouse conditions, respectively, at the time Cry34/35Ab1 diet toxicity assays occurred.

Two additional colonies with resistance to mCry3A (Gassmann et al. 2011) and eCry3.1Ab (Frank et al. 2013) were also tested. The colony selected on eCry3.1Abexpressing corn will hereafter be known as 5307-S. We tested this strain after 35 generations of selection on maize containing event 5307 or an earlier event also expressing eCry3.1Ab. The MIR604-selected colony will hereafter be known as MIR604-S. The MIR604-S colony was evaluated after more than 50 generations of selection on MIR604 maize which expresses mCry3A protein. 
Equipment Sterilization. The WCRMO-1 diet was prepared in new 96-well immunoassay plates (product \#3370, Corning Inc., Corning, NY) using sterile techniques described in Huynh et al. (2017) All proprietary diets were prepared in 96-well immunoassay plates by the registrants. For shipment, proprietary diets were placed in sterile packaging and shipped to the BCIRL in styrofoam containers with ice packs. Diets were stored in a $4{ }^{\circ} \mathrm{C}$ refrigerator and infested within two weeks of arrival. Lids for diet were only removed inside a UV-sterilized biosafety cabinet. Paintbrushes, insect pins, deli containers, coffee filters, and beakers were all sterilized by UV lights in a biosafety cabinet prior to use. A spray bottle with autoclaved DI water was used to keep the coffee filter and neonate larvae moist.

Egg Sterilization. The methods used to surface sterilize eggs were modified from descriptions by Pleau et al. (2002). Briefly, eggs from each colony were incubated in Petri dishes with 70 mesh sieved soil within an incubator at $25^{\circ} \mathrm{C}$ in complete darkness until hatch started. Once approximately 10 percent of the eggs hatched, each dish was washed through a 60 mesh sieve. Remaining eggs were submerged in a beaker with water where debris (soil, fungus, hatched egg shells) floated to the water's surface and were then decanted. As much excess water as possible was poured off before the eggs were submerged in $20 \mathrm{~mL}$ of disinfectant (undiluted $\mathrm{Lysol}^{\circledR}$ ) for three minutes. The disinfectant was then decanted and the eggs were triple rinsed with distilled water. Approximately 20 $\mathrm{mL}$ of 10 percent buffered zinc formalin (10 percent formaldehyde) covered the eggs for three minutes. Again, a triple rinse with distilled water was used to remove any chemical residues. Eggs were then dispensed onto a UV-sterilized coffee filter with a $1.5 \mathrm{ml}$ transfer pipette. The coffee filter was then placed in a UV-sterilized 16 oz. Solo ${ }^{\circledR}$ deli container 
with holes (\#0 insect pin) punched in the lid to allow for air exchange. Incubation, typically less than three days, occurred until enough eggs hatched for infestation. If sufficient numbers of larvae did not hatch, then the coffee filter with eggs were transferred to a recently UV-sterilized deli container each additional day and placed back in the incubator. Contamination tends to increase when eggs are used more than three days after sterilization (personal observation). The deli container with larvae on its wall was placed in a sterilized biosafety cabinet. Neonate larvae were then transferred to diet using sterile equipment to prevent any possible contamination. Sealing film (Excel scientific, Inc., Thermalseal RTS $^{\mathrm{RM}}$, TSS-RTQ-100) was placed over the entire plate to prevent escape. A single hole (\#0 insect pin) was poked into the sealing film of each infested well for diffusion of oxygen.

Diet Toxicity Assays. All diet toxicity assays were conducted for a length of 10 days. Lyophilized proteins were dissolved in solution and then a serial dilution was made (Table 1). These solutions were then overlaid on artificial diet and allowed to dry before larvae were placed on the diet. Each row (12 wells) per plate received one dose and one colony, thereby constituting a single replication. Plates with more than 25 percent mortality on the control (buffer dose, $0 \mu \mathrm{g} / \mathrm{cm}^{2}$ ) were excluded from the study. The number of replications included in this study varied between diets and proteins (Table 2). Survival and molting were recorded prior to the collection of larvae. Surviving larvae were placed in ethanol for each dose and plate and then dried in an oven at $50^{\circ} \mathrm{C}$ for one week (Blue $\mathrm{M}$ Therm Dry Bacteriological Incubator, Model \#602752). After drying, larvae were weighed on a digital microbalance (Sartorius ${ }^{\mathrm{TM}} \mathrm{Cubis}^{\mathrm{TM}}, 6.6 \mathrm{~S}$ ), which weighed samples to one thousandth of a milligram. 
Statistical Analyses. Mortality was calculated by dividing the number of dead larvae by the initial number of larvae infested per dose. An average mortality value of the buffer dose was calculated. Then, mortality at each subsequent dose was divided by the average mortality of the buffer dose and multiplied by 100 (Abbott 1925). These mortality percentages were analyzed with a probit analysis to generate $\mathrm{LC}_{50}$ and 95 percent confidence intervals using SAS software version 9.2 (SAS Institute). Values were considered significantly different when 95 percent confidence intervals did not overlap.

Dry weight was calculated by dividing the total weight per dose by the initial number of larvae infested, effectively giving all dead larvae a weight of 0 . The average dry weight per larva recovered from the buffer dose was then averaged across replications to generate a mean value. The dry weight of larvae recovered from each dose was then divided by the buffer's mean dry weight and multiplied by 100 to generate a percentage relative to the buffer dose. These data were then analyzed with a nonlinear probit analysis described by Marçon et al. (1999) in SAS. This analysis calculated the $\mathrm{EC}_{50}$ and 95 percent confidence intervals.

Molting was calculated by dividing the number of molted individuals per dose by the initial number of larvae infested and multiplying by 100 to obtain a percentage. The average molting rate for each colony on the buffer dose was calculated. Each subsequent dose was divided by the buffer dose's average molting rate for the corresponding colony (Abbott 1925). These molting rates were then analyzed in SAS with a probit analysis to generate $\mathrm{MIC}_{50}$ values and 95 percent confidence intervals. $\mathrm{MIC}_{50}$ values between colonies on the same protein were considered significantly different when confidence intervals did not overlap. 


\section{ACKNOWLEDGEMENTS}

The authors would like to thank Monsanto Company for providing its proprietary diet, Cry3Bb1 protein, seed for rearing, corn root powder, and financial support through the Corn Rootworm Knowledge Grant program. The authors would also like to thank Dow AgroSciences for their proprietary diet and Cry34/35Ab1 protein. We thank Syngenta Biotechnology for providing their proprietary diet, mCry3 A and eCry3.1Ab proteins, and seed for rearing. We thank DuPont Pioneer for providing seed for rearing. We thank Chad Nielson for rearing the Brookings-ND colony at the USDA-ARS NCARL facility in Brookings, SD. Lastly, the authors would like to thank Drs. Deborah Finke and Kent

Shelby for discussions that aided in the development of this paper and comments that improved the text. 
Table 5. Buffers, doses, and proteins used with each colony.

\begin{tabular}{|c|c|c|c|c|c|c|c|c|c|c|c|}
\hline \multirow[b]{2}{*}{ Protein } & \multirow[b]{2}{*}{ Diet } & \multirow[b]{2}{*}{ Colony } & \multirow[b]{2}{*}{ Protein Buffer } & \multicolumn{8}{|c|}{ Dose $\left(\mu \mathrm{g} / \mathrm{cm}^{2}\right)$} \\
\hline & & & & Dose 1 & Dose 2 & Dose 3 & Dose 4 & Dose 5 & Dose 6 & Dose 7 & Dose 8 \\
\hline \multirow{4}{*}{ Cry34/35Ab1 } & Proprietary Diet A & Brookings-ND & \multirow{4}{*}{$\begin{array}{l}10 \mathrm{mM} \text { Sodium } \\
\text { Citrate } \mathrm{pH} 3.5\end{array}$} & 0.00 & 0.08 & 0.24 & 0.74 & 2.22 & 6.67 & 20.00 & 60.00 \\
\hline & \multirow{3}{*}{ WCRMO-1 } & Brookings-ND & & 0.00 & 0.09 & 0.28 & 0.85 & 2.55 & 7.65 & 22.94 & 68.82 \\
\hline & & DAS-59122-7-S1 (6 gen.) & & 0.00 & 0.09 & 0.28 & 0.85 & 2.55 & 7.65 & 22.94 & 68.82 \\
\hline & & DAS-59122-7-S2 (18 gen.) & & 0.00 & 0.09 & 0.28 & 0.85 & 2.55 & 7.65 & 22.94 & 68.82 \\
\hline \multirow{4}{*}{ Cry3Bb1 } & Proprietary Diet B & Brookings-ND & \multirow{10}{*}{$\begin{array}{l}10 \mathrm{mM} \text { Sodium } \\
\text { Carbonate } \\
\text { Bicarbonate } \mathrm{pH} \\
10\end{array}$} & 0.00 & 22.19 & 44.29 & 88.57 & 177.14 & & & \\
\hline & \multirow{3}{*}{ WCRMO-1 } & Brookings-ND & & 0.00 & 24.54 & 48.97 & 97.95 & 195.89 & & & \\
\hline & & MON88017-S1 (11 gen.) & & 0.00 & 24.54 & 48.97 & 97.95 & 195.89 & 391.79 & & \\
\hline & & MON88017-S2 (11 gen.) & & 0.00 & 24.54 & 48.97 & 97.95 & 195.89 & 391.79 & & \\
\hline \multirow{3}{*}{ mCry3A } & Proprietary Diet C & Brookings-ND & & 0.00 & 0.34 & 1.03 & 3.10 & 9.29 & 27.87 & & \\
\hline & \multirow{2}{*}{ WCRMO-1 } & Brookings-ND & & 0.00 & 0.34 & 1.03 & 3.10 & 9.29 & 27.87 & & \\
\hline & & MIR604-S (50+ gen.) & & 0.00 & 0.30 & 0.90 & 2.70 & 8.10 & 24.30 & & \\
\hline \multirow{3}{*}{ eCry3.1Ab } & Proprietary Diet C & Brookings-ND & & 0.00 & 0.34 & 1.03 & 3.10 & 9.29 & 27.87 & & \\
\hline & \multirow{2}{*}{ WCRMO-1 } & Brookings-ND & & 0.00 & 0.34 & 1.03 & 3.10 & 9.29 & 27.87 & & \\
\hline & & 5307-S (35 gen.) & & 0.00 & 0.30 & 0.90 & 2.70 & 8.10 & 24.30 & & \\
\hline
\end{tabular}


Table 6. Concentrations $\left(\mu \mathrm{g} / \mathrm{cm}^{2}\right)$ to kill 50 percent $\left(\mathrm{LC}_{50}\right)$, cause 50 percent weight inhibition $\left(\mathrm{EC}_{50}\right.$ values), and cause 50 percent molt inhibition $\left(\mathrm{MIC}_{50}\right)$ with 95 percent confidence intervals for corresponding colony, diet, and Bt protein treatments. Non-overlapping confidence intervals indicate significant differences. Confidence intervals could not be calculated for some of the estimates.

\begin{tabular}{|c|c|c|c|c|c|c|}
\hline Bt Protein & Diet & Colony & Reps & LC $_{50}(95 \%$ C.I. $)$ & $\mathbf{E C}_{50}(95 \%$ C.I. $)$ & $\operatorname{MIC}_{50}(95 \%$ C.I. $)$ \\
\hline \multirow{4}{*}{ Cry34/35Ab1 } & Proprietary Diet A & Brookings-ND & 3 & $6.28(2.60-22.64)$ & $2.01(0.33-12.05)$ & $0.96(0.33-2.85)$ \\
\hline & \multirow{3}{*}{ WCRMO-1 } & Brookings-ND & 4 & $1.60(0.83-3.15)$ & $1.31(0.15-11.26)$ & $0.92(0.27-3.35)$ \\
\hline & & DAS-59122-7-S1 (6 gen.) & 5 & $>68.82$ & $5.99(3.37-9.13)$ & $3.48(0.59-18.51)$ \\
\hline & & DAS-59122-7-S2 (18 gen.) & 4 & $>68.82$ & $3.09(1.38-4.94)$ & $10.96(4.4-25.3)$ \\
\hline \multirow{4}{*}{ Cry3Bb1 } & Proprietary Diet B & Brookings-ND & 4 & $9.11(2.15-24.69)$ & $12.41(1.00-87.62)$ & 2.19 \\
\hline & \multirow{3}{*}{ WCRMO-1 } & Brookings-ND & 3 & $3.36(0.35-15.17)$ & $10.20(0.32-88.80)$ & 0.48 \\
\hline & & MON88017-S1 (11 gen.) & 5 & $>391.8$ & $409.23(250.35-1092.77)$ & $>391.8$ \\
\hline & & MON88017-S2 (11 gen.) & 4 & $>391.8$ & $614.77(333.64-2311.32)$ & $>391.8$ \\
\hline \multirow{3}{*}{ eCry3.1Ab } & Proprietary Diet C & Brookings-ND & 3 & $12.74(5.10-61.54)$ & $4.02(1.89-9.20)$ & N/A \\
\hline & \multirow{2}{*}{ WCRMO-1 } & Brookings-ND & 4 & $1.75(0.93-3.57)$ & 20.09 & $0.35(0.02-2.44)$ \\
\hline & & MIR604-S (35 gen.) & 5 & $>24.3$ & $>24.3$ & $>24.3$ \\
\hline \multirow{3}{*}{ mCry3A } & Proprietary Diet C & Brookings-ND & 5 & $3.71(1.93-8.08)$ & $3.13(1.80-5.42)$ & N/A \\
\hline & \multirow{2}{*}{ WCRMO-1 } & Brookings-ND & 6 & $6.39(2.82-20.39)$ & $1.23(0.14-9.7)$ & $0.5(0.12-1.48)$ \\
\hline & & MIR604-S (50+ gen.) & 5 & $>24.3$ & $>24.3$ & $>24.3$ \\
\hline
\end{tabular}


a

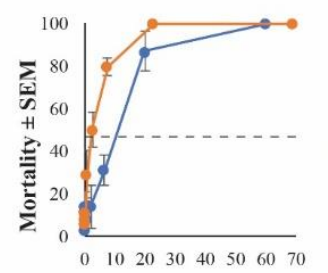

b

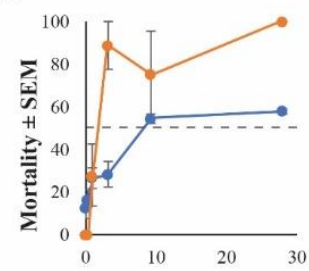

c

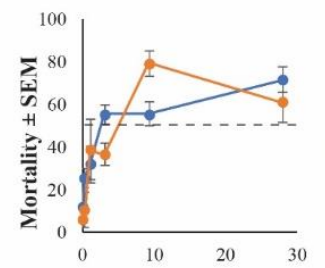

d

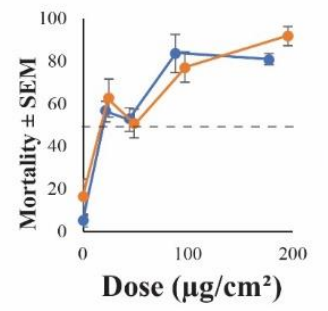

Cry34/35Ab1
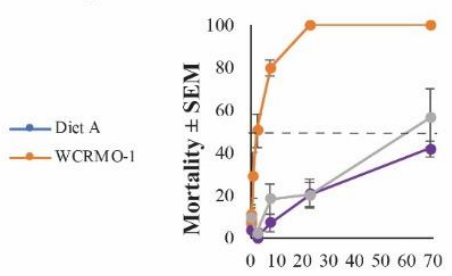

eCry3.1Ab
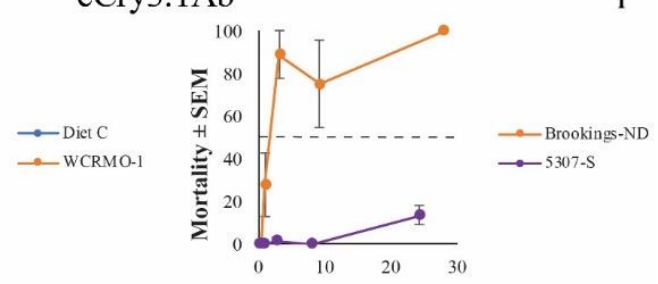

mCry $3 \mathrm{~A}$
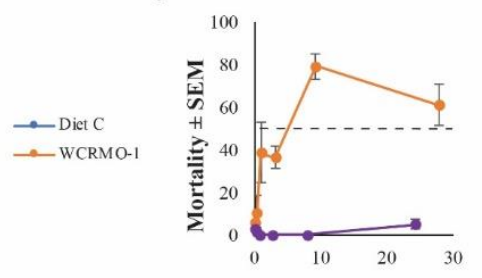

Cry3Bb 1

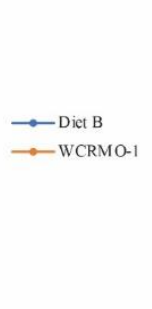

e

$\rightarrow$ Brookings-ND $\rightarrow$ DAS-59122-7-S1 -DAS-59122-7.S2

g

- Brooking-ND

h

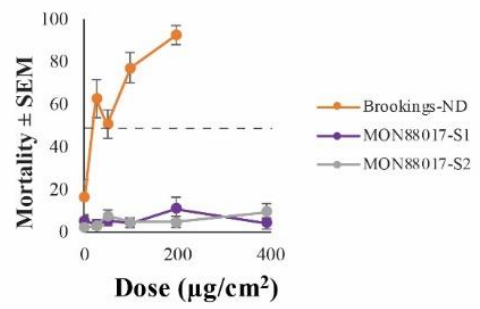

Figure 3. Impact of Bt Protein on Mortality. Percent mortality of Brookings-ND (a-d) with exposure to $\mathrm{Bt}$ proteins on proprietary and WCRMO-1 diets, and mortality of Brookings-ND and selected colonies (e-h) with exposure to Bt proteins on the WCRMO-1 diet. Mortality was calculated as the number of larvae that died following exposure to $\mathrm{Bt}$ protein(s) divided by the initial number infested. Bars represent the standard error of the mean (SEM). The dashed line represents 50 percent mortality. 

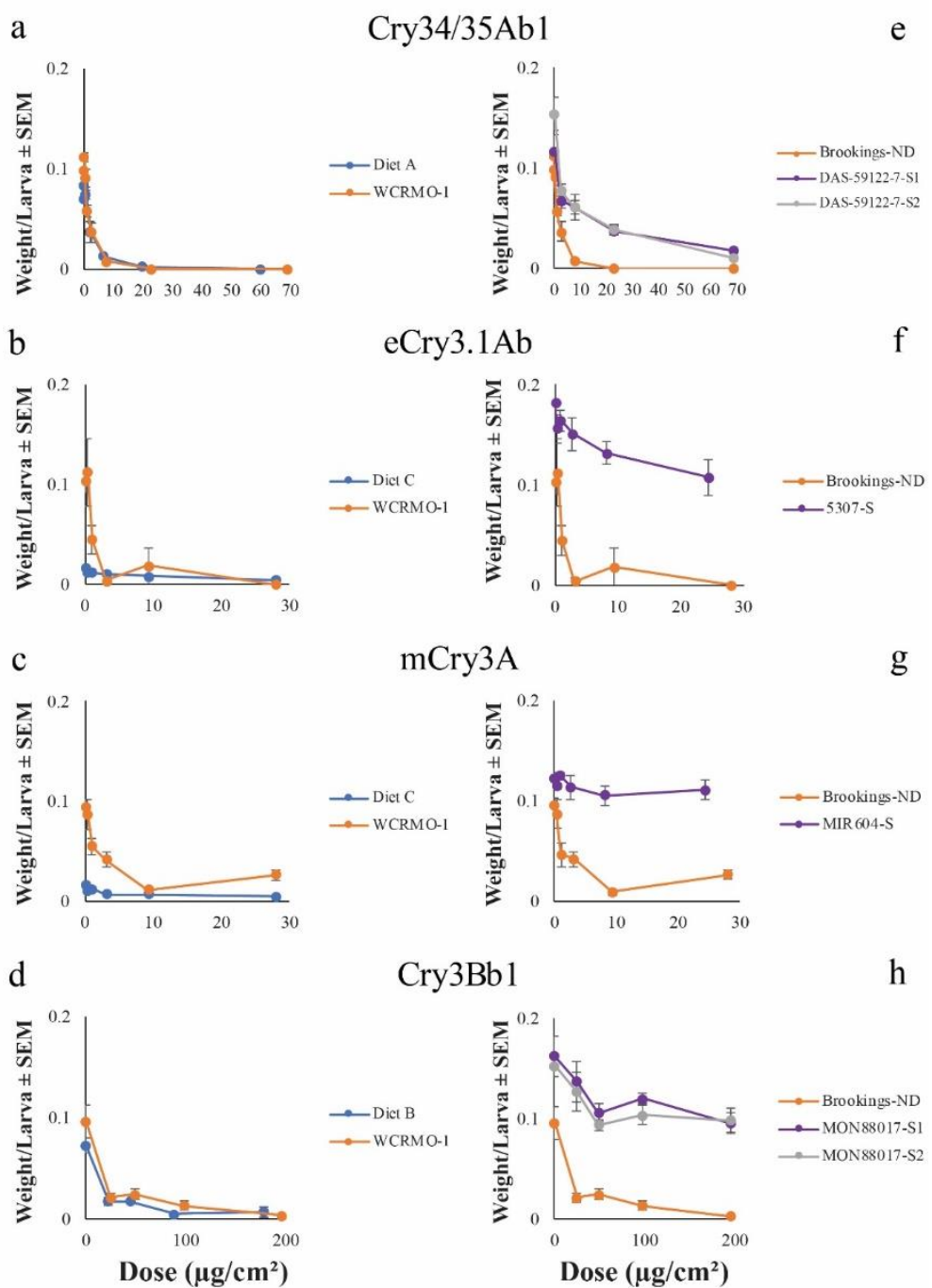

Cry3Bb 1

$\mathrm{h}$

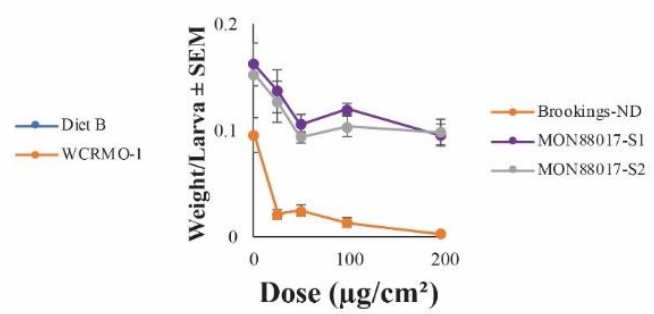

Figure 4. Impact of Bt Protein on Dry Weight. Dry weight per larva (mg) of BrookingsND (a-d) with exposure to Bt proteins on proprietary and WCRMO-1 diets, and dry weight per larva of Brookings-ND and selected colonies (e-h) with exposure to Bt proteins on the WCRMO-1 diet. Dry weight per larva was calculated as the dry weight of larvae recovered following exposure to Bt protein(s) divided by the initial number infested. Bars represent the standard error of the mean (SEM). 

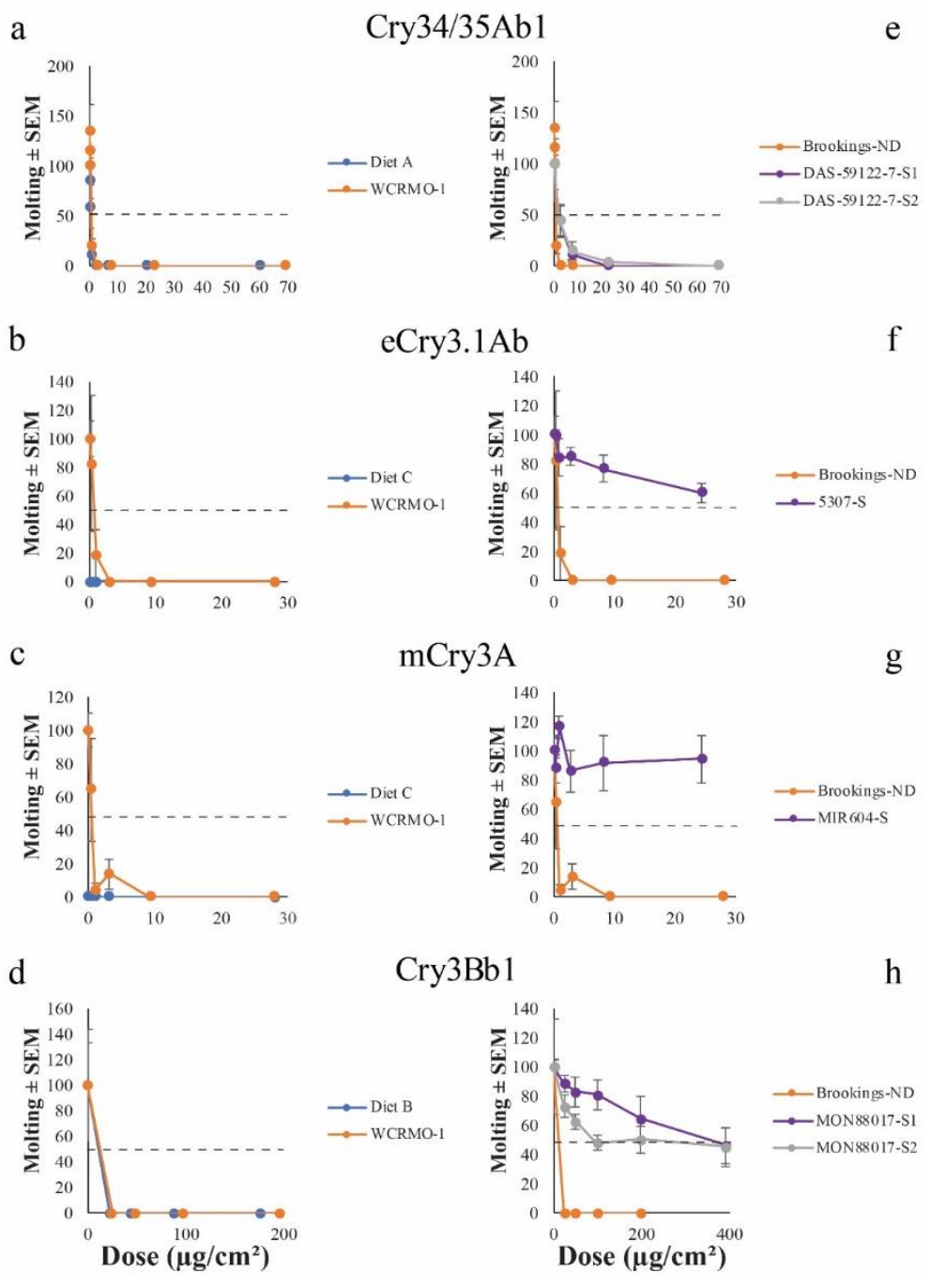

Figure 5. Impact of Bt Protein on Molting. Molting of Brookings-ND (a-d) with exposure to Bt proteins on proprietary and WCRMO-1 diets, and molting of BrookingsND and selected colonies (e-h) with exposure to Bt proteins on the WCRMO-1 diet. First, the molting rate on the buffer was calculated by dividing the number of larvae which molted by the initial number of larvae. This established a baseline response of the insect to the diet and buffer. All values for each colony, including the buffer dose (Dose 1) for the same colony, were then divided by the buffer dose value to establish relationships relative to the buffer dose. Each of the resulting values were then multiplied by 100 . Bars represent the standard error of the mean (SEM). 


\section{References Cited}

Abbott, W.S. 1925. A Method of Computing the Effectiveness of an Insecticide. Journal of Economic Entomology 18 (265-267).

Ball, H.J., and G.T. Weekman. 1962. Insecticide Resistance in the Adult Western Corn Rootworm in Nebraska. Journal of Economic Entomology 55 (439-441).

Branson, T.F. 1976. The Selection of a Non-Diapause Strain of Diabrotica virgifera virgifera (COLEOPTERA: CHRYSOMELIDAE). Entomologia Experimentalis et Applicata 19 (2): 148-54. https://doi.org/10.1111/j.15707458.1976.tb02591.x.

Deans, C.A., S.T. Behmer, A.E. Tessnow, P. Tamez-Guerra, M. Pusaztai-Carey, and G.A. Sword. 2017. Nutrition Affects Insect Susceptibility to Bt Toxins. Scientific Reports 7.

Deitloff, J., M.W. Dunbar, D.A. Ingber, B.E. Hibbard, and A.J. Gassmann. 2016. Effects of Refuges on the Evolution of Resistance to Transgenic Corn by the Western Corn Rootworm, Diabrotica virgifera virgifera LeConte. Pest Management Science 72 (1): 190-98. https://doi.org/10.1002/ps.3988.

[EPA] Environmental Protection Agency. 2013a. BPPD IRM Team Review of Monsanto’s Corn Rootworm Monitoring Data, Unexpected Damage Reports for Cry3Bb1 Expressing Bt Corn and Academic Reports of Cry3Bb1 Field Failures as Well as Corn Rootworm Resistance.

[EPA] Environmental Protection Agency. 2013b. Review of Corn Rootworm Resistance Monitoring Submissions and Data (2009-2011) for Bt Corn Products Containing Cry34/35Ab1. 
[EPA] Environmental Protection Agency. 2014. EPA Framework for PIP Registrants: Proposal to Address Key SAP Recommendations for Corn Rootworm (CRW) IRM.

[EPA] Environmental Protection Agency. 2016. EPA Docket for Corn Rootworm Resistance Management and Framework for Bt Corn. Docket ID: EPA-HQOPP-2014-0805.

Frank, D.L., A. Zukoff, J. Barry, M.L. Higdon, and B.E. Hibbard. 2013. Development of Resistance to eCry3.1Ab-Expressing Transgenic Maize in a LaboratorySelected Population of Western Corn Rootworm (Coleoptera: Chrysomelidae). Journal of Economic Entomology 106 (6): 2506-13. https://doi.org/10.1603/EC13148.

Gassmann, A. J., J. L. Petzold-Maxwell, E. H. Clifton, M. W. Dunbar, A. M. Hoffmann, D. A. Ingber, and R. S. Keweshan. 2014. Field-Evolved Resistance by Western Corn Rootworm to Multiple Bacillus thuringiensis Toxins in Transgenic Maize. Proceedings of the National Academy of Sciences 111 (14): 5141-46. https://doi.org/10.1073/pnas.1317179111.

Gassmann, A.J., J.L. Petzold-Maxwell, R.S. Keweshan, and M.W. Dunbar. 2011. Field-Evolved Resistance to Bt Maize by Western Corn Rootworm. PLoS ONE 6 (7). https://doi.org/10.1371/journal.pone.0022629.

Gassmann, A.J., R.B. Shrestha, S.R.K. Jakka, M.W. Dunbar, E.H. Clifton, A.R. Paolino, D.A. Ingber, et al. 2016. Evidence of Resistance to Cry34/35Ab1 Corn by Western Corn Rootworm (Coleoptera: Chrysomelidae): Root Injury in the Field and Larval Survival in Plant-Based Bioassays. Journal of 
$\begin{array}{lll}\text { Economic } & \text { Entomology } & 109\end{array}$

https://doi.org/10.1093/jee/tow110.

Gillette, C P. 1912. Diabrotica virgifera Lec. as a Corn Rootworm. Journal of Economic Entomology 5: 364-66.

Huynh, M.P., L.N. Meihls, B.E. Hibbard, S.L. Lapointe, R.P. Niedz, D.C. Ludwick, and T.A. Coudron. 2017. Diet Improvement for Western Corn Rootworm (Coleoptera: Chrysomelidae) Larvae. PLoS ONE. Vol. 12. https://doi.org/10.1371/journal.pone.0187997.

Ingber, D.A., and A.J. Gassmann. 2015. Inheritance and Fitness Costs of Resistance to Cry3Bb1 Corn by Western Corn Rootworm (Coleoptera: Chrysomelidae). Journal of Economic Entomology $108 \quad$ (5): 2421-32. https://doi.org/10.1093/jee/tov199.

Jakka, S.R.K., R.B. Shrestha, and A.J. Gassmann. 2016. Broad-Spectrum Resistance to Bacillus thuringiensis Toxins by Western Corn Rootworm (Diabrotica virgifera virgifera). $\quad$ Scientific $\quad$ Reports 6. https://doi.org/10.1038/srep27860.

Kang, J.K., C.H. Krupke, A.F. Murphy, J.L. Spencer, M.E. Gray, and D.W. Onstad. 2014. Modeling a Western Corn Rootworm, Diabrotica virgifera virgifera (Coleoptera: Chrysomelidae), Maturation Delay and Resistance Evolution in Bt Corn. Pest Management Science 70 (6): 996-1007. https://doi.org/10.1002/ps.3642.

Lefko, S. A., T. M. Nowatzki, S. D. Thompson, R. R. Binning, M. A. Pascual, M. L. Peters, E. J. Simbro, and B. H. Stanley. 2008. Characterizing Laboratory 
Colonies of Western Corn Rootworm (Coleoptera: Chrysomelidae) Selected for Survival on Maize Containing Event DAS-59122-7. Journal of Applied Entomology 132 (3): 189-204. https://doi.org/10.1111/j.14390418.2008.01279.x.

Levine, E., J.L. Spencer, S.A. Isard, D.W. Onstad, and M.E. Gray. 2002. Adaptation of the Western Corn Rootworm to Crop Rotation: Evolution of a New Strain in Response to a Management Practice. American Entomologist 48: 94107.

Ludwick, D. C., L. N. Meihls, K. R. Ostlie, B. D. Potter, L. French, and B. E. Hibbard. 2017. Minnesota Field Population of Western Corn Rootworm (Coleoptera: Chrysomelidae) Shows Incomplete Resistance to Cry34Ab1/Cry35Ab1 and Cry3Bb1. Journal of Applied Entomology 141 (1-2): 28-40. https://doi.org/10.1111/jen.12377.

Ludwick, D.C., and B.E. Hibbard. 2016. Rootworm Management: Status of GM Traits, Insecticides and Potential New Tools. CAB Reviews: Perspectives in Agriculture, Veterinary Science, Nutrition and Natural Resources 11. https://doi.org/10.1079/PAVSNNR201611048.

Marcon, P.C.R.G., L.J. Young, K.L. Steffey, and B.D. Siegfried. 1999. Baseline Susceptibility of European Corn Borer (Lepidoptera: Crambidae) to Bacillus thuringiensis Toxins. Journal of Economic Entomology 92 (2): 279-85. https://doi.org/10.1093/jee/92.2.279.

Meihls, L.N., M.L. Higdon, B.D. Siegfried, N.J. Miller, T.W. Sappington, M.R. Ellersieck, T.A. Spencer, and B.E. Hibbard. 2008. Increased Survival of 
Western Corn Rootworm on Transgenic Corn within Three Generations of on-Plant Greenhouse Selection. Proceedings of the National Academy of Sciences of the United States of America 105 (49): 19177-82. https://doi.org/10.1073/pnas.0805565105.

Meihls, L.N., M.L Higdon, M. Ellersieck, and B.E. Hibbard. 2011. Selection for Resistance to mCry3A-Expressing Transgenic Corn in Western Corn Rootworm. Journal of Economic Entomology 104 (3): 1045-54. https://doi.org/10.1603/EC10320.

Meinke, L.J., B.D. Siegfried, R.J. Wright, and L.D. Chandler. 1998. Adult Susceptibility of Nebraska Western Corn Rootworm (Coleoptera: Chrysomelidae) Populations to Selected Insecticides. Journal of Economic Entomology 91 (3): 594-600. https://doi.org/10.1093/jee/91.3.594.

Metcalf, R.J. 1986. Foreword. In Methods for the Study of Pest Diabrotica, edited by J.L. Krysan and T.A. Miller, vii-xv. New York, New York: Springer-Verlag.

Nowatzki, T.M., S.A. Lefko, R.R. Binning, S.D. Thompson, T.A. Spencer, and B.D. Siegfried. 2008. Validation of a Novel Resistance Monitoring Technique for Corn Rootworm (Coleoptera: Chrysomelidae) and Event DAS-59122-7 Maize. Journal of Applied Entomology 132 (3): 177-88. https://doi.org/10.1111/j.1439-0418.2008.01270.x.

Onstad, D.W. 2006. Modeling Larval Survival and Movement to Evaluate Seed Mixtures of Transgenic Corn for Control of Western Corn Rootworm (Coleoptera: Chrysomelidae). Journal of Economic Entomology 99 (4): 1407-14. 
Orpet, R.J., B.A. Degain, G.C. Unnithan, K.L. Welch, B.E. Tabashnik, and Y. Carrière. 2015. Effects of Dietary Protein to Carbohydrate Ratio on Bt Toxicity and Fitness Costs of Resistance in Helicoverpa zea. Entomologia Experimentalis et Applicata $156 \quad$ (1): 28-36. https://doi.org/10.1111/eea.12308.

Pereira, A.E., H. Wang, S.N. Zukoff, L.J. Meinke, B. Wade French, and B.D. Siegfried. 2015. Evidence of Field-Evolved Resistance to Bifenthrin in Western Corn Rootworm (Diabrotica virgifera virgifera LeConte) Populations in Western Nebraska and Kansas. PLoS ONE 10 (11). https://doi.org/10.1371/journal.pone.0142299.

Pleau, M.J., J.E. Huesing, G.P. Head, and D.J. Feir. 2002. Development of an Artificial Diet for the Western Corn Rootworm. Entomologia Experimentalis et Applicata, 1-11. https://doi.org/10.1046/j.1570-7458.2002.01027.x.

Pruess, K.P., J.F. Wilkowski, and E.S. Raun. 1974. Population Suppression of Western Corn Rootworm by Adult with ULV Malathion. Journal of Economic Entomology 67: 651-55.

Tabashnik, B.E., and Y. Carrière. 2017. Surge in Insect Resistance to Transgenic Crops and Prospects for Sustainability. Nature Biotechnology 35 (10): 926-35. https://doi.org/10.1038/nbt.3974.

Tabashnik, B.E., and F. Gould. 2012. Delaying Corn Rootworm Resistance to Bt Corn. Journal of Economic Entomology $105 \quad$ (3): 767-76. https://doi.org/10.1603/EC12080. 
Thieme, T. G. M., C. Buuk, K. Gloyna, F. Ortego, and G. P. Farinós. 2017. Ten Years of MON810 Resistance Monitoring of Field Populations of Ostrinia Nubilalis in Europe. Journal of Applied Entomology, no. April: 1-9. https://doi.org/10.1111/jen.12420.

Tinsley, N. A., J. L. Spencer, R. E. Estes, J. R. Prasifka, P. M. Schrader, B. W. French, and M. E. Gray. 2015. Larval Mortality and Development for RotationResistant and Rotation-Susceptible Populations of Western Corn Rootworm on Bt Corn. Journal of Applied Entomology 139 (1-2): 46-54. https://doi.org/10.1111/jen.12149.

Wangila, D.S., A.J. Gassmann, J.L. Petzold-Maxwell, B.W. French, and L.J. Meinke. 2015. Susceptibility of Nebraska Western Corn Rootworm (Coleoptera: Chrysomelidae) Populations to Bt Corn Events. Journal of Economic Entomology 108 (2): 742-51. https://doi.org/10.1093/jee/tou063.

Zukoff S.N., K.R. Ostlie, B. Potter, L.N. Meihls, A.L. Zukoff, L. French, M.R. Ellersieck, B.W. French, and B.E. Hibbard. 2016. Multiple Assays Indicate Varying Levels of Cross Resistance in Cry3Bb1-Selected Field Populations of the Western Corn Rootworm to mCry3A, eCry3.1Ab, and Cry34/35Ab1. Journal of Economic Entomology 109 (3): 1387-98. https://doi.org/10.1093/jee/tow073. 


\section{Chapter 4}

Survey of bacteria associated with western corn rootworm life stages reveals no difference between insects reared in different soils 


\begin{abstract}
Western corn rootworm (Diabrotica virgifera virgifera LeConte) is a serious pest of maize (Zea mays L.) in North America and parts of Europe. With most of its life cycle spent in the soil feeding on maize root tissues, this insect is likely to encounter and interact with a wide range of soil and root rhizosphere microbes. Our knowledge of the role of microbes play in insect pests, pest management, and plant health remains incomplete. An important component of an effective pest management strategy is to know which microorganisms are present that could play a role in life history or management. For this study, insects were reared in either autoclaved soil or soil from a geographically separate location that had not been autoclaved. Insects were sampled at each life stage to determine the possible core bacteriome. Additionally, soil was sampled at each life stage and resulting bacteria were identified to determine the contribution of soil to the rootworm bacteriome, if any. We analyzed the V4 hypervariable region of bacterial 16S rRNA genes with Illumina MiSeq to survey the different species of bacteria associated with the insect and the soils. Significant differences in bacterial communities were noted between soil and insects with principal coordinate analysis. No significant differences in community composition existed between the insects reared on soils which did or did not undergo the autoclave process, or between non-diapausing and diapausing insects. The bacteria present in immature stages and in male and female adults revealed a possible core bacteriome of approximately 16 operational taxonomic units. This research may give insights into how resistance to $\mathrm{Bt}$ develops, improved nutrition in artificial rearing systems, and new management strategies.
\end{abstract}




\section{BACKGROUND/INTRODUCTION}

Several studies have evaluated the microbial communities associated with lepidopteran pests and other insects that attack food crops (Caccia et al. 2016; Dhammi et al. 2016; Hadapad et al. 2016; Snyman et al. 2016). Interestingly, shifts in community composition or absence of bacteria can reduce the effectiveness of widely adopted management tactics such as crop rotation or maize expressing Bacillus thuringiensis Berliner (Bt) proteins. However, few studies have been conducted to document microbiomes within beetles attacking crops.

The western corn rootworm (Diabrotica virgifera virgifera LeConte, WCR) is a chrysomelid beetle whose larvae cause damage by feeding on maize root systems. While native to North America, this pest was introduced multiple times to Europe over 20 years ago (Baca 1994, Miller et al. 2005). Most recent estimates indicate this pest causes two billion dollars (USD) in yield loss and control costs worldwide annually (Metcalf 1986; Mitchell 2011), and any regions growing maize should monitor for the presence or arrival of this species. Since its discovery as a pest of maize, the primary control tactic has been crop rotation (Gillette 1912). Recently, transgenic maize hybrids expressing insecticidal proteins from Bt have been used to reduce root damage and economic losses. However, both of these control strategies have instances of failure in the United States of America (Gassmann et al. 2011, 2014, 2016; Levine et al. 2002; Ludwick et al 2017; Zukoff et al. 2016).

Rootworm larvae (WCR and D. barberi Smith \& Lawrence) burrow through the soil searching for maize root tissues, and then through surrounding maize roots while feeding on root tissue. Thus, larvae of these species are exposed to many species of bacteria 
and fungi in the soil and rhizosphere. The diversity of bacteria encountered is reflected on larval surfaces and digestive tracts. The microbiomes of larvae and later life stages may be assembled from bacterial and fungal species present during larval development in soil.

Insect gut microbiomes are known to influence many aspects of insect growth, nutrition, reproduction, Bt resistance, and pathogen resistance (Broderick et al. 2006; Caccia et al. 2016; Douglas 1998; Dematheis et al. 2012a, 2012; Paramasiva 2014a, 2014b; Visweshwar et al. 2015). Gut microbiota have been shown to affect the response of insects to Bt proteins in Lepidoptera (Broderick et al. 2006; Paramasiva et al. 2014a, 2014b; Visweshwar et al. 2015) and in mosquitoes (Patil et al. 2015), but this has not been investigated for Coleoptera. In the Old World bollworm (Helicoverpa armigera Hübner) the manipulation of the larval gut microbiota with antibiotics resulted in reduced susceptibility to a commercial formulation of $\mathrm{Bt}$, as well as the purified $\delta$-endotoxins Cry1 Ab and Cry1 Ac (Paramasiva et al. 2014a). In general, the use of antibiotics to manipulate lepidopteran gut microbiota resulted in reduced mortality due to Bt proteins. Selection experiments with $H$. armigera on transgenic plants were also conducted in addition to manipulation of gut microbiota with antibiotics (Visweshwar et al. 2015). When antibiotics were included, susceptibility to Bt was not altered, even with increasing generations of selection. However, selection in the absence of antibiotics (gut microbiota unaltered) resulted in a nearly $30 \%$ increase in larval survival by the F3 generation (Visweshwar et al. 2015). Thus, resistance to Bt by H. armigera developed only when gut microbiota were present. In fact, the reduction in susceptibility to Bt with the addition of antibiotics was greater than the reduction of susceptibility to Bt due to three generations of selection when gut microbiota were present. Gut microbiota were also required for 
susceptibility of the gypsy moth, Lymantria dispar (L.), to Bt proteins (Broderick et al. 2006).

Larval gut tissue of WCR has a diverse microbial community (Dematheis et al. 2012a; Chu et al. 2013). In WCR, a shift in gut microbiota enterotype was associated with increased resistance to soybean defense compounds, which may have contributed to the development of resistance to crop rotation (Chu et al. 2013). Comparison of gut microbiota between rotation-resistant WCR populations and wild-type WCR populations revealed shifts in the microbial community composition. Manipulation of WCR gut microbiota with antibiotics reduced the resistance to soybean defensive compounds to a level similar to that of wild- type WCR (Chu et al. 2013).

The contribution of gut microbiota to nutrition, physiology, and Bt resistance in WCR is unknown (Dematheis et al. 2012a). Feeding of larval WCR on maize root tissue was shown to affect root rhizosphere microbiota composition, indicating a complex, multitrophic interaction (Dematheis et al. 2012b). Since gut microbiota play a role in Bt susceptibility in lepidopteran pests and a role in crop rotation resistance in WCR, it is reasonable to hypothesize that the microbiota of WCR can affect how larvae respond to $\mathrm{Bt}$ toxins expressed in maize. Consequently, a better understanding of which microbes are associated with WCR and how the insects acquire the bacteriome is needed. In this study, we compared the microbial composition of WCR grown in two different soil environments, at each developmental stage, alongside the soil from which the various life stages were collected and show that WCR larvae can carry a core bacteriome from the egg to adult stage. 


\section{RESULTS AND DISCUSSION}

To better understand the role(s) of bacteria associated with WCR, we conducted the first survey of the WCR bacteriome across all life stages and corresponding soil samples. After following several different protocols, we found one protocol extracted sufficient DNA. Insects from a non-diapausing laboratory colony, often used as a proxy for diapausing, wild-type insects, were reared to each life stage in an autoclaved soil from Columbia. All life stages and corresponding soil samples were collected and processed to extract and purify DNA. The V4 region of the 16S ribosomal gene was amplified and sequenced to putatively identify bacteria.

Uncertain whether differences existed between diapausing and non-diapausing insects, we reared insects from a diapausing laboratory colony in autoclaved soil from the same origin under the same conditions. Once the identities of the bacteria were determined, we compared the bacteriomes between the two colonies. Permutational multivariate analyses of variance (PERMANOVA) with Bray-Curtis and Jaccard indices were conducted to determine whether significant differences existed. No significant differences were detected between these colonies with the Bray-Curtis index $(p=0.10 ; \mathrm{F}=1.90)$. Nondiapausing insects appear to retain a similar bacteriome despite hundreds of generations of laboratory selection. However, PERMANOVA with a Jaccard index revealed significant

differences in bacterial communities between diapausing and non-diapausing insects $(p=0.0001 ; \mathrm{F}=2.90)$. Insects from both groups appear to share many dominant taxa while rarer species appear to be isolated to individual groups.

WCR occurs across a large region in many different soils throughout the United States of America and has also colonized a new area, Europe, as well. Without access to 
insects from different regions, we set forth to determine the effect the soil from different regions may have on the bacteriome. Soil was collected from a different geographic region to survey the soil bacterial background from which insects emerged. Over 2,200 unique operational taxonomic units (OTUs) were putatively identified in soil and insect samples from both colonies and soils. The results show that earlier life stages reared in differing soils contained a significantly different assemblage of bacterial species. However, as the insects matured, those differences declined and all life stages of the insects converged to a similar bacterial microbiome. Out of all samples, 16 OTUs were found in every sample regardless of the colony or rearing soil. We believe these 16 OTUs comprise a core bacteriome for WCR.

Sequencing of WCR and soil samples resulted in a mean $( \pm$ SEM) of $66,759( \pm$ $3,895)$ and $72,868( \pm 5,308)$ reads per sample, respectively. To account for the potential influence of differential coverage on downstream analyses, data were randomly subsampled to a uniform depth of 10,000 reads per sample and all subsequent analyses were performed on this rarefied dataset.

Annotated to the taxonomic level of class, the WCR samples were dominated by Alphaproteobacteria and Gammaproteobacteria, with lower and inconsistent relative abundance of Actinobacteria, Cytophaga, Sphingobacteria, Betaproteobacteria, and in the case of surface-sterilized eggs, Flavobacteriia and Deltaproteobacteria (Fig. 6A). Soil samples demonstrated a seemingly more complex composition comprising a greater number of classes and more even distribution (Fig. 6B).

Microbial richness and $\alpha$-diversity are two metrics of polymicrobial communities often correlated with the health of an ecosystem, be it environmental or host-associated. 
Richness simply denotes the overall number of detected phylotypes in a sample, whereas $\alpha$-diversity denotes both the richness and evenness of distribution of phylotypes in a sample and can be calculated many different ways. In both cases, the underlying assumption is that increased numbers of different taxa and more even distributions of those taxa are representative of ecosystems fostering cross-feeding and syntrophic relationships among microbes. In contrast, low richness or asymmetrical distributions might represent an environment with high selective pressures or the presence of dominant taxa in a competitive environment.

Analysis of richness and $\alpha$-diversity in WCR and the soil in which they were maintained revealed several interesting trends. To first determine whether sample site influenced the richness or $\alpha$-diversity of WCR microbiota, a two-way ANOVA was performed with sample site (i.e., Columbia or Higginsville) and life-stage as fixed variables. Significant main effects of WCR life-stage were detected in richness $(p<0.001$, $\mathrm{F}=8.14)$ and $\alpha$-diversity using both the Shannon $(p=0.011, \mathrm{~F}=3.48)$ and Simpson $(p<$ $0.001, F=5.78)$ indices. No differences were detected between sample sites in richness or $\alpha$-diversity of WCR-associated microbiota $(p=0.338,0.072$, and 0.244 , respectively). Of note however, similar testing of the soil communities at each site revealed significant sitedependent differences in richness and $\alpha$-diversity $(p<0.001$ for all three metrics, $\mathrm{F}=38.52$, 197.64, and 25.04, respectively). No life-stage-dependent differences in microbial richness were detected between soil plots, although $\alpha$-diversity within soil did significantly vary between life-stage $(p=0.030, \mathrm{~F}=2.88$ and $p<0.001, \mathrm{~F}=5.53$ for Shannon and Simpson indices, respectively). 
Collectively, we interpret these data as evidence that the environment has limited effect on the relative uniformity and richness of the WCR bacteriome. This hypothesis is supported by the nearly log-fold difference in richness between soil and rootworm samples. The fact that no site-dependent differences were detected in the rootworms themselves, despite the stark differences in the microbial richness of their respective environments, stands in contrast to the life-stage-dependent differences in richness observed in the rootworms only and not in the soil samples.

Considering WCR samples from the two sites collectively, there was a general trend toward increasing richness in each successive life-stage from egg to pupa followed by a precipitous decline during the pupal molt to adulthood (Fig. 7A). Pairwise comparisons of richness between life-stages detected significantly decreased richness of adult WCR relative to several earlier life-stages. Interestingly, an inverse trend was observed in the richness of soil samples across life-stages (Fig. 7B). In contrast, $\alpha$-diversity, as assessed via the Simpson index, was higher in sterilized eggs relative to other life-stages while adult rootworms were much lower (Fig. 9A), likely reflecting the increasingly skewed microbial community structure as the rootworms develop. No life-stage-dependent differences were detected in soil $\alpha$-diversity (Fig. 9B).

In order to provide a more comprehensive comparison of the microbial communities present in each sample, incorporating not just the number but also the identities of shared and unique taxa, principal coordinate analysis (PCoA) and PERMANOVA were performed to visualize and statistically test for differences in community structure, respectively. In both methods, the similarity of any given pair of samples can be determined several different ways. To ensure that any differences detected 
were robust and to determine the nature of detected differences, we compared samples using both the Bray-Curtis and Jaccard similarity indices. While the Jaccard index is relatively unweighted and determines sample similarity based on the shared presence or absence of taxa, the Bray-Curtis index is weighted to also incorporate similarity in the relative abundance of any shared taxa.

Regardless of the index used, robust compositional differences were detected between all groups with the exception of the WCR samples collected at the two sample sites, again suggesting selection for a specific bacterial community within the rootworms. Specifically, testing for differences using the Bray-Curtis distances detected significant compositional differences between all pairwise comparisons except between WCR samples from the two sample sites (Table 5). Accordingly, PCoA demonstrated a clear separation of soil and WCR samples along PC1 (38.1\% of the total variation in the dataset), complete separation of soil communities from the two sample sites along PC2, and partial overlap between WCR communities (Fig. 8). Testing based on the Jaccard index found significant differences between all pairwise comparisons. Ordination resulted in a similar pattern and the F value generated from the comparison of WCR collected from the two sites was extremely low relative to the other comparisons, despite having the highest total number of samples included in the comparison (Table 6). Collectively, these data complement the analyses of richness and $\alpha$-diversity in supporting the hypothesis that WCR select for a limited subset of host-associated microbes, largely irrespective of their environment.

Annotated to the level of operational taxonomic unit (i.e., the best taxonomic resolution afforded by the $16 \mathrm{~S}$ rRNA amplicons), the microbial composition of the adult 
WCR was incredibly sparse. Of the 474 operational taxonomic units (OTUs) detected in anywhere from 1 of $18(5.6 \%)$ to 15 of $18(83.3 \%)$ of the adults rootworms, the mean relative abundance was uniformly below $0.3 \%$ (Fig. 10). Conversely, the 13 OTUs detected in 16 or greater of the 18 adult rootworms were present at a mean relative abundance of greater than $1.5 \%$. Notably, $95.4 \%$ of the microbial DNA recovered from adult rootworms was annotated to three OTUs: Wolbachia sp. $(85.5 \pm 24.0 \%$ in 18 of 18 adults $)$, unclassified family Enterobacteriaceae $(6.2 \pm 13.0 \%$ in 16 of 18 adults), and Acinetobacter sp. $(4.7 \pm$ $11.6 \%$ in 17 of 18 adults).

A survey across all life stages identified 1,126 OTUs. Specifically, 16 OTUs were present in every life stage regardless of soil type and diapausing status (Table 7). No significant differences existed between non-diapausing and diapausing WCR reared in autoclaved soil (Fig. 8). Adults had significantly fewer OTUs than neonate, second and third instar larvae, and pupae (Table 5, Fig. 7). Similarly, adults had significantly less diversity than eggs or third instar larvae. Neonates had significantly less diversity than unhatched eggs (Fig. 7). Additionally, the insect microbial community differed significantly from the soils in which they were reared (Table 5, Fig. 8).

Exploratory studies documenting the bacterial communities in different organisms may lead to new insights as to the role(s) they may fill or even new management tactics. Our study documented more than 1,100 OTUs present throughout the WCR life cycle. Of these OTUs, 16 were found in every life stage of insects. Furthermore, some of these bacteria were never found in the soil suggesting vertical transmission (i.e. parent to progeny) of bacteria is the most likely mechanism for at least some of the WCR microbiome (Table 9). 
Many OTUs were discovered in the sterilized eggs of diapausing insects. However, we cannot be certain whether these bacteria were alive inside the egg or dead on the surface of the egg shell. Given the sculpturing of the chorion, it is possible dead bacteria remained on the surface served as a source of non-viable DNA (Dematheis et al. 2012b; Krysan 1986). The protocol we used does not discern between live and dead bacteria. If the bacteria were alive, then it is possible the eggs serve as a source of bacteria which colonize the neonatal gut. There is evidence that some of the bacteria are passed from parents to offspring (Table 7), but we cannot be certain without additional studies. Future experiments should extract rRNA and generate cDNA before sequencing the resulting strands. This method would reduce the likelihood of dead bacterial sequences entering the analysis as RNA degrades rapidly while DNA can persist for many years.

We infer that some of these bacteria may be endosymbionts of WCR as particular OTUs never appeared outside of insect samples (Table 9). However, we used laboratory colonies to make inferences about wild-type populations. In theory, the differences between wild-type populations and laboratory colonies should be minimal. In reality, we simply do not know. The geographic distribution of this insect encompasses most of the United States of America and parts of Europe. The soils across these regions are also diverse as are the management tactics employed by farmers. It stands to reason the microbial communities are different within and between fields. Future studies will need to include more samples, samples from different locations across the Corn Belt and other regions, and wild-type specimens to validate or invalidate the findings of this research.

WCR continues to evolve and adapt to the different management tactics that maize growers are implementing now. Future technologies for pest control, including RNA 
interference, are still years away from field implementation. New tools and knowledge are needed to combat this pest. This study documents the plethora of bacteria encountered by WCR in different soils and identifies a small core bacterial microbiome retained by WCR. Clearly, there is much to learn about the functions of these different bacteria with regards to WCR.

\section{MATERIALS AND METHODS}

Insect rearing. Eggs from non-diapausing and diapausing colonies of WCR were obtained from the Agricultural Research Service of the United States Department of Agriculture (USDA-ARS). The non-diapausing colony had been derived from the primary non-diapausing colony held at Brookings, SD (Branson 1976). The diapausing colony eggs were from the primary diapausing colony (Jackson 1986) also held at Brookings, SD, and remained in cold storage until needed.

For the non-diapausing colony maintained in Columbia, MO, adults of both sexes were placed in cages $\left(30 \mathrm{~cm}^{3}\right.$, Megaview Science Co., Ltd., Taichung, Taiwan) with a photoperiod of $14: 10$ (L:D) h at $25^{\circ} \mathrm{C}$. Adults were supplied with corn leaf tissue, slices of zucchini, an agar gel to serve as a water source, and an artificial diet for adult rearing (Frontier Agricultural Sciences, Newark, DE). Petri dishes with 70 mesh sieved field soil served as an oviposition site for females. The oviposition site was moistened throughout the week and replaced weekly. The eggs in the Petri dish were separated from the soil by washing through a 60 mesh sieve. The eggs were then divided and placed in two plastic containers $\left(15 \times 10 \mathrm{~cm}\right.$, GladWare ${ }^{\circledR}$, The Glad Products Company, Oakland, CA) with 70 mesh sieved field soil. The plastic containers were covered with lids and placed on the bottom racks of a Percival incubator set to run at $25^{\circ} \mathrm{C}$. 


\section{Seedling Mats}

Non-diapausing insects. Fifteen seedling mats were planted in March 2016. Each seedling mat contained approximately $15 \mathrm{~g}$ of maize seed (Monsanto Company, variety DKC 61-79), $6 \mathrm{~cm}$ of autoclaved growth medium, and $80 \mathrm{ml}$ of tap water in a $15 \times 10 \mathrm{~cm}$ plastic container. The growth medium consisted of a mixture of field soil:Pro-Mix BX potting medium (Premier Horticulture Inc., Quakertown, PA) at a 2:1 ratio (v/v) prior to being autoclaved. Seedling mats were allowed to germinate, and coleoptiles emerged through the soil surface prior to infestation.

Seedling mat containers were placed on the top rack of the same Percival incubator in which eggs were incubated. Six time points were established as points of interest for this study, and were as follows: $0 \mathrm{~d}$ (neonate larvae), $5 \mathrm{~d}, 10 \mathrm{~d}, 15 \mathrm{~d}, 22 \mathrm{~d}$, and adult emergence. Three replicates were used for this survey of non-diapausing insects. Randomization of time points occurred within each replicate. All containers, except for the $0 \mathrm{~d}$ time point, received 25 neonate larvae. For the $0 \mathrm{~d}$ time point, 10 neonate larvae were collected into $1.5 \mathrm{ml}$ microcentrifuge tubes (USA Scientific) and then stored at $-80^{\circ} \mathrm{C}$ (So-Low, Environmental Equipment, Cincinnati, $\mathrm{OH})$.

Diapausing insects. A total of five replications were conducted for this survey of diapausing insects. During this survey, two different growth media were used. The first growth medium remained the same as the non-diapausing insect survey, while the second growth media was soil collected from Higginsville, MO, in July 2016. This soil was not autoclaved and remained enclosed in a metal container until use in October 2016. In addition to the time points listed previously, two types of eggs were sampled: eggs washed 
from sieved soil, and eggs washed from sieved soil that were then surface sterilized (Pleau et al. 2002).

Once the desired time point was reached, the seedling mats were processed in the same manner as Meihls et al. (2008). For the 5, 10, 15, and $22 \mathrm{~d}$ time points, all aboveground plant material was removed from the container. Next, the soil and root tissue were placed into a Berlese funnel with an attached jar. The jar with a moist filter paper at the bottom was used to collect the larvae. Specimens of each age were transferred from the jar to a microcentrifuge tube at least once every three hours throughout a typical work day. This tube was then immediately placed into the $-80^{\circ} \mathrm{C}$ freezer for storage until DNA extraction occurred. A new tube was used for each collection time and sample to prevent additional freezing and thawing. Soil was also collected from the bottom of the seedling mat for larval specimens.

For the adult emergence time point in the non-diapausing insect survey, we planted a fresh seedling mat in a larger container $(33 \times 19 \mathrm{~cm}$, Sterilite Corporation, Birmingham, AL) and allowed the maize to grow for one week prior to infestation. The first and smaller seedling mat had plant tissue removed before being inverted onto the second and larger seedling mat. After one week, the larger seedling mat was covered with a mesh screen to prevent escape of emerging adults. No secondary container was used for the diapausing insect survey, but mesh screens were used to keep the adults from escaping the container. Adult emergence containers were checked daily, and adults from each container on a given day were placed into microcentrifuge tubes. Soil was collected from the soil surface where adults must pass to emerge through the soil. 
DNA Extraction and Quantitation. Whole insects (1-8 larvae/treatment; 1-2 pupae/treatment; a single adult/treatment) were pooled, and DNA extracted using accepted methods (Chen et al. 2010). The samples were extracted using PowerFecal® DNA Isolation Kit (MO BIO Laboratories, Inc. Catalog No. 12830-50) following the manufacturer's protocol (https://mobio.com/media/wysiwyg/pdfs/protocols/12830.pdf) with the following modifications: one sterile $0.5 \mathrm{~cm}$ diameter stainless steel ball bearing was added to the Dry Bead Tube for each adult and soil sample prior to shaking; shaking time was reduced to 5 minutes for adults and 3 minutes for all other samples. DNA quality and concentration was determined for each sample by Nanodrop 2000 Spectrophotometer (Thermo Scientific, Wilmington, DE) and stored at $-80^{\circ} \mathrm{C}$.

Library construction and sequencing. All PCR and sequencing was performed at the University of Missouri DNA Core. DNA concentration was determined fluorometrically (Qubit 2.0, Life Technologies) prior to analysis. Based on results of fluorometry, all samples were normalized to a standard concentration for PCR amplification. Bacterial 16S rRNA amplicons were generated via amplification of the V4 hypervariable region of the $16 \mathrm{~S}$ rRNA gene using single-indexed universal primers (U515F/806R) flanked by Illumina standard adapter sequences and the following parameters: $98^{\circ} \mathrm{C}^{(3: 00)}+\left[98^{\circ} \mathrm{C}^{(0: 15)}+50^{\circ} \mathrm{C}^{(0: 30)}+72^{\circ} \mathrm{C}^{(0: 30)}\right] \times 25$ cycles $+72^{\circ} \mathrm{C}^{(7: 00)}$. Amplicons were then pooled for sequencing using the Illumina MiSeq platform and V2 chemistry with $2 \times 250 \mathrm{bp}$ paired-end reads, as previously described (Ericsson et al. 2015).

Informatics analysis. All informatics analyses were performed as previously described (Hart et al. 2015), at the University of Missouri Informatics Research Core Facility. Input is typically for 2x350 bp reads from one of the two MiSeq machines in the 
DNA Core. The read pairs are joined into contigs by the program FLASH (http://bioinformatics.oxfordjournals.org/content/27/21/2957.long) (Magoc et al. 2011), and culled if found to be short after trimming for a base quality less than 31 , and those that are not joined, or are too long or short after contig formation, leaving those that are 275 to 300 nts. Cutadapt (http://journal.embnet.org/index.php/embnetjournal/article/view/200/479) was used to find and trim the primers from the 5' and the 3' ends, culling those contigs lacking both primers. Contigs with the expected number of errors greater than 0.5 were removed by Usearch (http://drive5.com/index.htm), and the remainder were trimmed to length 248. The contig read ids were modified so that samples could be followed throughout by using the Qiime script split_libraries_fastq.py. All samples were then pooled into one fasta file and metrics for all samples collated into one table. Contigs were clustered de novo into an OTU table using the uparse (http://drive5.com/uparse/) algorithm. De novo and reference-based chimera detection and removal was performed using Qiime v1.8 (Kuczynski et al. 2012) software, and remaining contiguous sequences were assigned to operational taxonomic units (OTUs) via de novo OTU clustering and a criterion of $97 \%$ nucleotide identity. Annotation of selected OTUs was performed using BLAST (Altschul et al. 1997) against the Silva database (https://www.arb-silva.de/) (DeSantis et al. 2006) of 16S rRNA sequences and taxonomy. Principal coordinate analysis and PERMANOVA testing were performed using $1 / 4$ root-transformed and non-transformed OTU relative abundance data, respectively, using Past 3.16 (https://folk.uio.no/ohammer/past/) (Hammer et al. 2016). Richness and $\alpha$-diversity metrics were determined in Past 3.16 using Qiime-generated otu_biom.table files. 
Statistical analysis. Differences in raw and binned OTU richness were tested via ANOVA using SigmaPlot 12.3 (Systat Software Inc., San Jose, CA); $p$ values less than 0.05 were considered significant. Differences in the overall composition of the different regions were tested via two- and one-way PERMANOVA of ranked Bray-Curtis or Jaccard distances using the open access Past 3.16 software package (Quast et al. 2013), downloaded on April 2, 2016.

\section{ACKNOWLEDGEMENTS}

Funding for this project, in part, was provided by Syngenta Crop Protection. Sequencing services were performed at the University of Missouri DNA Core Facility by Nathan Bivens and Karen Bromert. We thank Bill Spollen and Christopher Bottoms (University of Missouri Informatics Core), Rebecca Dorfmeyer and Giedre Turner (University of Missouri Metagenomics Center), and Karen Clifford (University of Missouri College of Veterinary Medicine), Julie Barry (USDA-ARS) for insect rearing, Adriano Pereira for assistance with collecting insects, and Chad Nielson and Wade French (USDA-ARS) for maintaining colonies used in this study. Mention of trade names or commercial products in this publication is solely for the purpose of providing specific information and does not imply recommendation or endorsement by the U.S. Department of Agriculture (USDA). USDA is an equal opportunity provider and employer. 
Table 7. Results of PERMANOVA testing for differences in $\beta$-diversity between western corn rootworm (WCR) and soil samples collected from two different sites, based on the Bray-Curtis distance. $p$ values and $\mathrm{F}$ values are shown in the upper right and lower left portions of the table, respectively.

\begin{tabular}{|c|c|c|c|c|c|}
\hline \multirow{2}{*}{ F values } & $p$ values & \multicolumn{2}{|c|}{ Soil } & \multicolumn{2}{c|}{ WCR from "X" soil } \\
\cline { 3 - 6 } & & Columbia & Higginsville & Columbia & Higginsville \\
\hline Soil & Columbia & & 0.0001 & 0.0001 & 0.0001 \\
\cline { 2 - 6 } & Higginsville & 27.62 & & 0.0001 & 0.0001 \\
\hline $\begin{array}{c}\text { WCR } \\
\text { from "X" } \\
\text { soil }\end{array}$ & Columbia & 57.08 & 104.5 & & 0.1498 \\
\cline { 2 - 6 } & Higginsville & 38.43 & 119.7 & 1.657 & \\
\hline
\end{tabular}


Table 8. Results of PERMANOVA testing for differences in $\beta$-diversity between western corn rootworm (WCR) and soil samples collected from two different sites, based on the Jaccard distance. $p$ values and $\mathrm{F}$ values are shown in the upper right and lower left portions of the table, respectively.

\begin{tabular}{|c|c|c|c|c|c|}
\hline \multirow{2}{*}{\multicolumn{2}{|c|}{$\begin{array}{ll}\text { F values } & p \text { values }\end{array}$}} & \multicolumn{2}{|c|}{ Soil } & \multicolumn{2}{|c|}{ WCR } \\
\hline & & Columbia & Higginsville & Columbia & Higginsville \\
\hline \multirow[t]{2}{*}{ Soil } & Columbia & & 0.0001 & 0.0001 & 0.0001 \\
\hline & Higginsville & 24.93 & & 0.0001 & 0.0001 \\
\hline \multirow[t]{2}{*}{ WCR } & Columbia & 19.62 & 23.66 & & 0.0001 \\
\hline & Higginsville & 18.56 & 18.6 & 3.972 & \\
\hline
\end{tabular}


Table 9. Unique operational taxonomic units (OTUs) found in all insect samples regardless of soil origin.

\begin{tabular}{|c|c|c|c|}
\hline OTUs & $\begin{array}{l}\text { Taxonomic } \\
\text { Rank }\end{array}$ & Present in egg soil? & First found in soil ${ }^{1}$ \\
\hline Ruminococcaceae & Family & Yes & Egg \\
\hline Lachnospiraceae & Family & Yes & Egg \\
\hline Bacteroidales S24-7 & Group & Yes & Egg \\
\hline $\begin{array}{l}\text { Wolbachia (Delia } \\
\text { antiqua) }\end{array}$ & Genus & No & Neonate \\
\hline Tsukamurella sp. & Genus & No & Never \\
\hline Gordonia sp. & Genus & Yes & Egg \\
\hline Oscillibacter $\mathrm{sp}$. & Genus & Yes & Egg \\
\hline Microbacterium sp. & Genus & Yes & Egg \\
\hline Bacillus megaterium & Species & No & Never \\
\hline Geobacillus toebii & Species & Yes & Egg \\
\hline Klebsiella sp. Z1 & Species & Yes & Egg \\
\hline Mycobacterium fortuitum & Species & No & Never \\
\hline $\begin{array}{l}\text { Streptomyces } \\
\text { rectiviolaceus }\end{array}$ & Species & No & Never \\
\hline $\begin{array}{l}\text { Lachnospiraceae } \\
\text { NK4A136 }\end{array}$ & Species & Yes & Egg \\
\hline $\begin{array}{l}\text { Pseudomonas sp. } \\
\text { FSGRN7 }\end{array}$ & Species & No & Never \\
\hline $\begin{array}{l}\text { Pseudonocardia sp. YIM } \\
68245\end{array}$ & Species & No & Never \\
\hline
\end{tabular}

${ }^{1}$ A particular OTU was found in one or more soil samples corresponding to the life stage denoted 


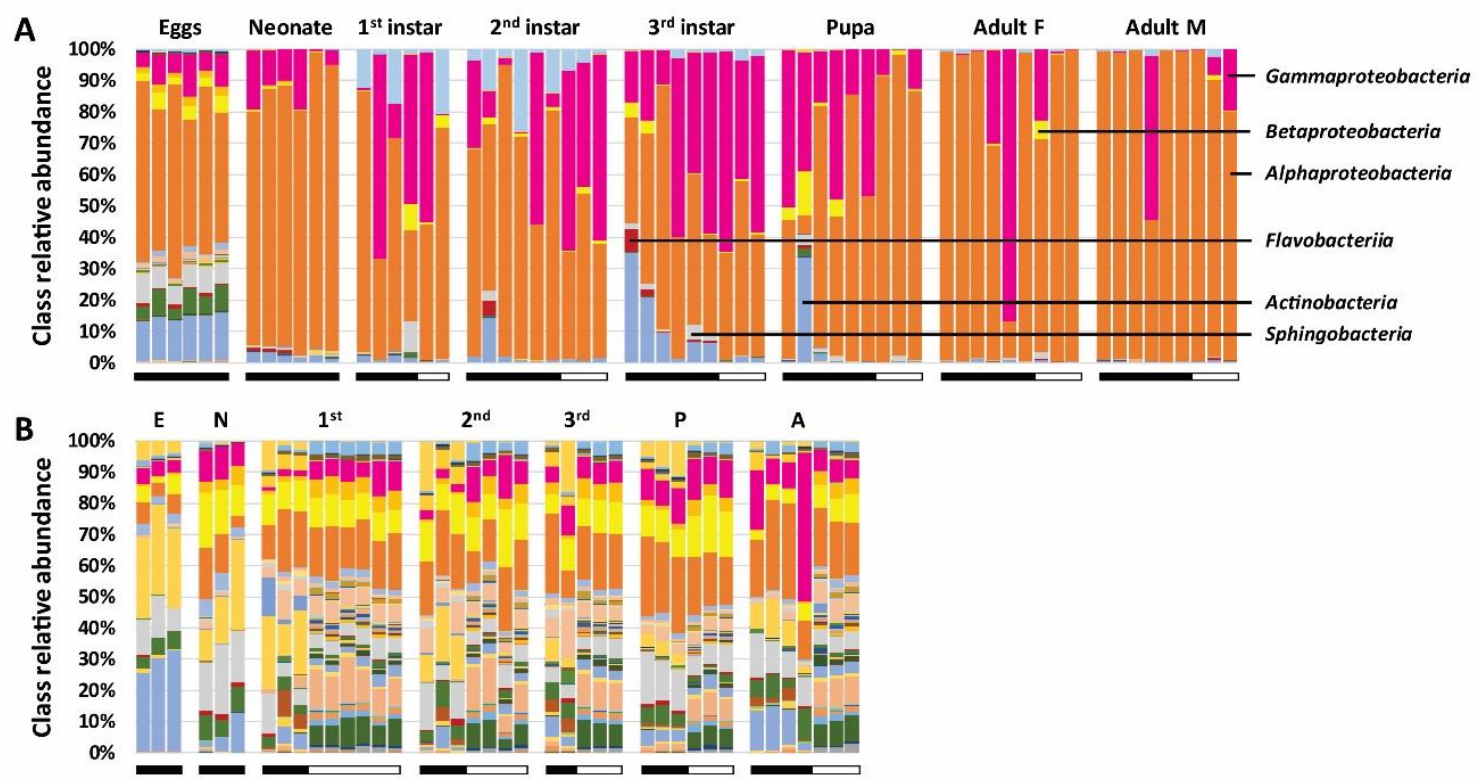

Figure 6. Stacked bar charts showing relative abundances of microbial classes detect in corn rootworms at different life stages (A) and in soil from which rootworm samples were collected (B). Horizontal bars below the vertical bars indicate original of soil; black bars = Columbia, MO, white bars = Higginsville, $\mathrm{MO}$. 

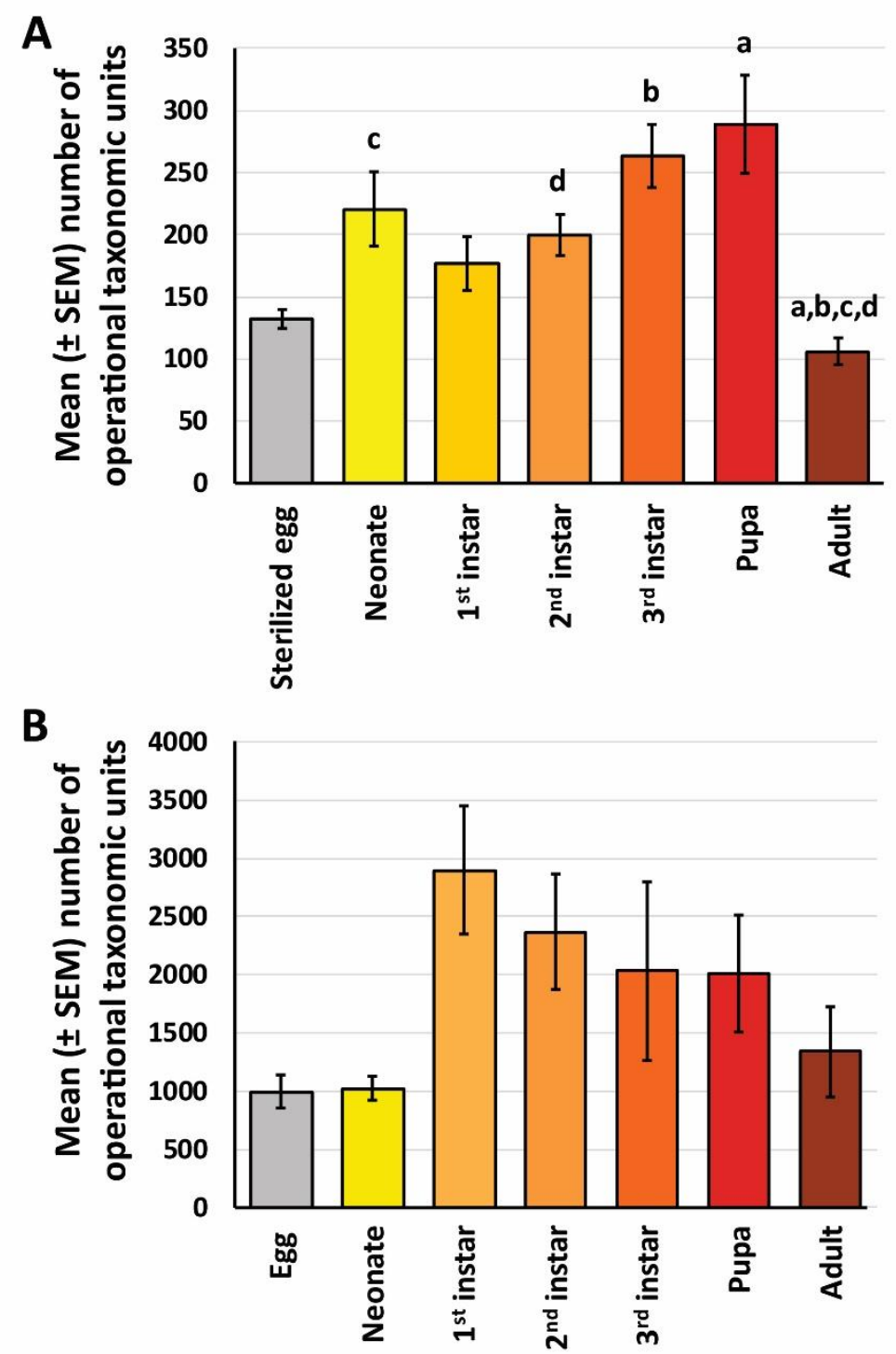

Figure 7. Main effect of life stage on microbial richness in western corn rootworm (A, $p<0.001)$, or the soil from which WCR samples were collected $(\mathbf{B}, p=0.040)$. Significant pairwise differences are indicated by like letters (Kruskal-Wallis one-way ANOVA on ranks with Dunn's post hoc). 


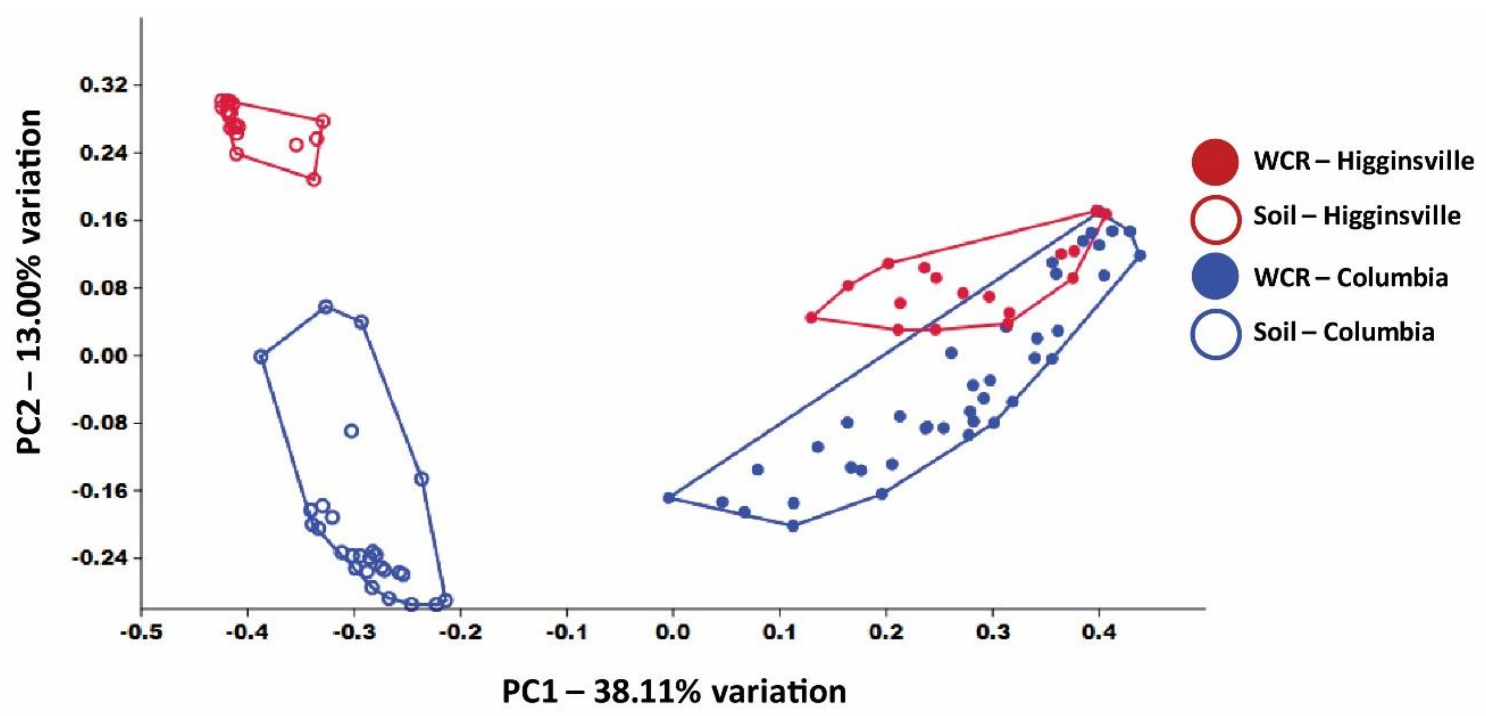

Figure 8. Principal coordinate analysis based on Bray-Curtis similarity between microbial communities detected in western corn rootworm (WCR) at various life stages and soil samples collected from two different sites. 

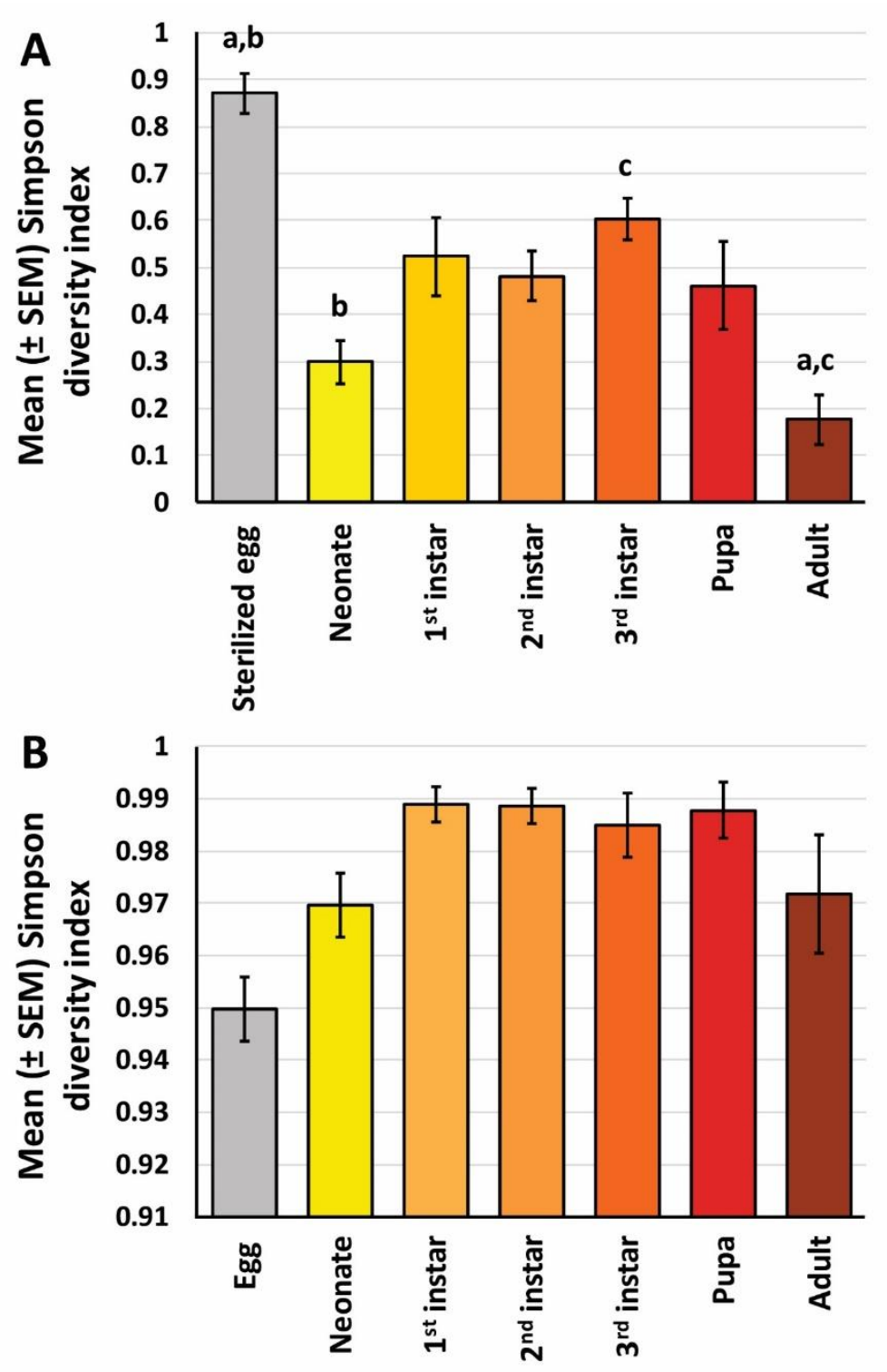

Figure 9. Main effect of life stage on microbiota $\alpha$-diversity in western corn rootworms (A, $p<0.001)$, or the soil from which the WCR samples were collected $(\mathbf{B}, p=0.040)$. Significant pairwise differences indicated like letters (Kruskal-Wallis one-way ANOVA on ranks with Dunn's post hoc). 


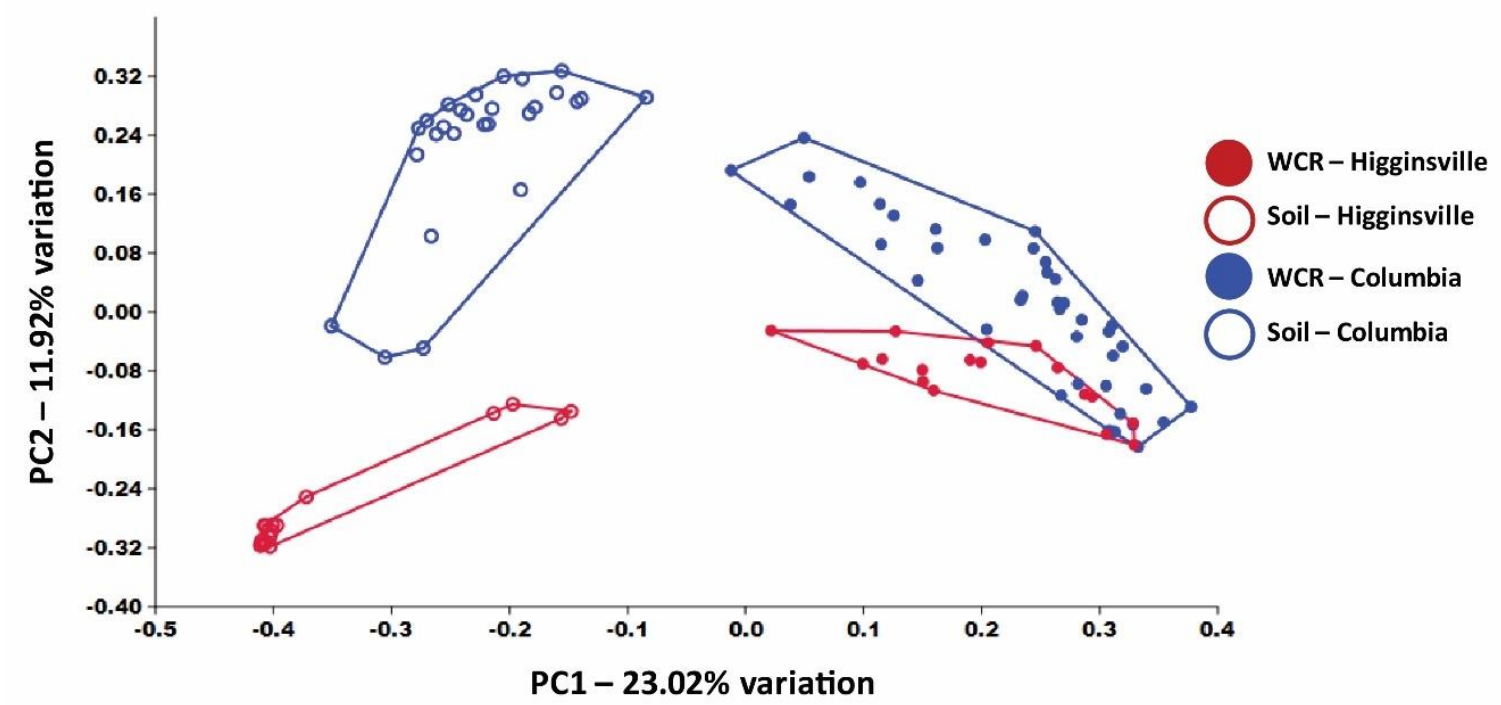

Figure 10. Principal coordinate analysis based on Jaccard similarity between microbial communities detected in western corn rootworms (WCR) at various life stages and soil samples collected from two different sites. 


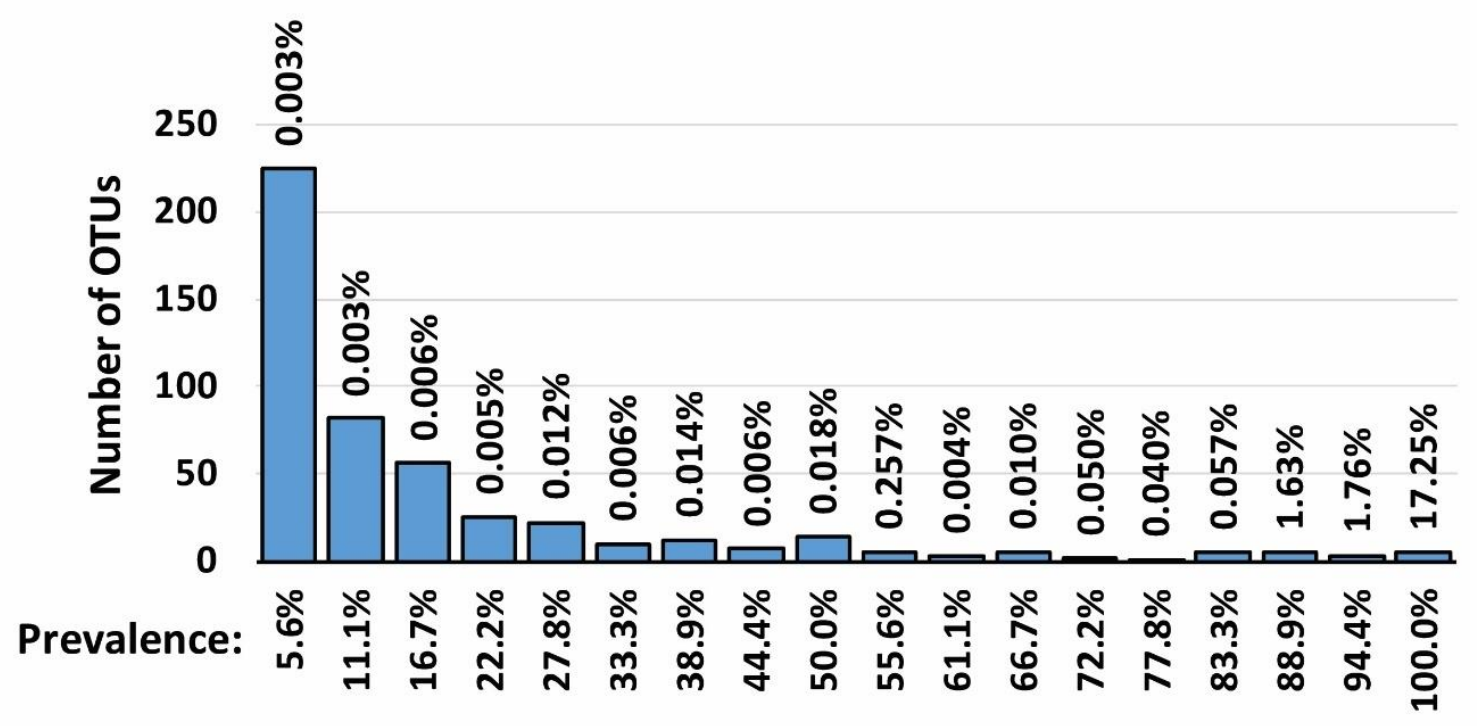

Figure 11. Number and mean relative abundance (above bars) of operational taxonomic units (OTUs) detected at increasing prevalence in adult western corn rootworm samples. 


\section{References Cited}

Altschul, S., T. Madden, A. Schaffer, J. Zhang, Z. Zhang, W. Miller, and D. Lipman. 1998. Gapped Blast and Psi-Blast: A New Generation of Protein Database Search Programs. FASEB Journal 12 (8).

Baca, F. 1994. New Member of the Harmful Entomofauna of Yugoslavia Diabrotica virgifera virgifera LeConte (Coleoptera: Chrysomelidae). Zaštita Bilja 45: 125-31.

Branson, T.F. 1976. The Selection of A Non-diapause Strain of Diabrotica virgifera virgifera (Coleoptera: Chrysomelidae). Entomologia Experimentalis et Applicata 19 (2): 148-54. https://doi.org/10.1111/j.1570-7458.1976.tb02591.x.

Broderick, N.A., K.F. Raffa, and J. Handelsman. 2006. Midgut Bacteria Require for Bacillus thuringiensis Insecticidal Activity. Proceedings of the National Academy of Sciences 103: 15196-99.

Caccia, S., I.D. Lelio, A.L. Storia, A. Marinelli, P. Varricchio, E. Franzetti, N. Banvuls, et al. 2016. Midgut Microbiota and Host Immunocompetence Underlie Bacillus thuringiensis Killing Mechanism. Proceedings of the National Academy of Sciences 113: 9486-91.

Chen, H., M. Rangasamy, S.Y. Tan, H. Wang, and B.D. Siegfried. 2010. Evaluation of Five Methods for Total DNA Extraction from Western Corn Rootworm Beetles. PLoS ONE 5 (8). https://doi.org/10.1371/journal.pone.0011963.

Chu, C.C., J.L. Spencer, M.J. Curzi, J.A. Zavala, and M.J. Seufferheld. 2013. Gut Bacteria Facilitate Adaptation to Crop Rotation in the Western Corn Rootworm. Proceedings of the National Academy of Sciences 110: 11917-22. 
Dematheis, F., B. Kurtz, S. Vidal, and K. Smalla. 2012. Microbial Communities Associated with the Larval Gut and Eggs of the Western Corn Rootworm. PLoS ONE 7 (10). https://doi.org/10.1371/journal.pone.0044685.

DeSantis, T.Z., P. Hugenholtz, N. Larsen, M. Rojas, E.L. Brodie, K. Keller, T. Huber, D. Dalevi, P. Hu, and G.L. Andersen. 2006. Greengenes, a Chimera-Checked 16S rRNA Gene Database and Workbench Compatible with ARB. Applied and $\begin{array}{llll}\text { Environmental } & \text { Microbiology } & 72 & \text { 5069-72. }\end{array}$ https://doi.org/10.1128/AEM.03006-05.

Dhammi, A., J.B. van Krestchmar, L. Ponnusamy, J.S. Bacheler, D.D. Reisig, A. Herbert, A.I. Del Pozo-Valdivia, and R.M. Roe. 2016. Biology, Pest Status, Microbiome and Control of Kudzu Bug (Hemiptera: Heteroptera: Plataspidae): A New Invasive Pest in the U.S. International Journal of Molecular Sciences 17 (9). https://doi.org/10.3390/ijms17091570.

Douglas, A.E. 1998. Nutritional Interactions in Insect-Microbial Symbioses: Aphids and Their Symbiotic Bacteria Buchnera. Annual Review of Entomology. Vol. 43. https://doi.org/10.1146/annurev.ento.43.1.17.

Gassmann, A. J., J. L. Petzold-Maxwell, E. H. Clifton, M. W. Dunbar, A. M. Hoffmann, D. A. Ingber, and R. S. Keweshan. 2014. Field-Evolved Resistance by Western Corn Rootworm to Multiple Bacillus thuringiensis Toxins in Transgenic Maize. Proceedings of the National Academy of Sciences 111 (14): 5141-46. https://doi.org/10.1073/pnas.1317179111.

Gassmann, A.J., J.L. Petzold-Maxwell, R.S. Keweshan, and M.W. Dunbar. 2011. 
Field-Evolved Resistance to Bt Maize by Western Corn Rootworm. PLoS ONE 6 (7). https://doi.org/10.1371/journal.pone.0022629.

\section{Gassmann, Aaron J., Ram B. Shrestha, Siva R.K. Jakka, Mike W. Dunbar, Eric H.} Clifton, Aubrey R. Paolino, David A. Ingber, et al. 2016. Evidence of Resistance to Cry34/35Ab1 Corn by Western Corn Rootworm (Coleoptera: Chrysomelidae): Root Injury in the Field and Larval Survival in Plant-Based Bioassays. Journal of Economic Entomology 109 (4): 1872-80. https://doi.org/10.1093/jee/tow110.

Gillette, C P. 1912. Diabrotica virgifera Lec. as a Corn Rootworm. Journal of Economic Entomology 5: 364-66.

Hadapad, A.B., C.S. Prabhakar, S.C. Chandekar, J. Tripathi, and R.S. Hire. 2016. Diversity of Bacterial Communities in the Midgut of Bactrocera Cucurbitae (Diptera: Tephritidae) Populations and Their Potential Use as Attractants. Pest Management Science 72 (6): 1222-30. https://doi.org/10.1002/ps.4102.

Hammer, Ø., D.A.T. Harper, and P.D. Ryan. 2001. Past: Paleontological Statistics Software Package for Education and Data Analysis. Palaeontologia Electronica 4 (1).

Hart, M.L., A. Meyer, P.J. Johnson, and A.C. Ericsson. 2015. Comparative Evaluation of DNA Extraction Methods from Feces of Multiple Host Species for Downstream $\begin{array}{llll}\text { next-Generation } & \text { Sequencing. } & \text { PLoS } & \text { ONE }\end{array}$ (11). https://doi.org/10.1371/journal.pone.0143334.

Jackson, J.J. 1986. Rearing and Handling of Diabrotica virgifera virgifera and Diabrotica undecimpunctata Howardi. In Methods for the Study of Pest Diabrotica, edited by 
J.L. Krysna and T.A. Miller, 25-47. New York, New York: Springer-Verlag.

Krysan, J. 1986. Introduction: Biology, Distribution and Identification of Pest Diabrotica. In Methods for the Study of Pest Diabrotica, edited by J.L. Krysan and T.A. Miller, 1-23. New York, New York: Springer-Verlag.

Kuczynski, J., J. Stombaugh, W.A. Walters, A. González, J.G. Caporaso, and R. Knight. 2012. Using QIIME to Analyze 16s rRNA Gene Sequences from Microbial Communities. Current Protocols in Microbiology, no. SUPPL.27. https://doi.org/10.1002/9780471729259.mc01e05s27.

Levine, E., J.L. Spencer, S.A. Isard, D.W. Onstad, and M.E. Gray. 2002. Adaptation of the Western Corn Rootworm to Crop Rotation: Evolution of a New Strain in Response to a Management Practice. American Entomologist 48: 94-107.

Ludwick, D.C., L.N. Meihls, K.R. Ostlie, B.D. Potter, L. French, and B.E. Hibbard. 2017. Minnesota Field Population of Western Corn Rootworm (Coleoptera: Chrysomelidae) Shows Incomplete Resistance to Cry34Ab1/Cry35Ab1 and Cry3Bb1. Journal of Applied Entomology 141 (1-2): 28-40. https://doi.org/10.1111/jen.12377.

Magoč, T., and S.L. Salzberg. 2011. FLASH: Fast Length Adjustment of Short Reads to Improve Genome Assemblies. Bioinformatics 27 (21): 2957-63. https://doi.org/10.1093/bioinformatics/btr507.

Meihls, L.N., M.L. Higdon, B.D. Siegfried, N.J. Miller, T.W. Sappington, M.R. Ellersieck, T.A. Spencer, and B.E. Hibbard. 2008. Increased Survival of Western Corn Rootworm on Transgenic Corn within Three Generations of on-Plant 
Greenhouse Selection. Proceedings of the National Academy of Sciences of the United States of America $105 \quad$ (49): 19177-82. https://doi.org/10.1073/pnas.0805565105.

Metcalf, R.J. 1986. Foreword. In Methods for the Study of Pest Diabrotica, edited by J.L. Krysan and T.A. Miller, vii-xv. New York, New York: Springer-Verlag.

Miller, N., A. Estoup, S. Toepfer, D. Bourguet, L. Lapchin, S. Derridj, K. S. Kim, P. Reynaud, L. Furlan, and T. Guillemaud. 2005. Multiple transatlantic introductions of the western corn rootworm. Science 310: 992.

Mitchell, P. 2011. Costs and Benefits of Controlling Pest Diabrotica in Maize in the United States. In 24th IWG Conference, 24-26. Freiburg, Germany.

Paramasiva, I., H.C. Sharma, and P.V. Krishnayya. 2014. Antibiotics Influence the Toxicity of the Delta Endotoxins of Bacillus thuringiensis towards the Cotton Bollworm, Helicoverpa armigera. BMC Microbiology 14.

Paramasiva, I., Y. Shouche, G.J. Kulkarni, P.V. Krishnayya, S.M. Akbar, and H.C. Sharma. 2014. Diversity in Gut Microflora of Helicoverpa armigera Populations from Different Regions in Relation to Biological Activity of Bacillus thuringiensis $\delta$-Endotoxin Cry1Ac. Archives of Insect Biochemistry and Physiology 87 (201213).

Patil, C.D., H.P. Borase, B.K. Salunke, and S.V. Patil. 2013. Alteration in Bacillus thuringiensis Toxicity by Curing Gut Flora: Novel Approach for Mosquito Resistance Management. Parasitology Research 112 (9): 3283-88. https://doi.org/10.1007/s00436-013-3507-z. 
Pleau, M.J., J.E. Huesing, G.P. Head, and D.J. Feir. 2002. Development of an Artificial Diet for the Western Corn Rootworm. Entomologia Experimentalis et Applicata, 1-11. https://doi.org/10.1046/j.1570-7458.2002.01027.x.

Quast, C., E. Pruesse, P. Yilmaz, J. Gerken, T. Schweer, P. Yarza, J. Peplies, and F.O. Glöckner. 2013. The SILVA Ribosomal RNA Gene Database Project: Improved Data Processing and Web-Based Tools. Nucleic Acids Research 41 (D1). https://doi.org/10.1093/nar/gks1219.

Snyman, M., A.K. Gupta, C.C. Bezuidenhout, S. Claassens, and J. van den Berg. 2016. Gut Microbiota of Busseola Fusca (Lepidoptera: Noctuidae). World Journal of Microbiology and Biotechnology 32 (7). https://doi.org/10.1007/s11274-0162066-8.

Visweshwar, R., H.C. Sharma, S.M.D. Akbar, and K. Sreeramulu. 2015. Elimination of Gut Microbes with Antibiotics Confers Resistance to Bacillus thuringiensis Toxin Proteins in Helicoverpa armigera (Hubner). Applied Biochemistry and Biotechnology 177: 1621-37.

Zukoff, S.N., K.R. Ostlie, B. Potter, L.N. Meihls, A.L. Zukoff, L. French, M.R. Ellersieck, B.W. French, and B.E. Hibbard. 2016. Multiple Assays Indicate Varying Levels of Cross Resistance in Cry3Bb1-Selected Field Populations of the Western Corn Rootworm to mCry3A, eCry3.1Ab, and Cry34/35Ab1. Journal of Economic Entomology 109 (3): 1387-98. https://doi.org/10.1093/jee/tow073. 
Dalton Ludwick was born in Keokuk, Iowa. He grew up in Clark County in the state of Missouri. After graduating Clark County R-1 High School in 2010, Dalton enrolled at the University of Missouri-Columbia for a Bachelor's of Science in Plant Sciences with an emphasis in plant protection. During his time as an undergraduate, Dalton taught high school students about insects, experienced the agricultural industry first-hand, and decided to move forward for a graduate degree in entomology. Following his desire to understand plant-insect interactions, Dalton joined the laboratories of Drs. Deborah Finke and Bruce Hibbard as a doctoral student in August 2014. During his time as a graduate student at the University of Missouri-Columbia, Dalton served as Graduate Teaching Assistant for an undergraduate entomology course and a graduate statistics course, in addition to his role as a Graduate Research Assistant. 